Florida International University

FIU Digital Commons

3-21-2019

\title{
The Impact of Microaggressions and Minority Stress on the Psychological Well-Being of Emerging Adult Sexual Minorities of Color
}

Michelle G. Thompson

Florida International University, mthom030@fiu.edu

Follow this and additional works at: https://digitalcommons.fiu.edu/etd

Part of the Cognitive Psychology Commons, Developmental Psychology Commons, Health

Psychology Commons, Lesbian, Gay, Bisexual, and Transgender Studies Commons, Social Psychology

Commons, and the Social Work Commons

\section{Recommended Citation}

Thompson, Michelle G., "The Impact of Microaggressions and Minority Stress on the Psychological WellBeing of Emerging Adult Sexual Minorities of Color" (2019). FIU Electronic Theses and Dissertations.

4007.

https://digitalcommons.fiu.edu/etd/4007

This work is brought to you for free and open access by the University Graduate School at FIU Digital Commons. It has been accepted for inclusion in FIU Electronic Theses and Dissertations by an authorized administrator of FIU Digital Commons. For more information, please contact dcc@fiu.edu. 


\title{
FLORIDA INTERNATIONAL UNIVERSITY
}

Miami, Florida

THE IMPACT OF MICROAGGRESSIONS AND MINORITY STRESS ON THE PSYCHOLOGICAL WELL-BEING OF EMERGING ADULT SEXUAL MINORITIES OF

COLOR

\author{
A dissertation submitted in partial fulfillment of \\ the requirements for the degree of \\ DOCTOR OF PHILOSOPHY \\ in
}

SOCIAL WELFARE

by

Michelle G. Thompson 
To: Dean Tomás R. Guilarte

R.Stempel College of Public Health and Social Work

This dissertation, written by Michelle G. Thompson, and entitled The Impact of Microaggressions and Minority Stress on the Psychological Well-Being of Emerging Adult Sexual Minorities of Color, having been approved in respect to style and intellectual content, is referred to you for judgment.

We have read this dissertation and recommend that it be approved.

Michelle Hospital

Paul Stuart

Tonette Rocco

Eric F. Wagner, Major Professor

Date of Defense: March 21, 2019

The dissertation of Michelle G. Thompson is approved.

Dean Tomás R. Guilarte R.Stempel College of Public Health and Social Work

Andrés G. Gil

Vice President for Research and Economic Development and Dean of the University Graduate School

Florida International University, 2019 


\section{DEDICATION}

To my grandparents, Juan and Hilda Lopez, and Hosiah and Rosetta Thompson. To my parents, Irene and Gerald (deceased) Lopez-Boston and Hosiah and Jozetta Thompson, my husband, Regainne Georges, my brother, Tyrone Maldonado, and my sister, best friend and biggest cheerleader, Sonia Thompson-Gordon (Scott too!). To my nieces and nephews, of which there are too many to name, who have endured the missed birthday parties and talks via video chat. To my family that I have acquired from all my many walks of life, and lastly, but not least, to my ancestors that paved the way for me to be in this place, at this time, and in this moment... I AM BECAUSE YOU ARE. 


\section{ACKNOWLEDGMENTS}

I would like to begin my acknowledgement with gratitude to my major professor and mentor, Dr. Eric Wagner, for believing in me when I wasn't certain that I still believed in myself. From humble beginnings in 2005, as an Evaluation Specialist for a CBIRG research project during the completion of my master's in psychology, until now, your door has always been open. Your trust in me to work in various capacities on several research projects, to continue to be a part of your team and space, has created an unexpected bond, and a connection that will last generations.

To my additional committee members, Dr. Michelle Hospital, Dr. Paul Stuart, and Dr. Tonette Rocco. Dr. Hospital, your simplistic breakdown of rather complex statistics was a sigh of relief during pressing times, and your open-door policy which provided support at nearly a moment's notice has been of great value to me over many years. Dr. Stuart, your wealth of knowledge, and many recommendations of key literature, truly guided my research. Dr. Rocco, your transparency and guidance on all matters, critical theory and LGBTQ, is greatly appreciated. I am grateful that you served as my external committee member and for your guidance and support on conceptualizing my research.

I would also like to thank my unofficial committee members, Dr. Staci LeonMorris, Dr. Hui Huang, and Dr. Rachel Clarke. Dr. Morris you have been a true beacon of light and warmth throughout my entire career at FIU, beginning with my master's program more than a decade prior. Dr. Huang, thank you for your support during the formative stages of developing my research questions and analytic plan as a member of my comprehensive exams committee. I also wish to express overwhelming gratitude for Dr. Rachel Clarke. Dr. Clarke, your time and dedication to all things \#TeamPhD is 
invaluable. I am forever grateful to the many lunch hour sessions, weekend evenings, and multitude of texts and phone calls. Thank you for being a mentor and a friend.

Further, I wish to express my appreciation and gratitude to my entire CBRI neé, FIU-BRIDGE, neé C-BIRG family. The many years of encouragement and enthusiastic support, the potlucks, and the willingness to indulge in my stress-baking will be forever etched in my heart. To my SACRED family, Mr. and Mrs. Jim Henson, Cheryl Riggs, and Dr. John Lowe, WADO. Special thanks to Roland Ramirez, former C-BIRG and FIU-BRIDGE member, and honorary CBRI member. Thank you for the many de-stress coffee breaks, lunches, campus walks, and office hideouts. To Italy and pasta making, because I am truly a "Master of None!"

To the school of Social Work, and special thanks to Dr. Richard Beaulaurier, Dr. Mary-Helen Hayden, Dr. Miriam Potocky, Zenaida Pirri, Gladys Ramos, Maria Gutierrez, Kelly Sydnor, and Natalia Giordano; your support has been of great value to me over these many years. I must also give a special moment of gratitude to Katie Boulos in Stempel administrative offices. Your words of encouragement and bright smiles pushed me through many long days.

The most difficult part is to offer my many thanks for the overwhelming, sometimes in absence of understanding, support to all my many family and friends outside of this university. To Fanis and Eric Ellis, thank you for always opening your home and family to my many needed weekend get-a-ways. To Pete and Tam Eugene, Carolyn and Nicole Rios-Lamy and baby Serei, Dana Williams, Chantale Achille, Dr. Grace Huxtable-Mount, Dr. Sharon Parker, Leonel Dorvil, Daniel Francis, Harry D’Metayer, Dr. Michael Pelts, Dr. George Turner, and Dr. Lisa Meyers, Chantale and 
Jason Leaks, Dr. Nche Zama, Freutz Lormine, Dr. Leisl, Sackschewsky, Jason A. Nichols, Dr. John L. Jackson, Dr. Jenny Jones, Dr. Mildred Joyner, Dr. Anthony Estreet, Dr. Ashley Austin, Dr. Shelly Craig, Pierre Noel, Dr. Linda Evans, and Dr. Rich Furman. You are all an inspiration and I thank you for allowing me to breathe, and for sending an abundance of love and energy to push me through my tough times. My Gratitude family, I truly am because you are. Olga, "No mud, No lotus!"

To my study buddies, fellow Ph.D. cohort mates, and program colleagues, some of which have already traversed this long and steady marathon, Dr. Christine Spadola, Dr. Meenal Sawant, Dr. Gira Ravelo, Dr. John Buschman, Dr. Sofia Fernandez, Cherelle Carrington, Andreja Lukic, Mitra Naseh, James Melton, and Michelle-Ann Rhoden. You have pushed and supported me throughout my many trials and tribulations. To the long weekends and late nights. I am forever indebted.

I apologize in advance if I have slighted anyone who was key during my process. Some things are now a blur. Know that I am truly grateful for you and the integral parts that you played in where I am today. It takes a village. Know that this is also for you. Last, but not least, I would like to acknowledge the FIU University Graduate School, and the Robert Stempel College of Public Health \& Social Work, for the 2018 - 2019 academic year, Dissertation Year Fellowship Award. Your leap of faith in me greatly supported the timely completion of my dissertation research. 


\begin{abstract}
OF THE DISSERTATION
THE IMPACT OF MICROAGGRESSIONS AND MINORITY STRESS ON THE PSYCHOLOGICAL WELL-BEING OF EMERGING ADULT SEXUAL MINORITIES OF

COLOR

by
\end{abstract}

Michelle G. Thompson

Florida International University, 2019

Miami, Florida

Professor Eric F. Wagner, Major Professor

Microaggressions impact psychological well-being (PWB) among sexual minorities and people of color (POC). Research to date has explored this relationship among White sexual minorities and POC independently, and not among sexual minorities of color (SMPOC). SMPOC may be at an even greater risk for low PWB due to compounded microaggressions. Emerging adults are also at risk for low PWB, but little is known about PWB among SMPOC emerging adults. The current study examined microaggressions and PWB among emerging adult SMPOC; it also examined outness and PWB among adult sexual minorities. It was hypothesized that: a) SMPOC would report greater microaggressions and lower PWB compared to heterosexuals and White non-Hispanic sexual minorities; b) the relationship between microaggressions and PWB would be stronger for SMPOC than White non-Hispanics; c) the relationship between microaggressions and PWB would be explained by outness; and d) the relationship between microaggressions and outness would be stronger for SMPOC than White nonHispanics. Results from structural equation modeling revealed: a) on average, SMPOC 
reported greater racial/ethnic microaggressions and lower PWB, compared to heterosexual POC; b) the mean differences of PWB between SMPOC and heterosexual and sexual minority White non-Hispanics were not statistically significant; c) on average, sexual orientation microaggressions was significantly related to outness, and race/ethnicity significantly moderated that relationship; d) race/ethnicity did not moderate the relationship between sexual orientation microaggressions and PWB; e) while outness did not mediate the relationship between sexual orientation microaggressions and PWB, outness was associated with greater PWB, holding constant sexual orientation microaggressions for all sexual minorities; and f) for SMPOC, outness did not mediate the relationship between intersectional microaggressions and PWB; holding constant intersectional microaggressions, outness was associated with greater PWB, and holding constant outness, intersectional microaggressions was associated with lower PWB. One hypothesis revealed contrary results; compared to White non-Hispanic sexual minorities, SMPOC reported less sexual orientation microaggressions. Findings offer support for increased attention to environmental approaches to preventing microaggressions on college campuses. Moreover, findings argue for developing programs for building resilience among SMPOC. 


\section{TABLE OF CONTENTS}

CHAPTER

PAGE

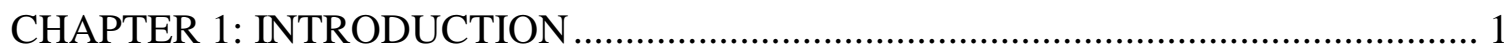

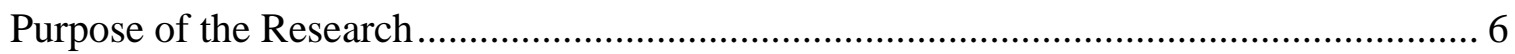

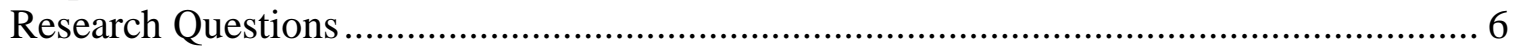

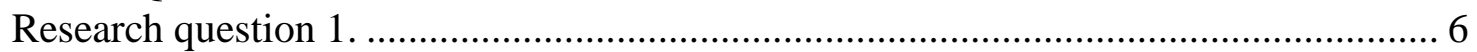

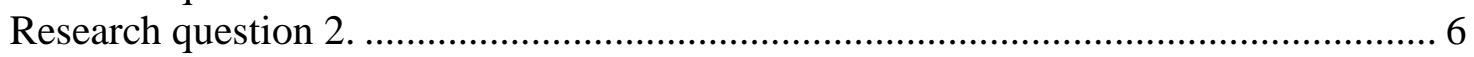

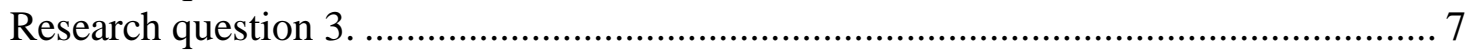

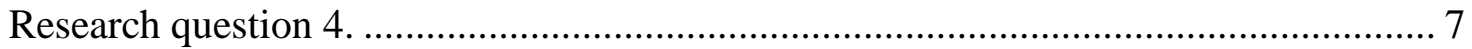

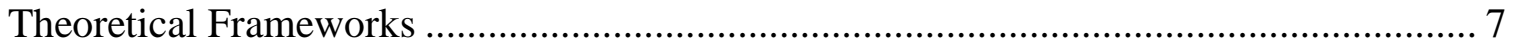

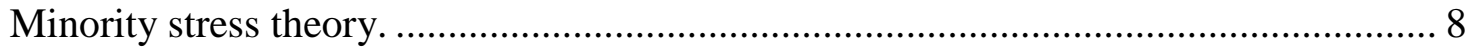

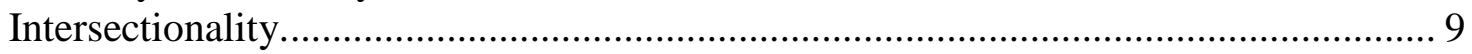

CHAPTER 2: CRITICAL REVIEW OF THE LITERATURE....................................... 12

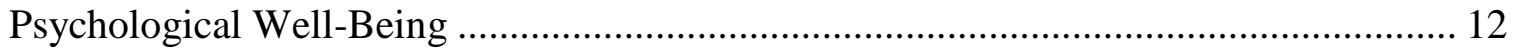

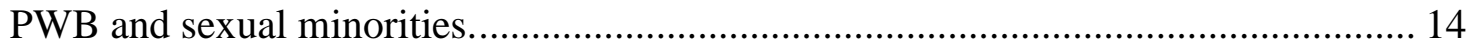

PWB and racial/ethnic minorities/people of color..................................................... 17

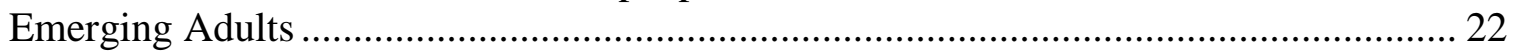

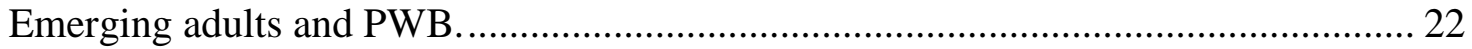

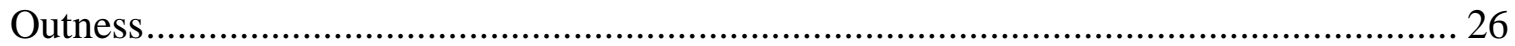

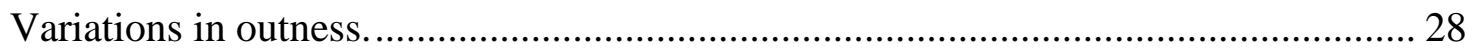

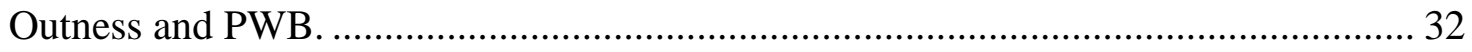

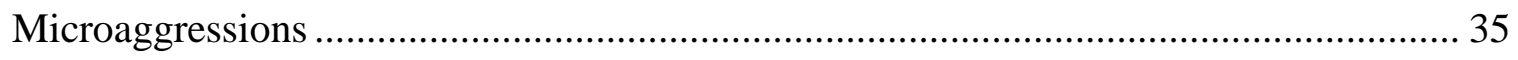

Taxonomy of sexual orientation microaggressions. ……....................................... 37

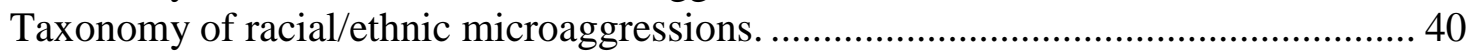

Microaggressions and PWB of sexual minorities.................................................... 43

Microaggressions and PWB of sexual minorities of color. ......................................... 46

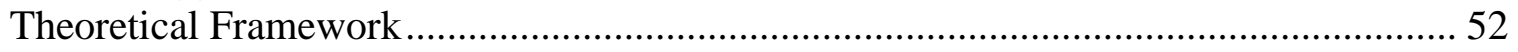

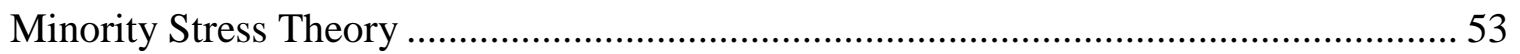

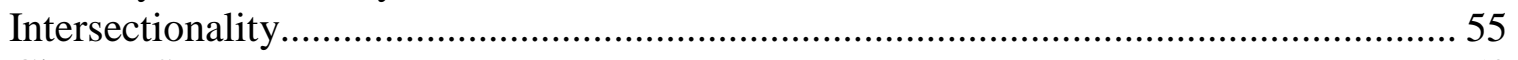

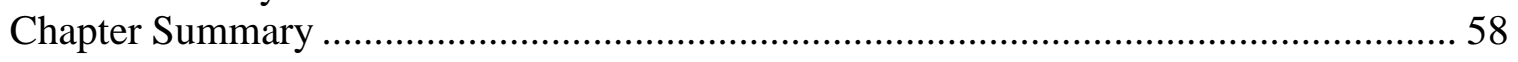

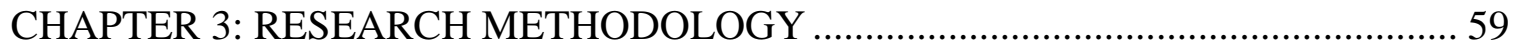

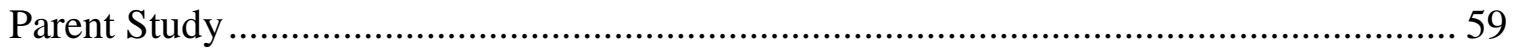

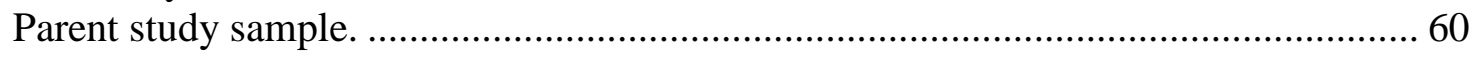

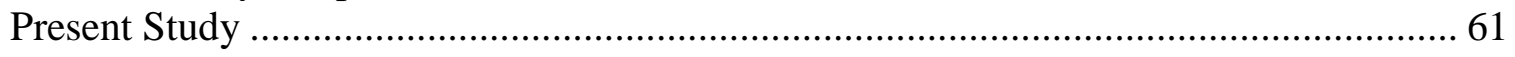

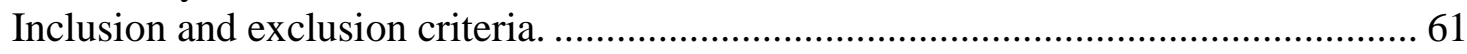

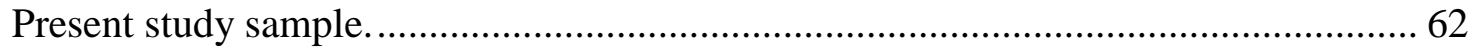

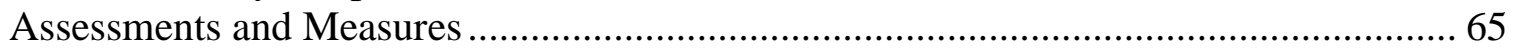

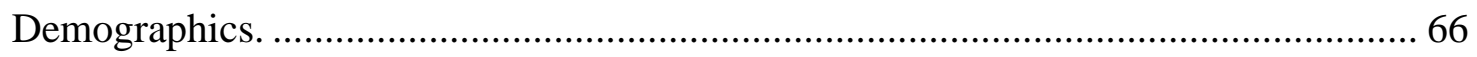

Outness Inventory (OI; Mohr \& Fassinger, 2000)................................................... 66

Racial and Ethnic Microaggressions Scale (REMS-45; Nadal, 2011). ....................... 67 
The Daily Heterosexist Experiences Questionnaire (DHEQ; Balsam, Beadnell, \&

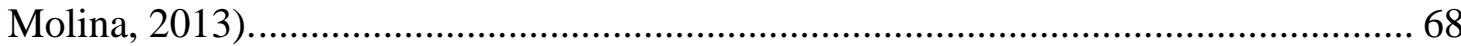
The LGBT People of Color Microaggressions Scale (LGBT-PCMS; Balsam, et al., 2011).

Ryff's Psychological Well-Being Scale (PWB; Ryff, 1989).................................. 70

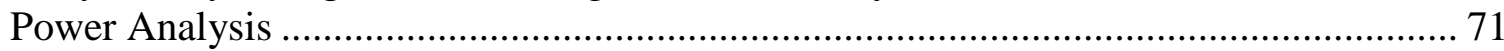

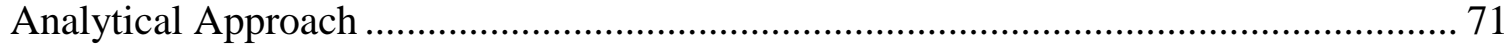

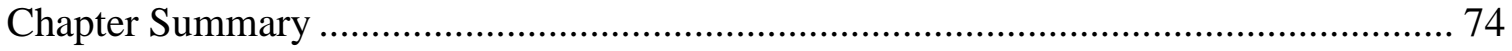

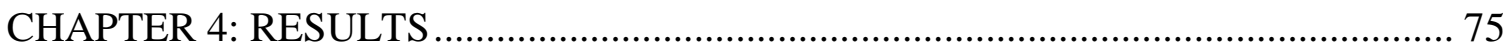

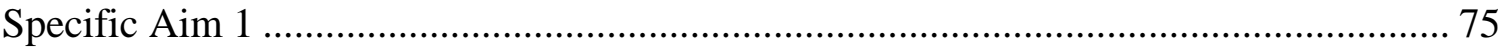

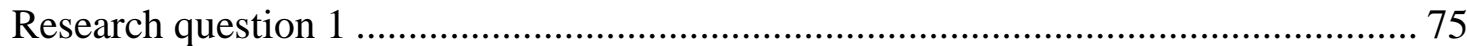

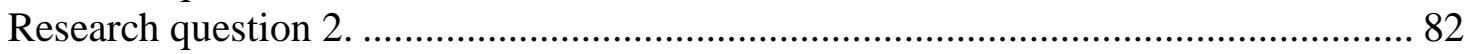

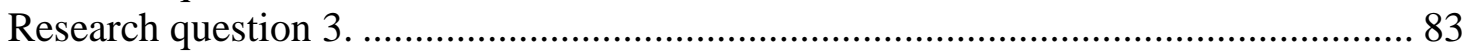

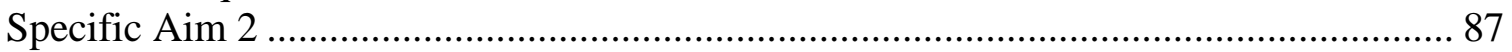

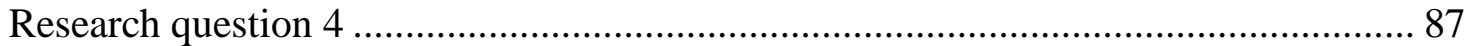

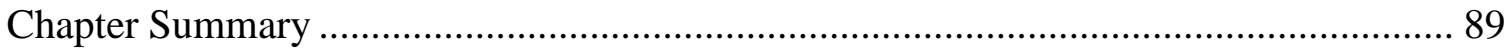

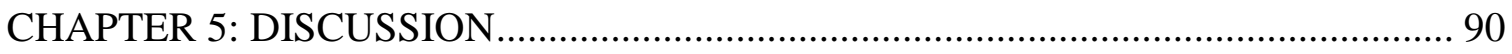

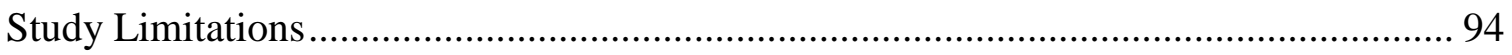

Research Implications and Future Directions for Social Work .................................... 97

Implications for Social Work Education and Practice ................................................ 101

Chapter Summary and Conclusions....................................................................... 104

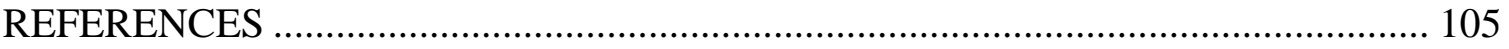

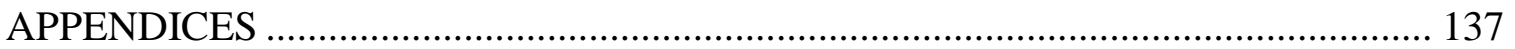

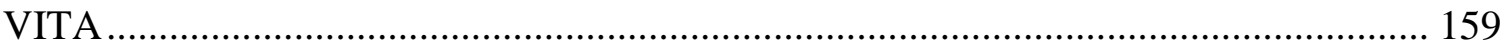




\section{LIST OF TABLES}

TABLE

PAGE

1. Taxonomy on Sexual Orientation and Gender Identity Microaggressions........... 38

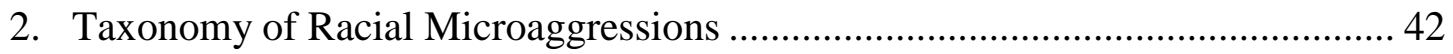

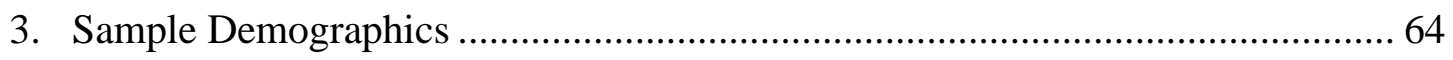

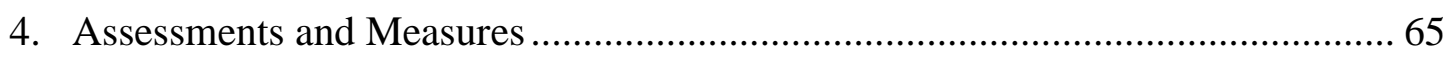

5. Mean Comparisons of Racial/Ethnic Microaggressions and Psychological WellBeing Predicted by Sexual Orientation for all POC ........................................ 77

6. Mean Comparisons of Sexual Orientation Microaggressions and Psychological Well-Being Predicted by Race/Ethnicity for all Sexual Minorities..................... 79

7. Mean Comparison of All Groups on Psychological Well-Being........................ 81

8. Means and Standard Deviations for Psychological Well-Being.......................... 81

9. Psychological Well-Being Predicted from Sexual Orientation Microaggressions as Moderated by Race/Ethnicity for Sexual Minorities ................................... 83

10. Relationship Between Sexual Orientation Microaggressions and Psychological Well-Being as Mediated by Level of Outness for Sexual Minorities .................. 85

11. Relationship Between Intersectional Microaggressions and Psychological WellBeing as Mediated by Level of Outness for Sexual Minorities of Color.

12. Outness Predicted from Sexual Orientation Microaggressions as Moderated by Race/Ethnicity for Sexual Minorities 


\section{LIST OF FIGURES}

FIGURE

PAGE

1. Minority stress processes in lesbian, gay, and bisexual populations .................. 11

2. Categories of Microaggressions and Corresponding Themes ............................ 41

3. Path Model for Research Question 1 Hypothesis 1a ........................................ 77

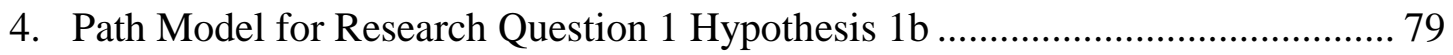

5. Path Model for Research Question 1 Hypothesis 1c ...................................... 81

6. Path Model for Research Question 2 Hypothesis 2a ..................................... 83

7. Path Model for Research Question 3 Hypothesis $3 \mathrm{a}$...................................... 85

8. Path Model for Research Question 3 Hypothesis 3b ….................................. 87

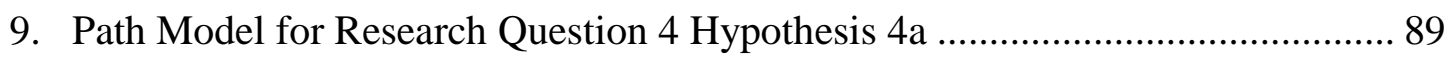

A. Institutional Review Board approval letter .................................................. 138

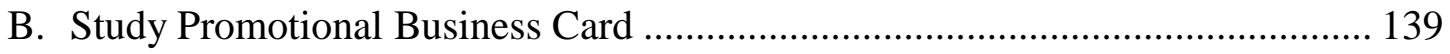

C. Florida International University research participation system ........................ 140

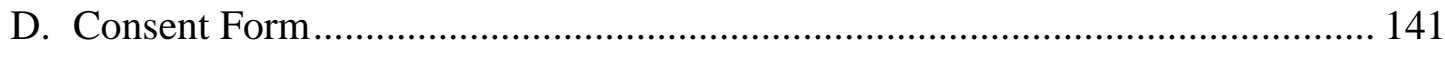

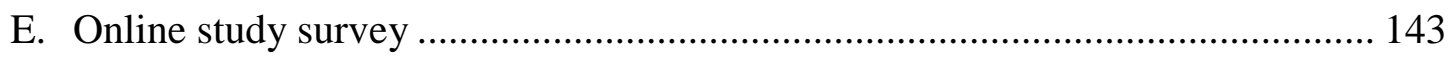

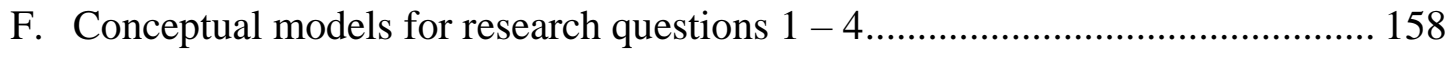




\section{ABBREVIATIONS AND ACRONYMS}

DL

DHEQ

DHEQIMP

HRSA

LGBQ

LGBT-PCSM

LGBTQ

MII

MSM

NIMHD

NSDUH

OI

OUTOVR

POC

PWB

REMS

REMIMP

SAMHSA

SEM

SOGIE

SMPOC
Down low

Daily Heterosexist Experiences Questionnaire

Sexual orientation microaggressions

Health Resources Services Administration

Lesbian, gay, bisexual, queer

LGBT People of Color Microaggressions Scale

Lesbian, gay, bisexual, transgender, queer

Microaggressions Intersectionality Index

Men who have sex with men

National Institute on Minority Health and Health Disparities

National Survey on Drug Use and Health

Outness Inventory

Overall outness

People of color

Psychological well-being, Psychological Well-Being Scale

Racial Ethnic Microaggressions Scale

Racial ethnic microaggressions

Substance Abuse and Mental Health Services Administration

Structural equation modeling

Sexual orientation and gender identity expression

Sexual minorities of color 


\section{CHAPTER 1: INTRODUCTION}

There are an estimated 8-9 million adults living in the U.S. who self-identify as lesbian, gay, bisexual, transgender, or queer (LGBTQ); also referred to as sexual minorities (Gates, 2011; Gates \& Newport, 2012). While sexual minorities make up a relatively small percentage of the U.S. population (4\%), sexual minorities face significant disparities in physical and mental health (Graham et al., 2011). In 2016, the National Institute of Minority Health and Health Disparities (NIMHD) designated sexual minorities as a health disparities research priority (Perez-Stable, 2016). Compared to their heterosexual counterparts, sexual minorities are less likely to receive routine preventive care, and as a result, are at higher risk for diagnoses of chronic and infectious diseases (e.g. heart disease, certain cancers, HIV/STIs) (Charlton et al., 2011; Mayer et al., 2008; Simon Rosser et a., 2016). Compared to heterosexuals, sexual minorities are also more likely to suffer from various eating related disorders (Boehmer, Bowen, \& Bauer, 2007; Diemer, Grant, Munn-Chernoff, Patterson, \& Duncan, 2015; Simon Rosser et al., 2016), are up to four times more likely to abuse alcohol and other substances, and are up to seven times more likely to report histories of depression, anxiety, and/or suicidality (Hatzenbuehler, 2011; King et al., 2008; Marshal et al., 2011; Silenzio, Pena, Duberstein, Cerel, \& Knox, 2007; Silvestre, Beatty, \& Friedman, 2013).

Emerging adulthood, the developmental period between adolescence and young adulthood (Arnett, 2000), spans the ages of 18 to 29 years, and is conceptualized as a time of exploration and the shifting of roles from a dependent to an independent adult. This developmental period also coincides with the median ages of onset for substance use disorders and treatments for psychosis (Kanny, Liu, Brewer, \& Lu, 2013; Kessler et al., 
2007). Much of the research on emerging adulthood clearly shows the everyday stress that accompanies this developmental period. It is common for emerging adults to have unstable housing and minimal paying odd jobs, to engage in numerous risky behaviors, and to have unsteady and multiple relationships, including various sexual partners (Halperin-Meerkin, Manning, Giordano, \& Longmore, 2012); all of which can exacerbate any issues in physical and mental health among this population. Gaining an understanding of stressors on the lives of emerging adults may have implications for early intervention and prevention efforts.

Sexual orientation identity exploration, on average, typically begins in adolescence and extends into the emerging adulthood stage (Dunlap, 2016; Floyd \& Bakeman, 2006; Rust, 1993). Exploring sexual orientation and ultimately "coming out" as a sexual minority poses many challenges (Dentato, Craig, Messenger, Lloyd, \& McInroy, 2014; Johns, Zimmerman, \& Bauermeister, 2013). Yet, a large proportion of the emerging adulthood literature to date has focused on heteronormative patterns of sexuality, leading to a gap in knowledge about emerging adult sexual minorities (Torkelson, 2012; Woodford, Paceley, Kulick, \& Hong, 2015). Focusing on emerging adults who also identify as a sexual minority may shed light on some of the difficulties that can be experienced by individuals traversing a normally tumultuous time in their life who are simultaneously navigating a space in a society that does not always readily accept them.

According to the Healthy People 2020 Initiative (2010) many of these disproportionate health outcomes among sexual minorities are linked to victimization and discrimination and the associated stress due to their sexual orientation and gender identity 
expression (SOGIE) (Bostwick \& Hequembourg, 2014; Hong, Woodford, Long, \& Ren, 2016; Pittman, Kim, Hunter, \& Obasi, 2017; Robinson \& Rubin, 2016; Seelman, Woodford, \& Nicolazzo, 2017). Discrimination towards sexual minorities is all too frequent. Gallup Poll (Jones, 2012) results have shown that $40 \%$ of sexual minorities and $42 \%$ of all Americans believe that discrimination against sexual minorities is still a serious problem. Sexual minorities are more likely to report being denied access to quality medical care (National Healthcare \& Quality Disparities Report, 2016), experience physical violence, receive poor service at business establishments (i.e. restaurants and hotels), and to hear homonegative slurs and jokes (A Survey of LGT Americans, 2013). Even with federal interventions such as the landmark Supreme Court case, Obergefell v. Hodges (2015), which legalized same-sex marriages in all 50 states, sexual minorities are often still denied their legal and basic human rights. Even after the Supreme Court's favorable decision, citing religious differences, some local court districts across the U.S. have outright denied sexual minorities the right to apply for marriage licenses (Blinder \& Perez-Pena, 2015). Moreover, various businesses have gone so far as to refuse to provide marriage ceremonies, floral decorations and even a samesex themed cake to same-sex couples (de Vogue \& Watkins, 2018)!

The list of experiences of discrimination towards sexual minorities has a long history and is exhaustive. While these traumatic experiences are likely to lead to negative mental health consequences among sexual minorities (Mustanski, Andrews, \& Puckett, 2016; Robinson \& Rubin, 2016), microaggressions (Sue et al., 2007a), a subtype of discrimination imparted on those who hold a minority status, may also be a contributing factor. Microaggressions are subtle insults that are subjective reminders to marginalized 
groups of their oppressed/second-class state in society (Sue, Capodilupo, \& Holder, 2008; Sue et al., 2007a; Sue, 2010). Similar to overt types of discrimination, over time, insults like microaggressions eat away at self-esteem and self-worth, both of which are essential to health and overall well-being.

Associations between the stress experienced from belonging to a marginalized group and microaggressions and their impact on psychological well-being has also been found among racial/ethnic minorities (Nadal et al., 2011; Sue et al., 2008). Both sexual minorities and racial/ethnic minorities, also referred to as people of color (POC), may experience multiple incidents of microaggressions throughout their day that are unique to their marginalized identities; and both groups are by far disproportionately represented in mental health and health disparities outcomes (Healthy People 2020 Initiative, 2010; National Healthcare Quality Disparities Report, 2016). Therefore, the literature indicates that persons with intersecting identities (e.g., those who are both a sexual minority and a POC; "intersectionality") (Crenshaw, 1991), may experience a) a compounding effect of microaggressions (Nadal, 2013; Sterzing, Gartner, Woodford, \& Fisher, 2017) and b) may be at a greatly increased risk for lessened psychological well-being (Balsam, Molina, Beadnell, Simoni, \& Walters, 2011; Bowleg, 2013; Bowleg, Teti, Malebranch, \& Tshcann, 2013; Moradi, et al., 2010).

Psychological well-being (PWB), commonly defined as overall positive psychological functioning, is an important component of our basic hierarchy of human needs (Maslow, 1968). Having positive psychological functioning can lead to better physical health and better physical health can lead to positive psychological functioning (Boylan \& Ryff, 2015; Galambos, Barker, \& Krahn, 2006; Hyunh \& Fuligni, 2010; 
Mouzon, Taylor, Woodward, \& Chatters, 2017; Poscoe \& Richman, 2009; Ryff et al., 2006). Distress associated with SOGIE has been found to be positively associated with depression and negatively associated with physical health among sexual minorities (Parra, Benibgui, Helm, \& Hastings, 2016). Moreover, chronic, daily, experiences of microaggressions has also been related to low PWB among sexual minorities (Nadal et al., 2011; Seelman, et al., 2017; Woodford, Howell, Silvershanz, \& Yu, 2012). Not only are sexual minorities at risk for low PWB, but emerging adults also appear to be at particular risk for low PWB, yet few studies of well-being have focused exclusively on this developmental period (Arnett, 2000; 2004; Hendry \& Kloep, 2010; Nelson \& Barry, 2005; Spencer \& Patrick, 2009).

Despite these assertions, the majority of the research on sexual orientation-based microaggressions typically has been conducted with White non-Hispanic lesbian, gay, bisexual, and queer (LGBQ) samples. The predominance of sexual orientation-based microaggressions research with White non-Hispanic LGBQ samples means that there remains a dearth of knowledge about microaggressions among LGBQ-POC, also referred to as sexual minorities of color. Moreover, the emerging adulthood literature is limited in research on emerging adults who are also sexual minorities. Given such, emerging adult persons of color who also identify as a sexual minority (e.g. emerging adult sexual minorities of color) may be at an increased risk for lower PWB on the account of homonegative experiences, like microaggressions (Sterzing, et al., 2017), and the compounding stressors associated with their intersecting marginalized identities (Hudson, 2015; Moradi, et al., 2010). 


\section{Purpose of the Research}

The purpose of this study was to empirically examine the experiences of microaggressions among emerging adult sexual minorities of color and the association between microaggressions and PWB among emerging adult sexual minorities of color. As a secondary aim, this study also explored the relationship between microaggressions and outness among emerging adult sexual minorities.

\section{Research Questions}

Research question 1. Do sexual minorities of color report greater experiences of microaggressions and lower PWB as compared with White non-Hispanic sexual minorities and heterosexuals?

Hypothesis 1a. Sexual minorities of color will report experiencing more racial/ethnic related microaggressions and lower PWB compared to heterosexual people of color.

Hypothesis 1b. Sexual minorities of color will report experiencing more sexual orientation related microaggressions and lower PWB compared to White non-Hispanic sexual minorities.

Hypothesis 1c. Sexual minorities of color will report lower overall PWB than White non-Hispanic sexual minorities and heterosexuals.

Research question 2. Does racial/ethnic identity moderate the relationship between experiencing microaggressions and PWB?

Hypothesis $2 a$. The associations between experiencing microaggressions and being bothered by microaggressions will be stronger among sexual minorities of color than among White sexual minorities. 
Research question 3. Does outness mediate the relationship between experiencing microaggressions and PWB among sexual minorities?

Hypothesis 3a. Among sexual minorities, the level of outness will mediate the relationship between experiencing sexual orientation related microaggressions and PWB.

Hypothesis 3 b. Among sexual minorities of color, the level of outness will mediate the relationship between experiencing intersectional microaggressions and PWB.

Research question 4. Does racial/ethnic identity moderate the relationship between experiencing sexual orientation related microaggressions and outness among sexual minorities?

Hypothesis 4a. The associations between experiencing microaggressions and outness will be stronger among sexual minorities of color than among White nonHispanic sexual minorities.

\section{Theoretical Frameworks}

My research questions exploring PWB among sexual minorities of color were guided by two theoretical frameworks: (1) minority stress theory, and (2) intersectionality. Minority stress theory (Meyer, 1995) refers to the unique stress related to sexual orientation and undergirds my aim to explore the microaggressions uniquely related to sexual orientation. An intersectional lens (Crenshaw, 1991) informs my research questions investigating the compounding effect of being a member of more than one socially and politically marginalized group (i.e. the intersection/s between race/ethnicity and sexual orientation). Below is a brief explanation of the guiding frameworks for this study. 
Minority stress theory. Stress theories have been used to explain how social interactions such as those involving prejudice and discrimination have a negative impact on a persons' health and well-being (Contrada et al., 2000; Meyer, 2003; Perry, StevensWatkins, \& Oser 2013). Minority stress theory (Meyer, 1995) is a framework that builds on general stress theories by pointing to the unique societal stressors experienced by sexual minorities. These unique stressors include heterosexism, and prejudice and discrimination directly related to a person's SOGIE. Minority stress (see Figure 1) involves a process that moves along a continuum from distal to proximal: (1) external objective stressful events, (2) expectations of such events and vigilance this expectation requires, (3) concealment of one's sexual identity, and finally (4) the internalization of negative social attitudes. Distal stressors are events from the external environment and are objective; proximal stressors are personal or internal processes that are subjective and based on the internalized experience of the distal stressor. Subjective experiences can often lead to hostile attribution biases and negative confirmatory experiences (Banaji \& Greenwald, 2013). Meyer hypothesizes that "a high level of perceived stigma would lead minority group members to maintain a high degree of vigilance - expectations of rejection, discrimination and violence - with regard to components of their minority identity in interactions with dominant group members" (1995, p. 41).

According to Meyer (1995), minority stress theory is not finite nor is it intended to be all-inclusive. Minority stress theory places a greater emphasis on subjective experiences of the person and how certain experiences negatively impact one's daily life which in turn can impact overall PWB. The subjectivity of minority stress is what makes the framework complementary in exploring experiences of microaggressions among 
sexual minorities. Like microaggressions, minority stress is unique (subjective to the individual), chronic (long lasting), and socially based (interactions within the environment).

Intersectionality. Intersectionality, a term coined by Kimberle Crenshaw, is used to explore the crossroads (intersections) of socially and politically constructed identities such as, but not exclusive to, gender, race, and sexuality, and their relations to historical and current oppression, discrimination, and marginalization by dominant groups (Crenshaw, 1991; Hill-Collins, 1990; Hill-Collins \& Bilge, 2016). While Crenshaw coined the term intersectionality, the seminal work, A Black Feminist Statement, released in 1977 by a group of Black lesbian feminists called the Combahee River Collective, began the conversation as a personal and political commitment towards activism focused on "struggling against racial, sexual, heterosexual, and class oppressions and see as our particular task the development of integrated analysis and practice based upon the fact that major systems of oppressions are interlocking" (p. 115). In other words, intersectionality theorists argue that one cannot simply silo oppressed identities when exploring origins of oppressive forces, these identities are intersected and are compounded to create new experiences (Crenshaw, 1991). As such, intersectionality is a form of identity politics (Hill-Collins \& Bilge, 2016).

Dill and Zambrana (2009) purport that the use of intersectionality in social justice advocacy and research "provides an important lens for reframing and creating new knowledge because it asserts new ways of studying power and inequality and challenges conventional understandings of oppressed and excluded groups and individuals (p. 285)." Black feminists and other feminists of color from around the world have utilized an 
intersectional lens as a form of critique for just over 40 years (Combahee River Collective, 1977; hooks, 1984; Hill-Collins, 1990; Crenshaw, 1991), and it is in the most recent 20 years that intersectional analyses are considered a "gold standard" (Mehrotra, 2010; Nash, 2008). As such, social work researchers have called for more research using an intersectional framework (Mehrotra, 2010; Sterzing et al., 2017). In their most recent review, Sterzing, Gartner, Woodford, and Fisher (2017) explored SOGIE-related microaggressions and called for more approaches using an intersectional lens.

As discussed, minority stress theory explores the additional stressors that are based on a marginalized identity that negatively impacts an individual's life. Given that the intersectionality framework also places emphasis on marginalized and oppressed identities, use of this framework will complement the minority stress theory through its conceptualization of the experiences of those individuals who hold overlapping identities (e.g. sexual minorities of color). Therefore, this study used an intersectional approach as one of the guiding frameworks in analyzing the compounding impact of microaggressions based on race, ethnic identity and sexual orientation and the impact of these socially marginalized identities on PWB. 
Figure 1. Minority stress processes in lesbian, gay, and bisexual populations

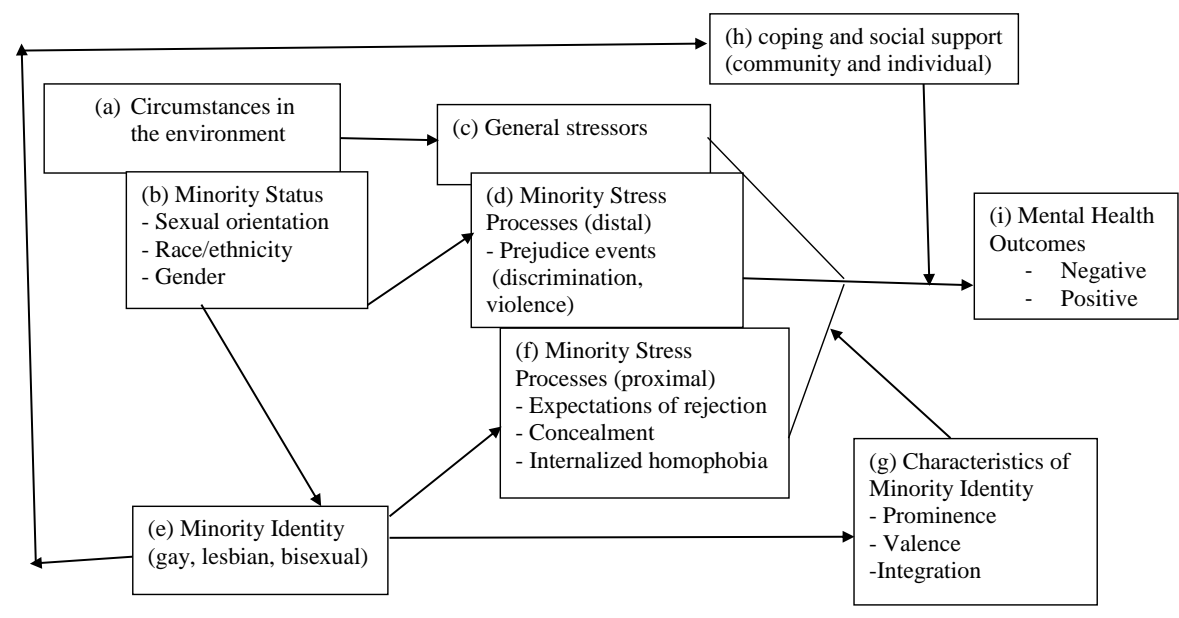

Source: Adapted from Meyer, 2003, p. 679. 


\section{CHAPTER 2: CRITICAL REVIEW OF THE LITERATURE}

The current social and political climate surrounding the basic human and civil rights of sexual minorities is most assuredly a chaotic one and a climate in which a sexual minority is unsure of whether their rights will be truly protected. Living in a state of fear of persecution can be taxing on the mental health of anyone, and a person who identifies as a sexual minority is surely someone. The history of oppression in the U.S., of both sexual minorities and people of color cannot be erased. The parallels of "othering" and minoritizing the "other" in terms of anyone who does not fit the White, heteronormative aesthetic is only obvious.

This study aimed to contribute to the literature by exploring the experiences and impact of everyday discrimination, microaggressions, among emerging adults who identify as a sexual minority, a racial/ethnic minority and emerging adults who dually identify as both a sexual minority and a racial/ethnic minority (e.g. emerging adult sexual minorities of color). This literature review will begin with an overview of the state of psychological well-being among sexual minorities and people of color. An introduction to the developmental period, emerging adulthood, and a review of the literature on outness and the prevalence and impact of microaggressions among sexual minorities will also be provided. This chapter will end with an exploration of the literature on the theoretical frameworks that guided this study.

\section{Psychological Well-Being}

Psychological well-being (PWB), or eudaimonic well-being, is commonly defined as overall positive psychological functioning (Ryff, 1989; Ryff \& Keyes, 1995). Ryff and Singer (2008) argue that a simplistic definition of eudaimonia as mere "happiness" is 
limiting, and that eudaimonic well-being is "construed as growth and human fulfillment, is profoundly influenced by the surrounding contexts of people's lives, and as such, ... eudaimonic well-being may be consequential for health" (pp. 14-15). PWB is comprised of six dimensions: 1) self-acceptance; 2) personal growth; 3) purpose in life; 4) positive relation with others; 5) environmental mastery; and 6) autonomy (Ryff, 1989; Ryff \& Keyes, 1995; Ryan \& Deci, 2001). Well-being is seen as a vital component to living a satisfied life and is key to theoretical foundations and practices that are rooted in selfactualization and mindfulness (Chang, Huang, \& Lin, 2015; Cohen \& Cairns. 2012; Peer \& McAuslan, 2016; Maslow, 1968).

In addition to Ryff and Singer's (2008) conceptualization of eudaimonia as paramount to human livelihood, associations between physiological and psychological health and overall well-being are more than evident in the literature (Boylan \& Ryff, 2015; Galambos et al., 2006; Gibbons et al., 2012; Hyunh \& Fuligni, 2010; Mouzon et al, 2017; Poscoe \& Richman, 2009; Ryff et al., 2006). For example, Poscoe and Richman (2009) found positive associations between PWB and engaging in physically healthy behaviors. Similarly, in a longitudinal study, Boylan and Ryff (2015) reported that positive affect and life satisfaction were linked to reduced cardiovascular risk. Low wellbeing has even been shown to predict increased depressive symptoms and physical complaints (Hyunh \& Fuligni, 2010; Ryff, Keyes, \& Hughes, 2003), and increased alcohol and substance abuse (Galambos, et al., 2006; Gibbons et al., 2012).

Not only is there research to support connections between physical well-being and PWB, there is also research to support a link between eudaimonia and individuals who report less control over their external environments, such as those who experience 
chronic everyday discrimination like sexual minorities (Davis, Saltzburg, \& Locke, 2009; Detrie \& Lease, 2007; Hudson, 2015; Johns, et al., 2013; Spencer \& Patrick, 2009; Woodford et al., 2012; Woodford et al., 2015), and people of color (POC) (Araujo \& Borrell, 2006; Hyunh \& Fuligni, 2010; Mouzon et al., 2017; Nadal, Griffin, Wong, Davidoff, \& Davis, 2017; Ryff et al., 2003; Simandan, 2014). The following subsections will present an overview of the literature on the PWB of (a) sexual minorities and (b) people of color (POC); two groups for whom discrimination has been linked to disparities in mental and physical well-being and social determinants of health.

PWB and sexual minorities. The exact number of adults living in the U.S. who are sexual minorities is unclear, however rough estimates report around $4 \%$ of the total U.S. population (Gates, 2011; Gates \& Newport, 2012). In comparison, $4 \%$ is only a speck of the more than 300 million people living in the U.S., yet sexual minorities are more at risk for lower physical and psychological health than their comparative heterosexual counterparts (Graham, et al., 2011). While the outcomes may vary by subgroup, some of the top issues effecting sexual minorities include certain cancers, obesity, depression, anxiety, suicide, and substance abuse (SAMHSA, 2012); all of which are interconnected and may impact PWB.

Sexual minorities, like people of color and other marginalized groups, may be more likely than their heterosexual counterparts to disproportionately experience problems in a variety of social determinants of health; which can lead to poorer overall health outcomes (Thomeer, 2013). For example, sexual minorities are less likely to have health insurance coverage, and are more likely to report low income, be at risk for homelessness and poverty, to receive cash assistance, and to experience barriers in 
employment and receiving proper healthcare (Burwick, Gates, Baumgartner, \& Friend, 2014; Gonzales \& Ortiz, 2015; Haider et al., 2017; Graham et al., 2011). Moreover, research has shown that sexual minorities may experience a reduction in life expectancy by a difference of more than 10 years (Hatzenbuehler et al., 2014).

Not only do sexual minorities experience disparities in physical health outcomes, sexual minorities are also disproportionately represented in outcomes on mental health. In comparison to their heterosexual counterparts, sexual minorities are up to 2.5 times more likely to report a history of suicidal ideation, up to 1.5 times more likely to experience anxiety and depression, and are up to 2.0 times more likely to receive treatment for substance abuse (King et al., 2008; Lee, Gamarel, Bryant, Zaller, \& Operario, 2016; SAMHSA, 2012; Schuler, Rice, Evans-Polce, \& Collins, 2018; Spencer \& Patrick, 2009). These disproportionate outcomes between sexual minorities and heterosexuals may be linked to discrimination (Gonzalez \& Oritz, 2015; Graham et al., 2011; Lee et al., 2016; Schmitt, Branscombe, Postmes, \& Garcia, 2014; Williams \& Mann, 2017).

In a meta-analysis exploring the association between perceived discrimination and PWB, Schmitt, Branscombe, Postmes, and Garcia (2014) found strong support that perceived discrimination in general is a threat to PWB. Importantly, these investigators noted that "compared to discrimination based on gender or race, perceived discrimination was more strongly related to well-being for sexual minorities, people with mental illness, people with physical disabilities, and people stigmatized as overweight (p. 17) [italics added]." When comparing sexual minorities who ever experienced discrimination to those who did not, Lee, Gamarel, Bryant, Zaller, and Operario (2016) found that sexual minority males who reported a history of experiencing discrimination had higher odds of 
any lifetime substance use disorder compared to sexual minority males who did not experience discrimination. Additionally, the study also found that among sexual minority women, those who reported ever experiencing discrimination had a greater odds of any lifetime mood or anxiety disorder compared to sexual minority women who did not experience discrimination (Lee et al., 2016). Spencer and Patrick (2009) reported similar results in their study in which sexual minorities had lower self-esteem, greater depressive symptoms and higher anxiety compared to heterosexuals.

Sexual minorities live in an environment that does not always socially accept them and at times, will overtly discriminate against them. Outness will be defined and discussed in a later section, however, it bears mentioning here. Research shows that belongingness and social support are important to well-being and living openly as a sexual minority (Davis et al., 2009; Hudson, 2015). The process of publicly identifying as a sexual minority may expose individuals to experiences of discrimination; socially and structurally, which may then cause lower PWB (Davis et al., 2009; Detrie \& Lease, 2009; Gonzales \& Ortiz, 2015; Hatzenbuehler et al., 2014). Sexual minorities who felt excluded from their communities have even expressed distress over not belonging (Detrie \& Lease, 2009; Hudson, 2015; Johns et al., 2013).

Detrie and Lease (2009) found that social support was a significant predictor of PWB among sexual minorities. Johns, Zimmerman, and Bauermeister (2013) found that women who identified as a sexual minority or reported same-sex attractions experienced greater anxiety and lower self-esteem compared to heterosexual women or women with opposite sex attractions. In their study, the sexual minority women who reported greater 
anxiety and lower self-esteem were also more likely to report less social support and less maternal support compared to heterosexual women (Johns et al., 2013).

Not only is social support important to PWB among sexual minorities, but structural support, such as policies that protect sexual minorities from discrimination, is also linked to PWB (Davis et al., 2009; Hatzenbuehler et al., 2014; HHS, 2016; Woodford et al., 2015). LGBT supporting policies have even been shown to increase life expectancy among sexual minorities (Hatzenbuehler et al., 2014). Using concept mapping, study participants in Davis, Salzburg, and Locke (2009) indicated that supportive policies, safe spaces and programs geared towards protecting sexual minorities in communities were a priority to advance the PWB of sexual minorities. Other studies have shown that experiencing, and living, in environments in which antiLGBQ policies exist can cause lower PWB among sexual minorities (Raifman, Moscoe, Austin, \& McConnell, 2017; Woodford et al., 2015). Raifman, Moscoe, Austin, and McConnell (2017) found a reduction in suicidality among sexual minorities after the passing of same-sex marriage equality. Lastly, the U.S. Department of Health and Human Services (HHS, 2016), has laid out strategic plans to advance the health and well-being of sexual minorities of which includes advances in implementing non-discrimination provisions in healthcare for sexual minorities; therefore, linking discrimination and PWB among sexual minorities. Similar outcomes on PWB can be seen among POC. The following subsection will review PWB among POC.

PWB and racial/ethnic minorities/people of color. According to the U.S. Census Bureau (2018), people of color (POC) make-up approximately $39 \%$ of the estimated 327 million people living in the U.S, of which the largest identified groups are 
Hispanics (18\%) and African Americans/Black (13\%). By 2044, more than half of all Americans are expected to belong to a minority group (Colby \& Ortman, 2015). It has been more than 70 years since President Truman's Committee on Civil Rights released To Secure These Rights (1946), and this year, 2018, marks the $50^{\text {th }}$ anniversary of the release of the Kerner Commission Report (1968), each of which were established to explore the social determinants of health and well-being among POC; yet POC as a whole remain on the lower end of the distributions for average household family income, employment, education and housing and, on the higher end for average rates of crime and incarceration (Alexander, 2010; Cook et al., 2018; Petit \& Western, 2004; SAMHSA, 2015; Singh et al., 2017).

In fact, the Health Resources and Services Administration's (HRSA) 2017 Health Equity Report (Singh et al., 2017) indicates that the poverty rates for POC (American Indians/Alaska Natives 26.6\%, African Americans/Blacks 25.4\%, Hispanics 22.6\%, and Native Hawaiians/Pacific Islanders 18.9\%) are two times higher than the poverty rates for non-Hispanic Whites (10.4\%). Similar numbers are reflected in unemployment and postsecondary education. For instance, the percent of non-Hispanic Whites (34\%) with postsecondary degrees nearly doubled that of the percent of POC with post-secondary degrees (African Americans/Blacks 20\%, Native Hawaiians/Pacific Islanders 15\%, American Indian/Alaska Natives 14\%, and Hispanics 14\%) (McFarland, 2017; Singh 2017).

In addition, POC are also disproportionately affected by health and mental health problems and suffer from health inequities and disparities (National Healthcare Quality \& Disparities Report, 2016). The U.S. Department of Health and Human Services (HHS, 2018) defines a health disparity as: 
[a] particular type of health difference that is closely linked with social or economic disadvantage. Health disparities adversely affect groups of people who have systematically experienced greater social and/or economic obstacles to health and/or a clean environment based on their racial or ethnic group; religion; socioeconomic status; gender; age; mental health; cognitive, sensory, or physical disability; sexual orientation; geographic location; or other characteristics historically linked to discrimination or exclusion ("Glossary of Terms", para 5) [italics added].

According to the 2015 National Healthcare Quality Disparities Report (2016), compared to non-Hispanic Whites, POC are less likely to have medical insurance, less likely to have routine medical check-ups, and are more likely to face difficulties in accessing quality care (Cook et al., 2018). Moreover, POC have a higher prevalence of diabetes, obesity, and hypertension (Singh et al., 2017); of which have led to much higher morbidity and mortality rates than non-Hispanic Whites (Meyer, Yoon, \& Kaufmann, 2013; Singh et al., 2017).

The rate of mental health and mental health service use among POC is complicated at best (Zemore et al., 2018). For example, whereas American Indian/Alaska Natives are among the highest in prevalence of any diagnosable mental, behavioral or emotional disorder, African Americans/Blacks are among the lowest (SAMHSA, 2014). In addition, American Indian/Alaska Natives have the highest rates of suicide and the highest rates of drug-induced deaths (Crosby, Ortega, \& Stevens, 2013; Mack, 2013) of any racial/ethnic group and, while binge drinking is reported at significantly higher rates among non-Hispanic Whites (21.1\%), American Indian/Alaska Natives binge drink at 
some of the most intensive levels ( 8 drinks in one session) (Kanny et al., 2013;

SAMHSA, 2014). Differences in prevalence of substance use and mental health disorders among POC are likely influenced by the rate of mental health service use among the various subgroups of POC. American Indian/Alaska Natives (16\%) (and 17\% of nonHispanic Whites) were twice as likely to utilize mental health services compared to African Americans/Blacks (9\%) and Hispanics (7\%) (SAMHSA, 2015).

Historical discrimination of POC is a putative argument that undergirds the disparities in health and well-being between POC overall, and non-Hispanic Whites (Colen, Ramey, Cooksey, \& Williams, 2018; Campbell \& Mowbrey, 2016; Cook et al., 2018; Hyunh \& Fuligni, 2010; Metzger et al., 2018; Woody \& Green, 2001). These experiences may include a long and ongoing history of distrust in the medical profession due to a history of inequitable treatment, cultural barriers that facilitate the neglect and/or mistreatment of underserved groups and, the associated stigma regarding mental health as a sign of weakness among some POC (Campbell \& Mowbray, 2016; Cook et al., 2018).

In a study exploring the effects of race and gender on social and PWB, Woody and Green (2001) found that among their sample of White $(n=3,549)$ and African American/Black $(\mathrm{n}=981)$ middle-class, non-disadvantaged, married couples, race/ethnicity significantly predicted generalized contentment (the Generalized Contentment Scale was used to measure PWB in this study $)(b=.050, p<.001)$. Also notable in the study, (a) White women reported the highest levels of PWB and African American/Black men reported the lowest levels of PWB and, (b) White respondents on average, had higher incomes and higher levels of academic achievement. (Woody \& Greene, 2001). 
In other more recent studies exploring the relationship between discrimination and PWB among various subgroups of POC, Hyunh \& Fuligni (2010) found that more than $60 \%$ of their sample reported experiencing discrimination, and the greater the amount of discrimination, the greater the reports of physical complaints. Additionally, Metzger and colleagues (2018) found significant associations among perceived stress from experiences of discrimination, alcohol use, and binge drinking in a sample of African Americans/Blacks. Moreover, Cobb and colleagues (2018) found a negative relationship between discrimination and PWB and life satisfaction among a sample of Hispanics. Finally, research has even shown that given higher education, and upper middle class income, POC remain at the bottom rung of the ladder in upward mobility which may contribute to lower PWB (Chetty, Hendren, Jones, \& Porter, 2018). In summary, the more experiences of discrimination, and perceptions of discriminatory experiences that POC face, the more the potential for low PWB among POC (Giamo, Schmitt, \& Outten, 2012; Hyungh \& Fuligni, 2010).

Thus far, this section has reviewed literature on the PWB of both sexual minorities and POC. In addition, this subsection has briefly reviewed the relationship between experiences of discrimination and PWB among sexual minorities and POC; each with the purpose of supporting the argument that individuals who dually identify as both a sexual minority and a POC may be even more likely to report lower PWB due to living in a world that assaults them on multiple fronts. The following section will define emerging adulthood and present literature on the PWB of emerging adults; the population chosen for the current study. 


\section{Emerging Adults}

Emerging adulthood is a relatively new stage in human growth and life span development. Introduced through the work of J. Arnett (2000; 2004; 2007; 2014), emerging adulthood begins in late adolescence and ends in young adulthood. Emerging adulthood has also been referred to as the "quarter life crisis" stage (Robinson, 2018). The age range that defines this period of development is between $18-25$ years but can include individuals up to 29 years of age. It is important to distinguish emerging adulthood from emerging adults. Emerging adulthood is the term used to describe the specific stage or developmental period of the human life span; whereas emerging adults are the individuals that are currently experiencing life within the developmental period emerging adulthood (Syed \& Mitchell, 2013). As quoted in Syed and Mitchell (2013), “[e]merging adults corresponds to the psychological aspect of the phenomenon, as it gets to the heart of the meaning and experiences of the individuals themselves" (pp. 84). The following subsection will explore the experiences of emerging adults within the life span stage emerging adulthood as it pertains to PWB.

Emerging adults and PWB. Emerging adults are nearly twice as likely to be medically uninsured compared to middle aged adults (Moonesinghe, Chang, \& Truman, 2013). Approximately $12 \%$ of all emerging adults have incomes below national poverty levels (Beckles \& Truman, 2013), and this age group experiences some of the highest rates in unemployment (Bureau of Labor Statistics, 2018). Arnett (2007) situates emerging adulthood within Marcia's (1980) moratorium stages of identity development where individuals often describe their life as being not quite a teenager but also not quite an adult; a period of transition. 
To bring context to the life of an emerging adult, consider the following: emerging adulthood is a transitional stage, many will have just graduated high school, are entering college, a technical school and/or the workforce. Some may even be living away from their parents for the first time, and quite possibly, living away from their home town for the first time. These transitions come with new found freedoms, experiences and responsibilities; as they are now of legal age. Problematic alcohol and substance use are also at their peak during the emerging adulthood stage, moreso than in any other developmental life span period (Kanny et al., 2013). Approximately $22 \%$ of emerging adults are current cigarette smokers, and nearly $56 \%$ of all emerging adults ( 20 million) drink alcohol (SAMHSA, 2018). According to the National Survey on Drug Use and Health (NSDUH; SAMHSA, 2018), nearly two out of every five emerging adults binge drink (37\%), and nearly a quarter (24\%) use illicit substances (e.g. marijuana, cocaine, methamphetamines).

Consistent with moratorium, key characteristics of emerging adulthood include a) identity exploration, b) instability, c) focusing on the self, d) feeling in-between, and e) exploration of life's possibilities (Arnett 2000; 2004; 2007; 2014); these characteristics can induce daily stress in the life of the emerging adult and can negatively impact PWB (Halpern-Meekin, Manning, Giordano, \& Longmore, 2013; Nelson \& Barry, 2005; O’Conner et al., 2011; Robinson, 2018; Sharon, 2016). Emerging adults may feel "locked in/locked out" of emerging adulthood (Robinson, 2018; Sharon, 2016). Large percentages of emerging adults in a study by Sharon (2016) (96\% and 95\%, respectively) felt that accepting responsibility for one's own actions and making independent decisions were markers of adulthood that they had yet to meet. They reported that this gap in attainment 
was associated with some form of distress. Higher socioeconomic status, positive peer and parental relationships, community and school involvement, and emotional stability were each found to be predictors of PWB for emerging adults (O'Conner et al., 2011).

Given the stress and pressures associated with attaining the socially defined status called adulthood, many emerging adults may be at risk for low PWB during this developmental period. In 2017, $13 \%$ of all emerging adults experienced a major depressive episode (MDE) in the past year, and approximately $9 \%$ of all emerging adults experienced a MDE with severe impairment in the past year (SAMHSA, 2018). Both estimates steadily increased each year dating back from 2005 and 2009, respectively. Moreover, approximately $51 \%$ of the 4 million emerging adults with a past year MDE and, $57.1 \%$ of the nearly 2 million emerging adults with a past year MDE with severe impairment, received treatment for depression in 2017 (SAMHSA, 2018). Furthermore, suicide is the second leading cause of death among emerging adults, next to accidents and homicides, respectively (Crosby et al., 2013). A homicide may not necessarily be something that emerging adults can control however, it is important to note that nearly half (43\%) of all homicides occur among youth and young adults between the ages of 15 - 29 years of age (Logan, Hall, McDaniel, \& Stevens, 2013). So not only are emerging adults at greater risk for lower PWB due to various social determinants of health (e.g. socioeconomic status, access to employment) and risky behaviors (e.g. alcohol and substance use), emerging adults also must consider their physical safety.

Much of the research to date has explored emerging adulthood as a socio-cultural construct most valued among Westernized, post-industrialized societies where delays in the achievement of adult milestones (e.g., financial independence, ownerships of one's 
actions, independent decision making) may be more permissible (Douglas, 2007; Fuligni, 2007; Galambos \& Martinez, 2007; Hendry \& Kloep, 2010; Nelson \& Chen, 2007; O’Conner, et al., 2011). For example, O’Conner and associates (2011) posit that emerging adulthood may be a privileged developmental life stage in which a healthy positive growth is dependent on socioeconomic status. Some have even questioned whether race or ethnicity plays a role in emerging adulthood and whether POC truly experience emerging adulthood (Syed \& Mitchell, 2013). Halpern-Meerkin, Manning, Giordano, and Longmore (2013) found that among their study participants, emerging adults who reported instability in their romantic relationships were significantly more likely to be an emerging adult POC who was raised in a home that modeled unstable relationships.

While never truly siding one way or the other about whether certain subgroups of emerging adults truly experience the developmental stage, emerging adulthood, Syed and Mitchell (2013) provide a thorough exploration of emerging adulthood literature through an intersectional lens. The authors found a dearth in literature exploring the experiences and well-being of emerging adult POC. This is significant in that many researchers have argued that cultural factors may also determine PWB of emerging adult individuals (Halpern-Meekin et al., 2013; Hendry \& Kloep, 2010). Given that not only is the rate of homicide highest during the emerging adulthood stage, but that this is specific to certain racial/ethnic groups (e.g. non-Hispanic Blacks, American Indian/Alaska Natives, and Hispanics) (Logan et al., 2013), focusing on PWB among emerging adult POC should be a focus and will contribute to the literature on emerging adulthood. 
A milestone that is culturally significant and important to PWB that bears mentioning here is sexuality (Spencer \& Patrick, 2009; Torkelson, 2012; Woodford et al., 2015). Sexual identity exploration typically begins in adolescence and can extend into the emerging adulthood stage. However, there is little research exploring sexuality and PWB among emerging adult sexual minorities (Spencer \& Patrick, 2009; Torkelson, 2012). Emerging adult sexual minorities may be at an even greater risk for lower PWB compared to emerging adult heterosexuals (Graham et al., 2011; Spencer \& Patrick, 2009; Woodford et al., 2015). In Spencer and Patrick (2009) emerging adult sexual minorities $(n=66)$ scored significantly higher on depression scores and lower on selfesteem measures compared to emerging adult heterosexuals in the study $(n=240)$. Additionally, Woodford and colleagues (2015) found that added stress associated with sexual orientation (i.e. minority stress) can mediate PWB among emerging adult sexual minorities. In the study, these added stressors were typically due to experiences of discrimination based on sexual orientation. Discrimination and outness in the community are two important factors that contribute to the extent of PWB among sexual minorities (Grov, Bimbi, Nanin, \& Parsons, 2006; Chonody, Rutledge, \& Smith, 2012; Spencer, \& Patrick, 2009). The following section will review literature on outness and discrimination as predictors of well-being for sexual minorities and more specifically sexual minorities of color.

\section{Outness}

Outness is the level in which a person who identifies as a sexual minority, or engages in same-sex sexual activity, discloses his or her sexual orientation (Mohr \& Fassinger, 2000). Historically, openly identifying as a sexual minority came with legal 
consequences. For example, in the early 1900s, same-sex sexual activities were categorized as "crimes against nature" and resulted in incarceration for many men and women (U.S. Census, 1883, 1901). In fact, a period between the 1920's and 1950's, later known as The Lavender Scare, consisted of witch hunts, dishonorable discharges from the military, police raids in the community, and loss of employment, housing, family, and friends for anyone who identified as, or was suspected of being, a sexual minority. Because of these periods of overt oppression and ostracization, many sexual minorities went underground and lived secretly; also known as living "closeted". After the Stonewall Riots of 1969 (Davis, Heilbroner, \& Samuels, 2010), a culminating point in history when sexual minorities actively resisted the longtime oppression that they were experiencing, many sexual minorities were urged to "come out" with popular chants such as "we're here, we're Queer, get used to it" and "out of the closets and into the streets" (Queer Nation); resulting in a concept now known as to be out of the closet or outness (Mohr \& Fasinger, 2000), and ultimately opening the door for scholarly discourse on the topic (Nicholas; 2014; Ross, 2005; Smith, Kippax, \& Chapple, 1998).

The process of coming out as a sexual minority subsequently opened up discourse on what it means to be "out" as a sexual minority as well as what it means to be "closeted" and, the various intersections along the spectrum that is the closet (Nicholas; 2014; Ross, 2005; Smith et al., 1998). Closet dynamics are "multiple discourses and practices through which homosexuality is made visible or invisible in different social contexts (Smith et al., 1998, pp. 54)." Covering, another form of the closet is when a sexual minority is not totally "out”, nor closeted, but tones down their sexuality (Nicholas, 2014). Covering may look like an individual who avoids conversations about 
their same-sex romantic partner at work in order to avoid that awkward moment when they will need to decide on whether to "out" themselves or stay "closeted." This may be as simple as using gender neutral pronouns in conversations at work about their partner(s). Closet dynamics discourse places emphasis on the importance of illuminating how outness can serve as both a protective and a risk factor, and can vary by race, ethnicity, gender, age, and sexual orientation (Asante \& Roberts, 2014; Dentato, et al., 2014; Eguchi, 2014; Hudson, 2015; Moradi \& DeBlaere, 2010; Moradi et al., 2010; Nicholas, 2014; Parks, Hughes, \& Matthews, 2004). The following subsections will discuss the various ways that sexual minorities perform outness, the protective and risk factors associated with outness, and the relationship between outness and PWB among sexual minorities.

Variations in outness. Coming out and being out in public spaces occurs along a spectrum that includes varying levels of disclosure (e.g. to family, friends, coworkers, one's local community, and the general public) that may read differently among subgroups of sexual minorities (Grov et al., 2006; Holloway, Padilla, Wilner, \& Guilamo-Ramos, 2015; Morris, Waldo, \& Rothblum, 2001; Parks et al., 2004). Some individuals fully embrace an openly same-sex loving lifestyle, while others may only embrace parts of the lifestyle (Nicholas, 2014; Rasmussen, 2004). For example, a gay male adolescent may be out among his friends but not his immediate family, a lesbian woman may be out to her friends and family but not to her coworkers, and/or a bisexual individual may secretly engage in same-sex sexual activities while in a heterosexual relationship with a partner who is not fully informed. These are simplified examples that 
can become more complex when other social identities are intersected with sexuality (i.e. race/ethnicity or gender).

Sexual minorities of color (SMPOC) may not always identify with the same labels as White sexual minorities (Bowleg, 2013; Hudson, 2015; Ross, 2005); making it more challenging to identify the subsects of this population. As an example, in some Native American/American Indian communities, individuals are commonly called Two-Spirited, or someone who possesses both masculine and feminine characteristic and/or may engage in same-sex sexual activities (Gilley, 2006). In African American/Black and Hispanic communities, it is common for male sexual minorities of color to engage in same-sex sexual activities while not openly identifying as gay or bisexual, and/or while also having heterosexual partners (Eguchi, 2014; Gilley, 2006; Harris, 1991; Holloway et al., 2015). Males in these communities will acquire labels such as non-gay identified bisexual behaving men or, men who have sex with men (MSM); commonly referred to as men living on the down low (DL).

The coming out process for SMPOC may also be very different compared to White sexual minorities (Asante \& Roberts, 2014; Choi, Han, Paul, \& Ayala, 2011; Grov et al., 2006; Holloway et al., 2015). As such, Rasmussen (2004) argues, "the need to challenge dominant discourses of celebration and the concomitant enforcement of coming out discourses, silencing and shaming people for whom coming out is not a realistic or preferred option" (p.146). It is not uncommon for SMPOC to minimize to whom they disclose their sexual orientation (Parks et al., 2004). In a study exploring the coming out process by race/ethnicity among sexual minorities, Grov, Bimbi, Nanin, and Parsons (2006) found that White women $(80 \%)$ were more likely to be out to their parents 
compared to Black/African American women (61\%), Hispanic/Latinas (72\%), and women identifying as Other races $(68 \%)$. Additionally, White men $(77 \%)$ were also more likely to be out to their parents compared to Black/African Americans (62\%), Hispanic/Latinos (69\%), Asian/Pacific Islanders (51\%) and men identifying as Other races $(71 \%)$ (Grov et al., 2006).

Outness can serve as both a protective and a risk factor for sexual minorities. Dentato and colleagues (2014) found that outness was associated with both positive and negative experiences among their sample; as many community and school organizations are available to support sexual minorities during their coming out process (e.g. The Trevor Project, GLSN, PFLAG, National LGBT Task Force etc.). For some sexual minorities, coming out is a celebratory experience that includes acceptance from family members, peers and their community; whereas for others, the coming out experience can lead to a loss of family and friends and community support (Pew Research Center, 2013). Pew Research reports showed that White sexual minorities (58\%) compared to SMPOC (42\%) were more likely to believe that society is currently more accepting of sexual minorities in general (Pew Research Center, 2013).

For SMPOC, being "out" does not always equate to automatic enrollment and acceptance into the LGBTQ community nor does it mean understanding and continued connections within their racial/ethnic communities (Hudson; 2015; Syzmanski \& Meyer, 2008). Loss of community support is one of the many risks that sexual minorities fear when coming out (Holloway et al., 2015). In the 2013 Pew Research Poll, SMPOC found a conflict between their community affiliations and their sexuality; meaning coming out risked loss of their local community support (Pew Research Center, 2013). 
Moreover, coming out may not necessarily be a priority for SMPOC, and may take a backseat to other more pressing concerns (Rasmussen, 2004; Ross, 2005; Swank \& Fahs, 2013). Deeply embedded ties to religious affiliations and to racial/ethnic communities are but two of the reasons that racial/ethnic identity salience may take precedence over sexuality for sexual minorities of color (Bowleg, 2013; Bowleg, Huang, Brooks, Black, \& Burkholder, 2003; Miller, 2007; Rasmussen, 2004; Ross, 2005; Walker \& Longmire-Avital, 2013).

Historically, religion has been used to colonize communities of color for centuries which has resulted in inextricable ties between culture and religion. While homosexuality and religion do have a rather complicated past (i.e. see Leviticus chapters 18 and 20 in the Bible for passages used to regard same-sex sexual behaviors as a sin and an abomination under God), many SMPOC find solace in their religious faith in times of distress (Bowleg et al., 2003; Miller, 2007; Walker \& Longmore-Avital, 2013).

Furthermore, skin color, for the most part, does not change; clothes and physical presentation can. Coming out and into an overtly oppressed community from an already marginalized, and at times, dehumanized position in society, may not be optimal for some POC (Ross, 2005). Foregoing identification with same-sex sexuality and attraction among SMPOC may buffer the impact of racism (Choi et al., 2011; Rasmussen, 2004; Ross, 2005; Swank \& Fahs, 2013). In a case study, Rasmussen's (2004) participant opted out of coming out as a sexual minority because it would sever her ties with her racial/ethnic community; "there is no escaping discrimination based on her color, but discrimination based on the grounds of her sexual identity is something she feels she has more agency in trying to control (pp. 147)." 
In addition, when sexual minorities of color are asked why they do not participate in LGBTQ rights activism efforts, SMPOC reportedly chose to spend their time and efforts on racism and the discrimination that they face due to race/ethnicity (Choi et al., 2011; Swank \& Fahs, 2013); this may be as a result of experiences of racism in the LGBTQ community and homophobia within the racial/ethnic community (Bowleg et al., 2003; Choi et al., 2011; DeBlaere, Brewster, Sarkees, \& Moradi, 2010). As such, the risks associated with being out of the closet can bear a heavy cost and can impact overall PWB (Harrisson, 2003; Holloway et al., 2015). The following subsection will review literature on outness and PWB.

Outness and PWB. To be closeted or not to be closeted? The answer to this question may vary among many sexual minorities and, as can be read from the above section, the answer is almost never as simple as "yes" or "no"; for living openly in public spaces as a sexual minority can lead to ostracization, public humiliation, and even death (Marzullo \& Libman, 2009). In fact, it was only in 2009 that Congress enacted the "Matthew Shepard and James Byrd Jr., Hate Crimes Prevention Act", a revision to the "Violent Crime Control and Law Enforcement Act" (1994) that would expand the existing United States federal hate crime law to apply to crimes motivated by a victim's actual or perceived gender, sexual orientation, gender identity, or disability. Matthew Shepard and James Byrd Jr. were both victims of horrific crimes in 1998 that involved brutal beatings and torture. The heinous nature of these crimes suggested that the criminals were motivated by hate of one or more of the victims' identities. Matthew Shepard was gay, and James Byrd Jr. was African American/Black. 
According to the most recently available Federal Bureau of Investigation (FBI) report on hate crimes statistics, $15.8 \%$ of single-bias related hate crimes were due to a person's sexual orientation (Hate Crimes Statistics, 2017). These numbers were third, after religion (20.6\%) and race/ethnicity/ancestry, which was at an astonishing 59.6\%; all of which are down from the previous years (Hate Crime Statistics, 2016). While it appears that single-bias hate crimes motivated by sexual orientation are on the decline, the recent mass murder of 49 people in June of 2016 at a local gay nightclub in Orlando, FL, the majority of whom were SMPOC, would paint a different picture and ignite the debates on hate crimes against sexual minorities, mass murders, and gun control in the United States. Although debatable, this event would be labeled as one of the deadliest mass killings in the history of the United States.

Given this tainted history, many sexual minorities must police their spaces and determine safety regarding whether to be "out" (Asante \& Roberts, 2014; Hudson, 2015; Rasmussen, 2004). In Hudson's (2015) study, SMPOC were less likely to disclose their sexuality to their family members and were also likely to report monitoring their sexual orientation and/or gender identity expression (SOGIE) to determine safety. Asante and Roberts (2014) provide great visualization through an auto-ethnographic approach of one of the author's experiences during an interview for entrance into an academic program: "[a]t the moment I asked myself Am I ready? Should I tell them? What are the implications if I tell them? (pp. 133)." The worry of perceived or actual threat is resounding.

There is a reciprocal relationship between outness and PWB (Dentato et al., 2014; Riggle, Rostosky, Black, \& Rosenkrantz, 2017). Research has shown that while outness 
can lead to experiences of discrimination and ostracization, concealing sexuality can also impact PWB (Holloway et al., 2015; Riggle et al., 2017). Riggle, Rostosky, Black, and Rosenkrantz (2017) found that concealment of sexual identity was significantly associated with low PWB, and outness was a significant predictor of depressive symptoms among a sample of 373 sexual minorities. Similar results were found in Holloway and associates (2015), where Hispanic men who had sex with men expressed greater distress at the thought of being "outed"; some even expressed fears of being murdered.

Sexual minorities of color may experience greater amounts of distress due to their own racial/ethnic communities’ paradigms surrounding homosexuality (Eguchi, 2015; Holloway et al., 2015; Rasmussen, 2004). Sexual minorities of color often must navigate between worlds (Parks et al., 2004) and as such, many SMPOC remain closeted or on the DL (DeBlaere, et al., 2010; Eguchi, 2014; Harris, 1991; Holloway et al., 2015; Nadal, 2013). One reason for DL lifestyles is that in many communities of color, homosexuality is considered a sign of weakness, that is, to be gay equates to the loss of manhood and masculinity (Chauncey, 1995; Eguchi, 2014; Harris, 1991). Eguchi (2014) provides a personalized narrative of his experiences as an openly gay Japanese male who faces internal conflict when he finds himself in same-sex relation/ships with Black men who were on the DL. E. Lynn Harris' (1991) Invisible Life is also a very telling tale of an African American man's journey through sexual exploration as a man living on the DL who struggled with acceptance of self and the perceived loss of his connections to his racial/ethnic community due to his sexuality. Unfortunately, narratives such as these are 
numerous, and highlight the impact of familial and community support, or lack thereof, on the PWB among SMPOC (Baldwin, 1956; McBride, 2005).

Sexual minorities of color who do come out may feel like they do not belong in White LGBQ communities (Hudson, 2015). In their research, DeBlaere and associates (2010) found that SMPOC experience discrimination in White LGBQ communities and in their racial/ethnic communities (Battle \& Crum 2006; Nadal, 2013). Some have called this catch 22, double and/or triple jeopardy (Bowleg et al., 2003). These negative discriminatory experiences can impact quality of life and therefore cause lower PWB (Nadal, 2013; Syzmanski \& Gupta, 2009). Meyer (2010) has called for further research exploring the intersections of race and sexuality on mental health and some researchers have answered this call by exploring the impact of types of discrimination on PWB (Nadal, 2013; Nadal, Griffin, Wong, Hamit, \& Rasmus, 2014a). The following section will define and discuss microaggressions, a type of discrimination, and will explore the relationship between discrimination and PWB for sexual minorities, with a separate section highlighting PWB among SMPOC; adding further support for my overall argument that those who are socially and systematically oppressed by multiple identities may be at an increased risk for low PWB.

\section{Microaggressions}

Discrimination is about subjugating and restricting the rights of persons with social and political minority status(s). Discrimination has been directly linked to the denial of basic civil and human rights, poverty, crime, and decreased mental and physical health among marginalized groups (Healthy People 2020 Initiative, 2010). While blatant discrimination against another may carry a legal consequence, other forms of 
discrimination may not. A concept that is increasingly becoming central in the social and academic discourse on discrimination is microaggressions (Campbell \& Manning, 2014; Shire, 2015). A relatively new term, microaggressions are considered the "new face" of discrimination (Nadal, 2013). In fact, microaggressions has become such a popular phenomenon that a) colleges and universities have developed social media pages dedicated for students to report their experiences (e.g. Harvard, Dartmouth, Brown, Ithaca, University of Virginia etc.), b) nonacademic blogs about the concept have sprouted throughout the world wide web (e.g. The Microaggressions Project and Big Green Microaggressions), and c) even a film and subsequent television show with the same title (Dear White People) was released in 2014 specifically dedicated to comically educating the public on examples of microaggressive offenses on college campuses. Dr. Marc Lamont Hill, a social justice advocate, journalist, author, and television personality, has even made it his purpose to speak widely on microaggressions.

It is important to note however, that the term microaggressions originated in the late 1970's by Chester Pierce and colleagues (1978) and originally referred to race (Sue, Bucerri, Lin, Nadal, \& Torino, 2007b); only later was it expanded to include other marginalized identities such as gender (Gartner \& Sterzing, 2016; Kaskan \& Ho, 2016), physical dis/abilities and health (Chapple, 2012; LeBron et al., 2017), religion (Hodge, 2019; Husain \& Howard, 2017), and SOGIE (Bostwick \& Hequembourg, 2014; Nadal, Rivera, \& Corpus, 2010; Nadal et al., 2011; Platt \& Lenzen, 2013; Seelman et al., 2017; Smith, Shin, \& Officer, 2011). Microaggressions are now defined as "brief and commonplace daily verbal, behavioral, and environmental indignities, whether intentional or unintentional, that communicate hostile, derogatory, or negative racial, 
gender, sexual orientation, and religious slights and insults to the target person or group" (Sue, 2010, p. 5).

Although overt forms of discrimination still exist and are well documented, the subtle nature of microaggressions leads to a subjective interpretation that can be more difficult to identify and can differ in experience from one person to the next. The very nature of this subjectivity often results in indiscernible experiences by those external to the event, thus leaving the victim feeling confused as to whether they experienced an act of discrimination. If the victim decides to approach the perpetrator about the incident, the perpetrator will often become defensive and allege that the victim is hypersensitive and could quite possibly deny any negative undertones.

The experience of the microaggression and/or anticipation of future microaggressions can affect risk taking behaviors, lead to psychological consequences (Jamieson, Koslov, Nock, \& Mendes, 2012), and impact overall PWB (Contrada et al., 2000; Meyer, 1995; 2010; Wang, Leu, \& Shoda, 2011; Wei et al., 2010). My study explored the intersections of microaggressions experienced by sexual minorities of color and therefore used taxonomies of microaggressions based on both sexual orientation and race/ethnicity. The following subsections will provide the defining taxonomies of microaggressions based on sexual orientation and race/ethnicity and, will explore the literature on the impact of microaggressions on PWB as they pertain to sexual minorities and more specifically, SMPOC.

Taxonomy of sexual orientation microaggressions. The creation of the taxonomy on microaggressions and the release of Sue's Microaggressions and marginality: Manifestations, dynamics, and impact (2010) have provided a roadmap for 
research exploring microaggressions among other marginalized groups. Kevin Nadal, a former student of Derald W. Sue and one of the original founding researchers on the taxonomy's development, is a frontrunner in exploring microaggressive experiences of sexual minorities. In his work, That's so gay! Microaggressions and the lesbian, gay, bisexual, and transgender community (2013), Nadal developed a sexual orientation-based taxonomy for understanding subtle transgressions experienced by sexual minorities. Eight subthemes were developed. Out of the three original main themes of microaggressions (microassaults, microinsults, and microinvalidations; for further detail see Figure 2), Nadal's (2013) eight subthemes for microaggressions based on sexual orientation are: a) use of heterosexist or transphobic terminology, b) endorsement of heteronormative or gender normative culture and behaviors, c) assumption of universal LGBT experiences, d) exoticization, e) discomfort with/disapproval of LGBT experience, f) denial of the reality of heterosexism or transphobia, g) assumption of sexual pathology/abnormality, and $h$ ) denial of individual heterosexism (for corresponding examples of each type of sexual orientation microaggression, see Table 1).

Table 1. Taxonomy on Sexual Orientation and Gender Identity Microaggressions

\begin{tabular}{|c|c|c|}
\hline Theme & Defined & Microaggression \\
\hline \multirow[t]{2}{*}{$\begin{array}{l}\text { Use of heterosexist or } \\
\text { transphobic terminology }\end{array}$} & $\begin{array}{l}\text { Experiences when someone } \\
\text { uses derogatory heterosexist or } \\
\text { transphobic language toward } \\
\text { LGBT persons. }\end{array}$ & "Faggot!" or "Dyke!" \\
\hline & & "That's so gay!" \\
\hline $\begin{array}{l}\text { Endorsement of } \\
\text { heteronormative or gender } \\
\text { normative culture and } \\
\text { hehaviors }\end{array}$ & $\begin{array}{l}\text { Experiences in which an LGBT } \\
\text { person is expected to act or be } \\
\text { heterosexual. }\end{array}$ & $\begin{array}{l}\text { A heterosexual person telling a } \\
\text { gay person not to "act gay in } \\
\text { public." }\end{array}$ \\
\hline
\end{tabular}




\section{Assumption of universal LGBT experience}

Exoticization

Discomfort with/disapproval of LGBT experience

Denial of the reality of heterosexism or transphobia

\section{Assumption of sexual pathology/abnormality}

\section{Denial of individual heterosexism}

Experiences in which heterosexual people assume that all LGBT persons are the same.

Experiences in which LGBT people are dehumanized or treated as objects

A cisgender parent forcing his or her child to dress according to the child's birth sex.

Stereotyping all gay men to be interested in fashion or interior design.

Assuming all lesbian women to look or act butch.

Heterosexual people stereotyping all LGBT people as being the "comedic relief".

A cisgender man who enjoys having sex with male-to-female (MTG) transgender women but is not open to a committed, romantic relationship.

When a stranger stares at an affectionate lesbian couple with disgust.

When a heterosexual person tells and LGBT individual he or she is going to hell.

Experiences in which people deny that heterosexism and transphobia exist.

A coworker telling a gay friend that he's being paranoid thinking someone is discriminating against him.

Someone telling a transgender person that she should stop complaining.

Experiences in which heterosexual people oversexualize LGBT persons and consider them as sexual deviants.

When people assume that all gay men have HIV/AIDS and are child molesters.

When people assume that all transgender women are sex workers.

Statements in which heterosexual people deny their own heterosexist and "I am not homophobic, I have a gay friend."

transgender biases and prejudice.

Source: Taken from Nadal, 2013, p. 46-47. 
Taxonomy of racial/ethnic microaggressions. In their seminal work, Derald W. Sue and colleagues produced three themes and nine subthemes of microaggressions (Sue, 2010; Sue et al., 2007a). These themes and subthemes are of the initial defining rubrics of microaggressions. The three themes are called microassaults, microinsults, and microinvalidations (see Figure 2). Microassaults are "explicit derogations characterized primarily by a verbal, nonverbal, or environmental attack meant to hurt the intended victim through name-calling, avoidant behavior, or purposeful discriminatory claims" (Sue, 2010, p.29). A microinsult can be a verbal or nonverbal communication that relays a hidden message of an insulting nature toward the target person (Sue et al., 2007a). Lastly, microinvalidations are characterized as "communications that exclude, negate, or nullify the psychological thoughts, feelings, or experiential reality" of the target person (Sue et al., 2007a, p. 274). Microassaults are associated with traditional forms of discrimination and are typically a conscious act whereas microinsults and microinvalidations are both typically unconscious acts. Microinvalidations are considered the most damaging of all microaggressions because they deny the reality of the person's subjective and negative experience (Sue, 2010). Among the three themes are nine connected and sometimes overlapping subthemes: a) alien in own land, b) ascription of intelligence, c) color blindness, d) criminality/assumption of criminal status, e) denial of individual racism, f) myth of meritocracy, g) pathologizing cultural values/communication styles, h) second-class citizen, and i) environmental microaggressions (see Table 2). 


\section{Figure 2. Categories of Microaggressions and Corresponding Themes}

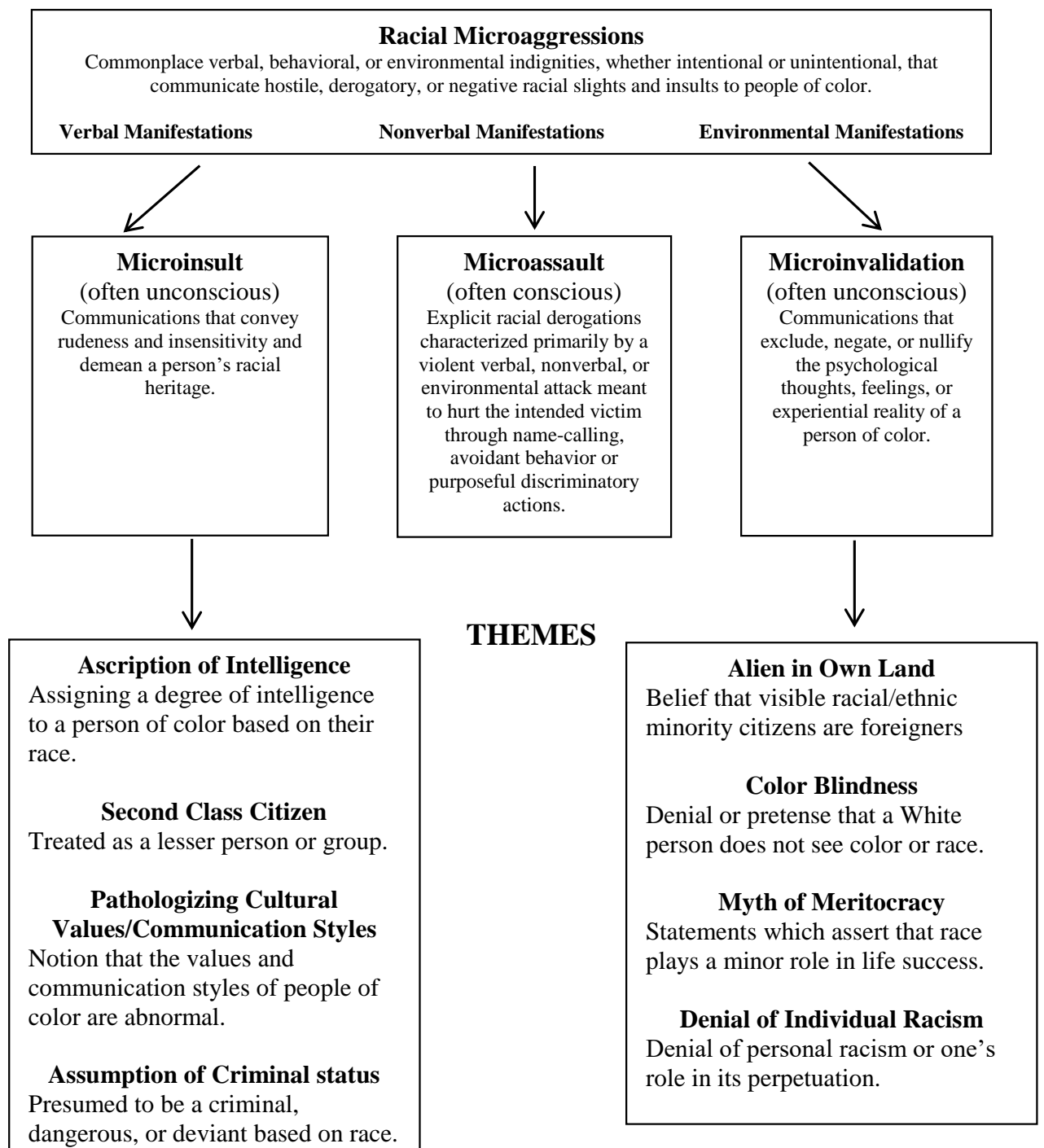

Source: Adapted n from Sue et. al., 2007, p. 278. 
Theme $\quad$ Microaggression

Alien in own land

Ascription of intelligence

Color blindness

\section{Criminality/assumption of criminal status}

Denial of individual racism

Myth of meritocracy

Pathologizing cultural values/ communication styles
"Where were you born?"

"You speak good English."

A person asking an Asian

American to teach them words in their native Language.

"You are so articulate"

Asking an Asian person to help with a math or science problem. You are a credit to your own race.

"When I look at you, I don't see color."

"America is a melting pot."

"There is only one race, the human race."

A White man or woman clutching their purse or checking their wallet as a Black or Latino approaches or passes A store owner following a customer of color around the store.

A White person waits to ride the next elevator when a person of color is in it.

"I'm not racist. I have several Black friends."

"As a woman, I know what you go through as a racial minority."

"I believe the most qualified person should get the job."

"Everyone can succeed in this society, if they work hard enough."

Asking a Black person: "Why do you have to be so loud/ animated? Just calm down." To and Asian or Latino person: "Why are you so quiet? We want to know what you think.

\section{Message}

You are not American.

You are a foreigner.

It is unusual for someone of your race to be intelligent.

All Asians are intelligent and good in math/sciences.

People of color are generally not as intelligent as Whites.

Denying a person of color's racial/ethnic experiences.

Assimilate/acculturate to the dominant culture.

Denying the individual as a racial/cultural being.

You are a criminal.

You are going to steal/ You are poor/ You do not belong.

You are dangerous.

I am immune to racism because I have friends of color.

Your racial oppression is no

different than my gender oppression. I can't be a racist. I'm like you.

People of color are given extra unfair benefits because of their race.

People of color are lazy and/or incompetent and need to work harder.

Assimilate to dominant culture. 


\begin{tabular}{|c|c|c|}
\hline & $\begin{array}{l}\text { Be more verbal. Speak up } \\
\text { more." }\end{array}$ & \\
\hline & $\begin{array}{l}\text { Dismissing an individual who } \\
\text { brings up race/ culture in work/ } \\
\text { school setting }\end{array}$ & $\begin{array}{r}\text { Leave your cultural baggage } \\
\text { outside }\end{array}$ \\
\hline \multirow[t]{4}{*}{ Second-class citizen } & $\begin{array}{l}\text { Person of color mistaken for a } \\
\text { service worker }\end{array}$ & $\begin{array}{l}\text { People of color are servants to } \\
\text { Whites. They couldn't possibly } \\
\text { occupy high-status positions }\end{array}$ \\
\hline & $\begin{array}{l}\text { Having a taxi cab pass a person } \\
\text { of color and pick up a White } \\
\text { passenger }\end{array}$ & $\begin{array}{r}\text { You are likely to cause trouble } \\
\text { and / or travel to a dangerous } \\
\text { neighborhood }\end{array}$ \\
\hline & $\begin{array}{l}\text { Being ignored at a store as } \\
\text { attention is given to the White } \\
\text { customer behind you }\end{array}$ & $\begin{array}{l}\text { Whites are more valued } \\
\text { customers than people of color }\end{array}$ \\
\hline & "You people..." & $\begin{array}{r}\text { You don't belong. You are a } \\
\text { lesser being }\end{array}$ \\
\hline Second-class citizen & $\begin{array}{l}\text { Person of color mistaken for a } \\
\text { service worker }\end{array}$ & $\begin{array}{l}\text { People of color are servants to } \\
\text { Whites. They couldn't possibly } \\
\text { occupy high-status positions. }\end{array}$ \\
\hline
\end{tabular}

Source: Taken from Sue et. al., 2007,

p. 276-277.

Microaggressions and PWB of sexual minorities. Like POC, sexual minorities are often overrepresented in health and mental health disparities (Healthy People 2020 Initiative, 2010; SAMHSA, 2014) yet, unlike POC, discrimination based on sexual orientation is not a protected class (Civil Rights Act, 1964). Because sexual minorities are not always legally protected, blatant discrimination is a serious problem (Pew Research Center, 2013). Consequently, perceived and actual discrimination can have a significant impact on the daily lives of sexual minorities.

Multiple studies have shown that members of sexual minorities who report experiencing discrimination based on their SOGIE are at a greater risk for suicide and mental health and substance-related disorders compared to their heterosexual counterparts (Burton, Marshal, Chisolm, Sucato, \& Freidman, 2013; Haas et al., 2011; Lehavot \& Simoni, 2011; Liu \& Mustanski, 2012; Silenzio et al., 2007). Moreover, 
experiencing sexual orientation microaggressions can facilitate similar negative consequences and effect overall PWB (Bostwick \& Hequembourg, 2014; Nadal, 2014; Nadal et al., 2011; Platt \& Lenzen, 2013; Robinson \& Rubin, 2016; Seelman et al., 2017; Woodford et al., 2012; Woodford et al., 2015; Wright \& Wegner, 2012).

Hearing phrases such as "that's so gay", the use of homophobic slurs, heterosexist terminology, and the endorsement of heteronormative behaviors (e.g. "be a man!", "don't be a pussy!") are all examples of microaggressions experienced by sexual minorities that can negatively impact sexual minorities' social and PWB. In a blog article entitled, Stop saying "that's so gay!": 6 types of microaggressions that harm LGBTQ people, Kevin Nadal (2014) discloses personal experiences of being bullied and ridiculed throughout his life for being gay. He describes incidents of being told that "boys don't cry" or "be a man!" and almost always being the brunt of many homophobic jokes. As an adult and after Dr. Nadal "came out" to family and friends he reflected that "while many loved ones later told me that they suspected that I was gay, no one gave me any reason to believe that they were gay-friendly" (Nadal, 2014; para. 3). Dr. Nadal's story is an all too familiar narration among people who identify along the SOGIE spectrum.

In measuring blatant or overt types of discrimination and sexual orientation microaggressions among sexual minorities, Seelman, Woodford, and Nicolazzo (2017) found that both blatant discrimination and microaggressions resulted in lower PWB among their 497 study participants. Study results revealed that microaggressions were a statistically significant predictor of high anxiety $(\beta=0.20, p<.001)$, increased levels of stress $(\beta=0.22, \mathrm{p}<.001$ and low self-esteem $(\beta=-0.16, \mathrm{p}<.01)$ (Seelman et al., 2017). The study also revealed similar results with blatant victimization as a predictor on anxiety 
$(\beta=0.23, p<.001)$, stress $(\beta=0.23, p<.001)$, and self-esteem $(\beta=-0.29, p<.001)$.

These results suggest that experiencing microaggressions can be just as detrimental to PWB as overt types of discrimination (Seelman et al., 2017).

In a qualitative study exploring the various types of sexual orientation microaggressions experienced by sexual minorities, Nadal et al. (2011) found that many of their participants reported feeling moments of distress, including some self-stated accounts of post-traumatic stress (PTSD), and that microaggressions impacted their ability to be publicly open about their sexuality (i.e. outness). Results such as these have been found in other studies looking at sexual orientation microaggressions (Bostwick \& Hequembourg, 2014; Platt \& Lenzen, 2013; Robinson \& Rubin, 2016; Woodford et al., 2015; Wright \& Wegner, 2012). As an example, Robinson and Rubin (2016) found that compared to their heterosexual counterparts $(n=80)$, sexual minorities $(n=90)$ who reported experiencing sexual orientation microaggressions scored significantly higher on a PTSD severity index; indicating that sexual orientation microaggressions may be associated with PTSD-like distress symptoms. In Wright and Wegner (2012), participants who reported a higher number of microaggressive experiences also reported a higher number of posttraumatic and distress like symptoms. As a final example, Woodford, Paceley, Kulick, and Hong (2015) found that higher reports of microaggressions predicted greater anxiety and stress symptoms among LGBTQ college-aged adults (also known as emerging adult sexual minorities). Further, this study also found that macrolevel experiential microaggressions (i.e., witnessing anti-LGBT protests and anti-LGBT political debates in the media, or living in environments that support anti-LGBT legislature) negatively impacted PWB (Raifman et al., 2017; Woodford et al., 2015). 
Thus far, I have explored microaggressions based on a single identity; sexual orientation. The following section will explore microaggressions among those who identify with multiple marginalized identities (SMPOC).

Microaggressions and PWB of sexual minorities of color. As previously noted, the seminal research on microaggressions initially focused on race, and a significant portion of literature reports on microaggressions experienced by POC. POC experience a greater number of microaggressions compared to their non-Hispanic White counterparts (Nadal et al., 2014a). Microaggressions have been linked to negative mental health outcomes such as depression, anxiety, and lack of behavioral control among African Americans (Hammond, 2012; Liao, Weng, \& West, 2016; Mouzon et al., 2017; Sue et al., 2008; Solozarno, Ceja, \& Yosso, 2000; Torres, Driscoll, \& Burrow, 2010), Asian Americans (Choi, Lewis, Harwood, Mendenhall, \& Hunt, 2017; Nadal, Wong, Sriken, Griffin, \& Fuiji-Doe, 2015; Sue et al., 2007b; Wang et al., 2011), Hispanics (Nadal, Mazzula, Rivera, \& Fuji-Doe, 2014b), Native Americans (Johnston-Goodstar \& Roholt, 2017), and Muslim Americans (Husain \& Howard, 2017). Interestingly, research has also shown differences in the types of microaggressions experienced by racial/ethnic subgroups (Nadal et al., 2014a). For example, African Americans may report more experiences of assumptions of criminality whereas Asian Americans may be more likely to identify with experiences of exoticization (Nadal et al., 2014a). This may also be true for subgroups of sexual minorities. At least one-third of those who identify as a sexual minority also identify as a racial and/or ethnic minority (Gates \& Newport, 2012). Sexual minorities of color must negotiate multiple identities as part of their development. Sexual minorities of color may experience microaggressions that are unique to both their 
racial/ethnic identity and their sexual identities (Bowleg, 2013; Meyer, Ouellette, Haile \& McFarlane, 2011). These are often referred to as intersections of identity or intersectionality (Crenshaw, 1991). When sexual minorities hold multiple intersecting minority identities, their experiences with microaggressions may be amplified and may place them at greater risk for lower PWB compared to those who may be marginalized based on a single minority status (Balsam, et al., 2011; Bowleg, 2013; Bowleg et al., 2013; Holley, Tavassoli, \& Stromwall, 2016; Sterzing et al., 2017). As SMPOC encounter experiences of overt and covert types of discrimination, they may be left to ponder whether the incident was due to their sexual orientation or their race/ethnicity, or both.

As a result, SMPOC may be at a greater risk for lower PWB due to the compounding effects of multiple experiences of microaggressions over time (Sue et al., 2008; Sue et al., 2007b; Nadal, 2011). To date, few studies have included this high-risk subgroup. DeBlaere, Brewster, Sarkees, and Moradi (2010) have pointed out "continued separation of sexual orientation and race/ethnicity renders invisible the experiences of LGB people of color" (p. 333). A literature review of publications (2000-2015) specific to sexual orientation microaggressions yielded 35 articles of which only four were specific to SMPOC (Nadal, Whitman, Davis, Erazo, \& Davidoff, 2016). Possible reasons for the tiny literature include lack of access to this subgroup due to discrimination in the research community, among subgroups within the LGBTQ community, and heterosexism in the cultural community that restrict them from being out in the open about their sexuality (Battle \& Crum, 2006; DeBlaere, et al., 2010; Hudson, 2015; Phillips, Ingram, Smith, \& Mindes, 2003; Nadal, 2013). 
Moreover, while there has been an increase in social and academic discourse on this important topic, to my knowledge, there are no reported micro-interventions targeting the effects of microaggressions. Consequently, the four articles found in Nadal and colleagues' (2016) review, plus two additional studies found in a search on microaggressions and intersectionality that have recently been published, one of which was a mixed-methods study (Balsam, et al., 2011), three of which were qualitative research studies (Bowleg, 2013; Follins, 2014; Holley et al., 2016) and two that were quantitative studies (Elias, Jaisle, \& Morton-Padovano, 2017; Oshi-Ojuri, 2013) will be critically reviewed in the following paragraphs.

Balsam, Molina, Beadnell, Simoni, and Walters' (2011) study was a multi-phase mixed-methods design which explored the intersecting identities of sexual orientation and race/ethnicity among SMPOC. The purpose of the study was to develop the first selfadministered questionnaire on microaggressions specific to SMPOC. The first phase of the study consisted of focus groups and in-depth interviews designed to explore the types of microaggressions experienced by SMPOC and resulted in the development of survey questions designed to identify microaggressions specific to SMPOC. The second and third phases of the study were for refining the survey. Results of the study's exploratory factor analysis (EFA) produced an 18-item self-administered questionnaire that showed good psychometric properties for use in future studies on the exploration of microaggressions and PWB among SMPOC. As a result, the measure was used in this current study to explore the experiences and impact of microaggressions among SMPOC (see Chapter 3 on methodology for further detail). 
Of the three qualitative research studies, Bowleg's (2013) study consisted of indepth interviews about the life experiences of 12 African American/Black gay and bisexual men in the local Washington D.C. area. The purpose of the study was three-fold: (1) adding to the literature on intersectionality through an exploration into the social inequalities of Black gay and bisexual men, (2) by exploring the disparities between power and privilege of Black gay and bisexual men, and (3) providing discourse on power by gender and oppression by sexuality. Microaggressions specific to study participant's sexuality and race/ethnicity were explored. Results of this study included a thematic analysis of the impact of intersecting identities (e.g. race, ethnicity and sexuality) on the social experiences of Black gay and bisexual men. Among the themes discussed, participants expressed experiences with racial microaggressions in general and specifically in White LGBTQ communities, they expressed the personal impact of negative stereotypes about Black and gay men, their experiences with heterosexism in Black communities, living on the DL or "covering" (acting more masculine to avoid being outed), and on a more positive note, participants also reported benefits of being Black, gay and/or bisexual men.

The second qualitative study was by Follins (2014). Follins (2014) conducted semi-structured interviews with $\mathrm{N}=12$ Black and Latino gay men about their experiences with microaggressions. The purpose of this study was to explore the ways in which Black and Latino gay men recognized and interpreted the oppressions related to their intersecting identities. Study results indicated four themes related to microaggressions: being sexually objectified, feeling like an alien in one's own land, 
reactions to racial/ethnic stereotypes inflicted upon them, and experiences with racial microaggressions.

The third qualitative study, Holley, Tavossoli, and Stromwall (2016), explored the intersections of race/ethnicity, sexual orientation, and mental health on experiences of discrimination at mental health treatment programs. The authors explored microaggressions at the individual, organizational, and societal level. The study sample included $\mathrm{N}=13$ persons living with a mental illness (PWMI) and $\mathrm{N}=7$ family members of PWMI. Twelve of the participants were identified as a sexual minority, 15 participants identified as a POC, and seven identified as a SMPOC. Findings from the study were delineated into five themes: ignoring/not listening, not viewed as complex individuals, condescension/lack of respect, violations of privacy or other rights, and presumed lack of intelligence; each of which were described as experiences of microaggressions based on sexual orientation, mental illness, race/ethnicity, and/or the intersections among race/ethnicity, sexuality and mental health.

The first of two studies with a quantitative design, was a dissertation by OshiOjuri (2013). The purpose of this research was to validate a survey index designed to explore the macro-level impacts of microaggressions on the intersecting identities of African American lesbian women. The Microaggressions and Intersectionality Index (MII) consisted of items designed to identify microaggressions based on the intersections of race, gender, and sexuality. The scale included four themes related to sexist, heterosexist, and racist events: denial, skepticism, disidentification, and hypervigilance. A principle components analysis (PCA) and an exploratory factor analysis (EFA) were 
conducted on the index; however, the findings of this study were limited and were indicated as "promising" due to a small sample size of only 30 participants.

The second quantitative study and final study for this review, Elias, Jaisle, and Morton-Padovano (2017) took a unique approach to exploring microaggressions. While the sample of participants in this study does not include SMPOC, the study warrants inclusion in this review due to the study's exploration of intersectional microaggressions among a diverse sample which included those with intersecting identities. The purpose of this study was to explore the likelihood of POC, White non-Hispanics, and Hispanics engaging in microaggressions of their own kind and/or on those who had sexuality as an intersecting identity (i.e. sexual minorities and SMPOC). The study sample consisted of 1,093 participants of which $36 \%$ of the sample were Black, $34 \%$ were White nonHispanic, and 30\% were Hispanic. The study included the LGBT People of Color Microaggressions Scale (Balsam et al., 2011) in their questionnaire, the only measure known to date to assess microaggressions along the intersections of race/ethnicity and sexuality. Interesting results from the study included that Black heterosexuals were more likely to have negative thoughts towards SMPOC but were less likely to commit a microaggression. White participants were more likely to perpetrate a microaggression when their ethnic identity was stronger whereas this was not the case with Blacks or Hispanics. The likelihood of Blacks and Hispanics to engage in microaggressions against Black or Hispanic sexual minorities was not determined by the strength of their racial/ethnic identity salience. Lastly, results also found that Blacks, White non-Hispanics and Hispanics each had significantly different likelihoods of perpetrating 
microaggressions toward sexual minorities within their own racial/ethnic communities versus those from other racial/ethnic groups.

To summarize, the scope of the literature that is focused on the experiences of microaggressions among SMPOC is still quite limited. What the few studies have shown is that the impact of microaggressions on SMPOC's PWB may be compounded. "[H]omophobia, racism, [heterosexism], and sexism are enduring and pervasive forces that chronically and systematically" marginalize people of color, sexual minorities, and more specifically, sexual minorities of color (Meyer et al., 2012, p. 212). Sexual minorities of color may experience double discrimination and at times triple jeopardy (Bowleg et al., 2003). In two of the qualitative studies (Bowleg, 2013; Follins, 2014) the participants had difficulties in deciphering whether a microaggressive experience was related to their race/ethnicity or their sexual orientation. Sexual minorities of color may be at the greatest risk for low PWB because of the assaults on all fronts and, some may even have to present with only parts of themselves to ensure safety and PWB (Holley et al., 2016). Each of these studies' results speak to the necessity for more discourse on intersectionality and the impact of microaggressions on PWB. This subsection has summarized the literature on microaggressions as they pertain to the PWB of sexual minorities and SMPOC. The following section will explore literature supporting the theoretical frameworks used in the present study.

\section{Theoretical Framework}

The theoretical frameworks that guided this study were: (1) minority stress theory, and (2) intersectionality. Meyer's (1995) minority stress theory posits that while everyone will experience common life stress, there are interactions uniquely experienced 
by minorities that are based on their marginalized status(es) in society. The intersectionality (Crenshaw, 1991) perspective contributes to the minority stress argument by suggesting that individuals often possess multiple socially and politically oppressed identities that cannot be segregated and therefore may result in stressful experiences that are compounded. As a result, both frameworks were used to support the argument in this study that the microaggressions experienced by sexual minorities of color (individuals who possess multiply marginalized identities) may be deleterious to PWB. The minority stress theory and the intersectionality perspectives were defined in Chapter 1, the following sections will present literature on the use of minority stress and intersectionality in research on sexual minorities and their relation to PWB.

\section{Minority Stress Theory}

There are several studies that support the use of Meyer's (1995) minority stress theory to explore the additive stressors related to SOGIE among sexual minorities. In many of the studies the relationship between minority stress is used to explain the disparities in mental health and substance abuse and overall PWB among sexual minorities (Burton et al., 2013; Kelleher, 2009; Lehavot \& Simoni, 2011). As an example, in a 6-month longitudinal study, Burton and associates (2013) explored the relationship between minority stress, depression, and suicidality, and after controlling for gender, age, race, and depressive symptoms, minority stress significantly mediated the

effect of sexual minority status on both depression and suicidality at 6-months follow-up.

Sexual minorities experience greater than double the rates of depression, substance abuse, and suicidality compared to heterosexuals (Bostwick et al., 2014; Burton et al., 2013; Lehavot \& Simoni, 2011; Marshal et al., 2011; Rosario \& 
Scrimshaw, 2013; Russell \& Joyner, 2001). Burton and colleagues' (2013) study supports the minority stress model which posits that there are factors uniquely related to identifying with the SOGIE spectrum that are at least partly responsible for disparities in mental health among sexual minorities (Bouris, Everett, Heath, Elsaesser, \& Neilands, 2016; Hong \& Garabino, 2012; Rosario \& Scrimshaw, 2013).

In Kelleher (2009), three types of minority stress, stigma consciousness (expectations of rejection of SOGIE by others), sexual identity distress (internalization of negative societal perceptions of identifying along the SOGIE spectrum), and heterosexist experiences, were each significant predictors of distress among sexual minorities $[F(3,201)=30.80, p \leq 0.001]$. These results further support the minority stress model's argument that there is a connection between the distal factors (external objective stressful events) and the proximal factors (the subjective processes), and that low PWB among sexual minorities is resultant from living in oppressive and discriminatory environments (Kelleher, 2009; Hong et al., 2016).

In a more recent study, Seelman et al. (2017) sought to explore whether microaggressions would support the minority stress model and impact PWB among sexual minorities. The study found that sexual orientation microaggressions were a statistically significant predictor of high anxiety, high stress and low self-esteem, supporting Meyer's (1995) minority stress framework (Seelman et al., 2017).

Much of the research to date on minority stress is limited to White non-Hispanic sexual minorities. Seelman et al.'s (2017) most recent study had a near $80 \%$ White majority sample. A content analysis spanning 10 years of LGBTQ related studies revealed that many studies did not specify race/ethnicity in their analyses and if they did, 
this was often limited to descriptive statistics and not fully explored (Phillips et al., 2003). As noted in an earlier section on sexual orientation microaggressions, there is little to no research on SMPOC (Nadal et al., 2016), thus, silencing the voices of those who may experience microaggressions and ultimately minority stress on multiple fronts; of which some have called multiple minority stress or double/triple jeopardy (Bowleg et al., 2003). The following section will present literature supporting the use of intersectionality to complement the minority stress theory.

\section{Intersectionality}

Intersectionality takes into account the historical and present state of socially marginalized identities, the interconnected privileges that may exist, and provides the means for giving deeper understandings to these complexities among systematically oppressed groups (Dale et al., 2016; Mehrotra, 2010). Essentially, intersectionality rejects the notion that individuals can be explored unilaterally, and places emphasis on the multiple ways in which the social environment acts upon and/or oppresses a person from a marginalized group(s) (Bowleg, 2012; Crenshaw, 1991). Sexual minorities of color may have at least two or more identities that may bring their own experiences of oppression that can impact quality of life (Bowleg et al., 2003). For example, an African American lesbian may experience marginalization because she is Black, a lesbian, and/or because she is a woman.

Research using the intersectional perspective has ranged from seeking connections between high school and college student leadership (Tillpaugh, Mitchell, \& Soria, 2017), to exploring inequities in health care and public healthcare policies (Bastos, Harnois, \& Paradies, 2018; Hankivsky, 2012; Seng, Lopez, Sperlich, Hamama, \& 
Meldrum, 2012), and to linking social inequities with overall quality of life and PWB (Bowleg et al., 2013; Dale et al., 2016). Studies have revealed that people with multiple minority statuses may experience more disparities in health and mental health outcomes than people with no- or a single disadvantaged identity (Bastos et al., 2018; Bowleg et al., 2013; Seng et al., 2012). As an example, Seng and colleagues (2012) found that among their sample of pregnant women $(\mathrm{N}=619)$, the number of marginalized identities increased the frequency of discrimination which resulted in more posttraumatic stress symptoms and lower quality of life scores.

The relationship between discrimination and PWB has been explored in other sections of this study. It is important however, to reiterate here that discrimination can have a negative impact on PWB (Mouzon et al., 2017; Woodford et al., 2015), and that microaggressions, whether by race (Sue et al., 2007a), gender (Gartner \& Sterzing, 2016), ethnicity (Nadal et al., 2014b), sexuality (Nadal, 2013) or any combination of marginalized identity (Bowleg, 2013), will reveal similar, if not more impactful, results. Moreover, although there is a paucity of research on microaggressions among SMPOC, these studies have specifically placed emphasis on intersectionality as a guiding framework to explore the impact of microaggressions (Balsam, et al., 2011; Bowleg, 2013; Elias et al., 2017; Follins, 2014; Holley et al., 2016; Oshi-Ojuri, 2013); each of which have been critically reviewed in literature above.

In the grand scheme, intersectionality presents an opportunity for researchers to give story to the entirety of a person without leaving key identities out (De Blaere et al., 2010; Holley et al., 2016; Mehrotra, 2010). However, intersectional research does not have a simple "fix" to the methodological challenges that present when attempting to take 
into account multiple social identities, also known as covarying factors (i.e. race, ethnicity, gender, SES, sexuality etc.) (DeBlaere et al., 2010; Seng et al., 2012). Intersectionality has been used in both qualitative and quantitative research (DeBlaere et al., 2010; Mehrotra, 2010; Seng et al., 2012). While Mehrotra (2010) provides an overview and support for the use of intersectionality, qualitatively, Seng and associates' (2012) study used advanced statistical methodology (e.g. structural equation modeling) to operationalize intersectionality for more robust quantitative research. Seng et al. (2012) found that through the use of structural equation modeling (SEM), they were able to operationalize intersectionality which resulted in improvements on the predictive value of their statistical models. Further, DeBlaere and colleagues (2010) have also called for the use of advanced statistical analyses (i.e. SEM) as a way of explaining the variance in multiple forms of systematic oppression.

Along with the dearth of research on microaggressions among SMPOC, there is also a paucity of available quantitative measures to assess the compounding nature of microaggressions due to intersecting identities. Balsam et al.'s (2011) LGBT People of Color Microaggressions scale (LGBT-PCMS) may be the only measure to date that explores intersections of race/ethnicity and sexuality (see microaggressions section for details on the study including scale development).

This study aimed to explore the impact of microaggressions on PWB. As such, this study included the LGBT -PCMS (Balsam et al., 2011) as one of the measures to assess the intersections of race/ethnicity and sexuality on the experiences of microaggressions among SMPOC. As a result, the intersectionality perspective has been used in concert with the minority stress theory to inform this study. While research on 
minority stress in general will add to the existing literature on sexual minorities, exploring microaggressions on the intersections of multiply marginalized identities, and the compounding impact on PWB, will be a significant contribution to the gap in research among SMPOC; a vastly underrepresented group.

\section{Chapter Summary}

In summary, despite the more than 50 years of civil rights protections for POC, and the Supreme Court rulings on same-sex marriage and scattered state and local antidiscrimination measures, both POC and sexual minorities experience greater burdens of health and mental health disparities, including limited or lack of access to care, inappropriate care, and other social, environmental, and economic risk factors (SAMHSA, 2014). This chapter has provided the following: (1) a definition of PWB and a review of literature on the state of PWB among sexual minorities and POC; (2) a definition of emerging adulthood and a review of literature on the PWB of emerging adults; (3) a definition of outness, the various subtypes of outness, and a review of literature on outness and PWB among sexual minorities; (4) a review of the defining taxonomies of microaggressions based on sexual orientation and race/ethnicity, and a review of the literature on the impact of microaggressions among sexual minorities and SMPOC; and (5) a review of supporting literature on the theoretical perspectives used to guide this present study. 


\section{CHAPTER 3: RESEARCH METHODOLOGY}

This chapter presents the methodology of the study. Research design, sample, and recruitment procedures of the parent study will be described. Research design, inclusion and exclusion criteria, sample description, measures used, and the analytical approach of the preset study will follow.

\section{Parent Study}

The parent study, entitled, "Examining the impact of microaggressions among racial/ethnic sexual minority emerging adults", was approved by the Florida International University Internal Review Board (IRB) on April 1st, 2014 with IRB approval protocol number IRB-14-0043 (see Figure A Appendix A). The parent study was conducted through the Community Based Research Institute (CBRI) née Florida International University-Banyan Research Institute on Dissemination, Grants, \& Evaluation (FIUBRIDGE) under Principal Investigator, Dr. Eric F. Wagner. This was a non-experimental, cross-sectional exploratory study and the overall aim of the study was to better understand the experiences of microaggressions.

Data Collection and Recruitment. Data were collected online between June 2014 and June 2016, using Qualtrics (https://fiu.qualtrics.com), a web-based survey software program. Recruitment for the parent study involved a combination of snowballing techniques and targeted sampling. The link to the confidential, anonymous survey was posted on social networking sites (e.g. Facebook, LinkedIn, Twitter, and Stonewall Pride), emails to the survey were distributed through professional academic networks, and flyers promoting the survey were distributed at local and non-local social events (e.g. Pride, Sweet Heat, and Aqua Girl in Miami Beach, LGBTQ Scholars of 
Color Conference in New York, Florida Collegiate Pride Coalition Conference in Jacksonville, Florida) (see Figure B in Appendix B). To bolster participation, the survey for the parent study was also posted on the university's FIU Psychology Research Participation System (see Figure C Appendix C). The system allows students opportunities to voluntarily participate in campus research studies for extra credit. Students who signed up for the study through the system were awarded 1.0 extra credit hours for participation. At the completion of the study, a copy and paste link was provided for all respondents with the request to forward to anyone whom they thought might be interested in participating in the study. Participants who used the copy and paste survey link were not provided with access to the secured data. The link only routed potential participants to the survey.

Upon accessing the link to the study survey, all participants were presented with an informed consent form (see Figure D Appendix D). Participants were required to consent to participate in the study by verifying that they were above 18 years of age and by clicking yes in response to the following statement; "I consent to participate in this study." Participants were required to have access to the internet for approximately $30-45$ minutes' duration, in a single session, in order to complete the online survey.

Parent study sample. The initial sample from the parent study included 872 cases of which 42 cases were removed due to no response or the indication of "no" for the item on consent; therefore, reducing the parent study sample to $\mathrm{N}=830$ cases. The mean age was $22.7(S D=4.6)$ and $76.7 \%$ of the sample $(\mathrm{n}=637)$ identified as female. Two participants identified as transgender male-to-female, four participants identified as transgender female-to-male, and 13 participants identified as intersex or other (responses 
included agender, gender fluid, gender queer, no-binary, and gender non-conforming. Participants of the study were permitted to indicate one or more racial and/or ethnic category. As a result, the racial/ethnic breakdown of the sample is as follows: $57.8 \%$ of the sample identified as Hispanic, 15.4\% as African American, $21.9 \%$ as White or Caucasian, and 9.47\% as Multicultural or other (categories included Asian or Pacific Islander, Native American or American Indian, and Multicultural or Other). Overall $32.5 \%$ of the sample identified as a sexual minority $(n=246)$. More than half of the sample (69.8\%) reported at least some college experience, of which $17.9 \%$ reported to have a college/4-year or post-graduate degree, $37.16 \%$ reported at least part-time employment, and slightly over half of the sample (52.3\%) reported an income between $\$ 0$ and $\$ 34,999$.

\section{Present Study}

The present study is a secondary analysis of data drawn from the previously mentioned non-experimental cross-sectional exploratory study entitled, "Examining the impact of microaggressions among racial/ethnic sexual minority emerging adults" (see parent study information in the above sub-section).

Inclusion and exclusion criteria. The present study aimed to explore the experiences and impact of microaggressions among emerging adult sexual minorities. The inclusion and exclusion criteria of this study required participants to self-identify their age, sexual orientation, and race/ethnicity. The age range that defines the developmental lifespan period emerging adulthood is between 18 and 25 years but can include individuals up to 29 years of age (Arnett, 2014). Participants who indicated an age range between the ages of 18 and 29 years were included in this study. 
In this study, sexual minorities were defined as those who self-identified as lesbian, gay, or bisexual. Identification as transgender is not a sexual orientation. To be transgender is to identify with a biological sex that is opposite of which has been assigned at birth. Research suggests that transgender and/or gender non-conforming persons may experience microaggressions significantly different from those who solely identify as lesbian, gay, or bisexual (Austin, et al., 2016; Pyne, 2016). Modeling Wright and Wegner (2012), participants who identified as transgender only and not also as a sexual minority were excluded from this present study's final analyses. All respondents who indicated a sexual orientation as lesbian, gay, bisexual, or heterosexual/straight met inclusion criteria for this study.

The primary aim of this study is to explore the compounding impact of microaggressions for those who dually identify as a sexual minority and a person of color. The following section will provide a description of the sample post meeting the inclusion and exclusion criteria of this present study.

Present study sample. Participants were included in this present study sample if they met the above referenced inclusion criteria (e.g. must indicate age between 18 to 29 years, indicate sexual orientation and provide race/ethnicity). Twenty-nine case were removed due to a response indicating an age greater than 29 years, and 37 cases were removed because there was no response given for age. Eleven respondents did not indicate a sexual orientation and were subsequently removed from the study sample. An additional 12 cases did not respond to any survey items past the demographics. These 12 cases were also removed from this study. 
Table 3 presents demographic data for this sample. In brief, the final $\mathrm{N}$ for the present study was 741 emerging adults between the ages of $18-29$ years. The mean age was $22.0(S D=3.0)$ years, and $79.4 \%(\mathrm{n}=588)$ of the sample were female. One participant identified as transgender male-to-female and two participants identified as transgender female-to-male; each of which also identified as a sexual minority. Respondents of the parent study were permitted to indicate one or more race (Black/African American, White/Caucasian, Asian/Pacific Islander, and American Indian/Native American) and/or an ethnicity (Hispanic/Latino). Given this, many cases within the sample selected multiple races and an ethnicity. A sample size of $\sim \mathrm{n}=100$ per subgroup is needed for a moderate effect size of .80 power for advanced statistical analysis (i.e. SEM). Consequently, for analytical purposes in this study, race/ethnicity was recoded into a dichotomous variable with "0" representing White non-Hispanics ( $\mathrm{n}=$ 104) and " 1 ” representing a combined group, POC $(\mathrm{n}=637)$ (see Table 3 for detailed descriptions of all demographics, including a breakdown of the combined group, POC). Overall, $68.7 \%$ of the sample identified as heterosexual or straight $(\mathrm{n}=509)$, and $31.3 \%$ identified as a sexual minority $(\mathrm{n}=232)$. Most of the sample $(70.8 \%)$ reported at least some college experience, $38.2 \%$ indicated at least part-time employment, and slightly over half of the sample (52.2\%) reported an income between $\$ 0$ and $\$ 34,999$. 
Table 3. Sample Demographics

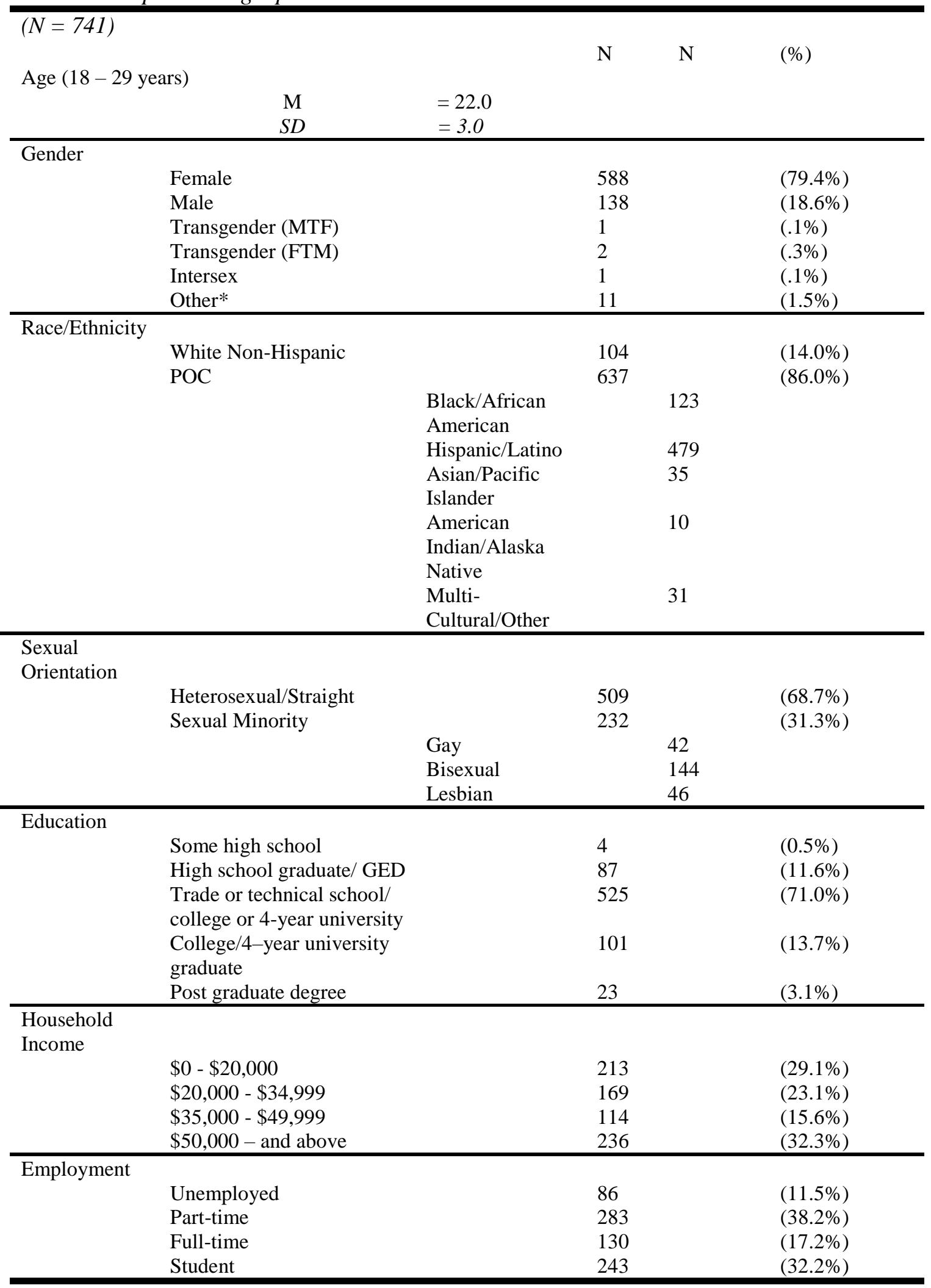

* Other = Gender non-conforming, gender fluid, non-binary, agender, gender queer 


\section{Assessments and Measures}

Participant data were collected via a structured online survey (see Figure E in Appendix E). Participants of the parent study were requested to provide a 12-month retrospective self-report of their experiences with microaggressions. Specific measures were administered to each participant and varied depending on their identified race/ethnicity and/or sexual orientation. Skip patterns were embedded into the survey to ensure that respondents would not receive questions that did not pertain to them (i.e. White heterosexual adults did not receive items that measured racial/ethnic or sexual orientation microaggressions). All participants of the study were administered a demographics questionnaire and the PWB Scale (Ryff, 1989). Table 4 presents the scales used in the current study to measure the constructs, the number of participant responses, the number of items in each scale, and their demonstrated internal consistency (reliability) in the current study with the Cronbach's alpha coefficient. A description of each of the measures used in this study is provided below.

Table 4. Assessments and Measures

\begin{tabular}{|c|c|c|c|}
\hline Measure & \# of Items & $\underline{\mathbf{n}^{*}}$ & Cronbach's Alpha \\
\hline Demographics & 7 & & \\
\hline $\begin{array}{l}\text { Outness Inventory (OI, Mohr \& } \\
\text { Fassinger, 2000)** }\end{array}$ & 11 & 205 & .87 \\
\hline $\begin{array}{l}\text { Racial and Ethnic Microaggressions } \\
\text { Scale (REMS; Nadal, 2011)** }\end{array}$ & 18 & 577 & .70 \\
\hline $\begin{array}{l}\text { Daily Heterosexist Experiences } \\
\text { Questionnaire (DHEQ; Balsam et al, } \\
\text { 2013)** }\end{array}$ & 18 & 211 & .84 \\
\hline $\begin{array}{l}\text { LGBT People of Color } \\
\text { Microaggressions Scale (LGBT-PCMS; } \\
\text { Balsam et al., 2011)** }\end{array}$ & 18 & 157 & .91 \\
\hline $\begin{array}{l}\text { Psychological Well-Being Scale (PWB; } \\
\text { Ryff, 1989)** }\end{array}$ & 18 & 680 & .82 \\
\hline
\end{tabular}

$*_{\mathrm{n}}$ represents the number of participants out of the pre-selected sample who completed the measure ** Likert scale and continuous 
Demographics. A 7-item measure was used to collect the following demographics: 1) age, 2) gender (male, female, transgender male to female, transgender female to male, intersex, or other), 3) race/ethnicity (White or Caucasian, Black or African American, Hispanic/Latino(a), American Indian/Native American, Asian/Pacific Islander, and/or Multicultural/Other), 4) sexual orientation (heterosexual or straight, lesbian, gay, or bisexual), 5) education (some high school, high school graduate or GED, some trade or technical school, trade or technical school, some college/4 yr. university, college/4 yr. university graduate, or post-graduate degree), 6) household income (ranged from less than $\$ 20,000$ to $\$ 65,000$ and above), and 7) employment (unemployed, parttime, full-time, student, or other).

Age, sexual orientation, and race/ethnicity were used for exclusion/inclusion criteria of this current study, and gender, education, employment, and income were used for descriptive purposes only. Additionally, sexual orientation and race/ethnicity were used for analytic purposes in the current study. Sexual orientation was recoded into a dichotomous variable SEXOR, with "0" representing heterosexuals $(\mathrm{n}=509)$, and "1" representing a combined group (lesbians, gays, and bisexuals) for all sexual minorities (n =232). As previously mentioned, race/ethnicity was recoded into a dichotomous variable RACEALL, with "0" representing White non-Hispanics ( $=104)$ and "1" representing a combined group, POC $(\mathrm{n}=637)$

Outness Inventory (OI; Mohr \& Fassinger, 2000). The OI is an 11-item scale used to assess the degree to which lesbian, gay, and bisexual persons are open about their sexual orientation in various domains such as family members, religious community, and 
the world (e.g. strangers and new acquaintances). The measure is based on a 7-point Likert rating scale ranging from "1" "person definitely does not know about your sexual orientation status" to "7" "person definitely knows about your sexual orientation status, and it is openly talked about." An indication of " 0 " was used for situations where the response was "not applicable to your situation; there is no such person or group of people in your life." Mohr and Fassinger 2000), indicate that data from the scale can be analyzed in three different ways (1) measures of outness to specific figures or types of figures (i.e. mom, peers), (2) levels of outness in life domains (family, everyday life, religion), and (3) an index of overall outness. An index of overall outness was used for this study and calculated by averaging the three subscales in which the greater the mean, the more out the respondent. Mean overall outness scores are reflected in the analyses by the variable name OUTOVR. Mohr and Fassinger (2000) reported alpha reliability coefficients for the three factors as follows: Out to World $(\alpha=.79)$, Out to Family $(\alpha=.74)$, and Out to Religion $(\alpha=.97)$. Reliability was slightly higher in this study and are reported as follows: Out to World ( $\alpha=.82)$, Out to Family $(\alpha=.84)$, Out to Religion $(\alpha=.98)$, and Overall Outness $(\alpha=.87)$.

\section{Racial and Ethnic Microaggressions Scale (REMS-45; Nadal, 2011). The}

REMS is a 45-item measure that collects data on microaggressions experienced by racial/ethnic minorities. The measure is comprised of six factors which are based on Sue and colleagues' (2007) original taxonomy of microaggressions and include the following: (a) assumptions of inferiority; (b) second-class citizen and assumptions of criminality; (c) microinvalidations; (d) exoticization/assumptions of similarity; (e) environmental microaggressions; and (f) workplace and school microaggressions (see Table 2). The item 
responses were measured on a 5-point Likert rating scale ranging from "1" "did not experience this event in the past 12 months" to " 5 " "I experienced this event 10 or more times in the past 12 months." In the parent study, the top three items in terms of factor loadings were selected from each of the six factors resulting in a shortened 18-item measure which was used in this study. An overall mean score of the 18 items was calculated to indicate the frequency of microaggressions; of which the higher scores represent greater experiences of racial/ethnic microaggressions (REM). Mean scores of racial/ethnic microaggressions are reflected in the analyses by the variable name REMFREQ. Nadal (2011) reported a reliability $\alpha=.91$ for the overall measure and a reliability for subscales ranging from $\alpha=.78$ to $\alpha=.87$. Overall reliability for the measure used in this study was lower at $\alpha=.70$ and the reliability for the subscales ranged from $\alpha$ $=.65$ to $\alpha=.80$.

\section{The Daily Heterosexist Experiences Questionnaire (DHEQ; Balsam,}

Beadnell, \& Molina, 2013). The DHEQ is a 50-item measure that collects data on a range of day to day stressors experienced by sexual minorities because of their sexuality. The measure is comprised of nine factors which are based on the theoretical assumptions of Meyer's (1995) minority stress theory and include the following: 1) gender expression, 2) vigilance, 3) parenting, 4) discrimination/harassment, 5) vicarious trauma, 6) family or origin, 7) HIV/AIDS, 8) victimization, and 9) isolation. The responses were measured on a 6-point Likert rating scale ranging from "1" "it happened, and it bothered me NOT AT ALL" to "5" "it happened, and it bothered me EXTREMELY." An indication of "0" was used for situations where the response was "did not happen/not applicable to me." The respondents were requested to answer based on a 12 - month experiential recall. The top 
two items in terms of factor loadings were selected from each of the nine subcategories resulting in a shortened 18-item measure in the parent study. An overall mean score was calculated to indicate the impact of the experienced sexual orientation microaggression; of which the higher scores represent greater experiences of sexual orientation microaggressions. Mean scores of sexual orientation microaggressions are reflected in the analyses by the variable name DHEQIMP. Balsam, Beadnell, and Molina (2013) reported a reliability of $\alpha=.92$ and reliability for subscales ranging from $\alpha=.76$ to $\alpha$ $=.87$. Overall reliability for the measure used in this study was lower at $\alpha=.84$ and the reliability for the subscales ranged from $\alpha=.61$ to $\alpha=.79$.

\section{The LGBT People of Color Microaggressions Scale (LGBT-PCMS; Balsam,}

et al., 2011). The LGBT-PCMS is an 18-item measure that collects data on the impact of microaggressions experienced by sexual minorities of color. The measure categorizes microaggressions experienced by SMPOC within a three factors model and is based on Sue and colleagues' (2007) original microaggressions taxonomy's three themes (microassaults, microinsults, and microinvalidations; see Figure 2) and include the following: 1) racism in the LGBT community, 2) heterosexism in racial/ethnic minority communities, and 3) racism in dating and close relationships. The responses were measured on a 6-point Likert rating scale ranging from "1" "it happened, and it bothered me NOT AT ALL" to "5" "it happened, and it bothered me EXTREMELY." An indication of " 0 " was used for situations where the response was "did not happen/not applicable to me." The respondents were requested to answer based on a 12 - month experiential recall. An overall mean score of the 18 items was calculated to indicate the impact of the experienced intersectional microaggression; of which the higher scores 
represent greater experiences of intersectional microaggressions. Mean scores of intersectional microaggressions are reflected in the analyses by the variable name PCMSIMP. Balsam and associates (2011) reported a reliability of $\alpha=.92$ for the overall model and a reliability for the subscales as follows: LGBT Racism $\alpha=.89$, POC Heterosexism $\alpha=.81$, and LGBT Relationship Racism $\alpha=.83$. Overall reliability for this study was consistent with the reported $\alpha$ in the original measure at $\alpha=.91$. The reliability for the subscales for this study were as follows: LGBT Racism $\alpha=.84$, POC

Heterosexism $\alpha=.84$, and slightly lower in comparison to the original measure for LGBT Relationship Racism at $\alpha=.73$.

Ryff's Psychological Well-Being Scale (PWB; Ryff, 1989). The Psychological Well-Being Scale (Ryff, 1989) is a 63-item measure that collects data on dimensions of wellness. The measure is comprised of six factors and include the following: 1) autonomy, 2) environmental mastery, 3) personal growth, 4) positive relations with others, 5) purpose in life, and 6) self-acceptance. The responses were measured on a 6point Likert type rating scale ranging from "1" "strongly agree" to "6" "strongly disagree." The top three items in terms of factor loadings were selected from each of six dimensions resulting in a shortened 18- item measure in the parent study and was used to analyze data in the present study. A composite mean score of the 18 items was calculated to indicate a score of overall PWB; of which the lower scores represent lower PWB and greater distress. Mean scores of PWB are reflected in the analyses by the variable name PWB. Ryff (1989) found the scale to have high internal consistency $\alpha=.91$ for the overall measure and a reliability for subscales ranging from low to moderate at $\alpha=.32$ to 
$\alpha=.76$ Overall reliability for the PWB measure used in this study was $\alpha=.82$ and the reliability for the subscales ranged from $\alpha=.20$ to $\alpha=.74$.

\section{Power Analysis}

At the original study design, a rough approximation equaling 200 or more participants was obtained by applying power analyses for a regression coefficient in multiple regression analyses. The present study $\mathrm{N}=741$ exceeded the number required to observe a moderate effect size at .80 power.

\section{Analytical Approach}

Due to skip patterns embedded in the survey (i.e. Heterosexual POC did not receive items that measured sexual orientation microaggressions), sample sizes varied per measure and, as a result, each conceptual model was analyzed using a subset of the overall sample. All analyses were conducted using SPSS version 20.0 (IBM Corp., 2011) and M Plus version 7 (Muthen \& Muthen, 2012). Structural equation modeling (SEM) was the primary analytic approach used to test all hypotheses for research questions one through four (for conceptual models see Figure F Appendix F). Moderation was explored through separate single degree of freedom interaction contrasts by creating a product term of a focal independent variable, race/ethnicity (Baron \& Kenny, 1986; Edwards \& Lambert, 2007). The predictor and the focal independent variable were then mean centered (subtracting the mean from all values to that the score was zero) and an interaction term was created between the focal independent variable (moderator) and the predicting variable by multiplying the centered predictor variable by the centered focal independent variable. Mediation analyses in this study were explored using the logic of 
the joint significance test (Baron \& Kenny, 1986; MacKinnon, Lockwood, Hoffman, West, \& Sheets, 2002).

Prior to all main analyses, each dataset was (1) screened for missing values, (2) screened for assumptions of normality by examining univariate indices of skewness and kurtosis and, (3) screened for non-model and model based outliers by examining leverage indices and standardized DFBetas. Given that the data was collected via an anonymous survey, missing data was expected. Parameter estimates, and model tests were pursued in the context of Full Information Maximum Likelihood (FIML) methods as implemented in MPlus (Muthen \& Muthen, 2012). Univariate indices of skewness and kurtosis were examined to determine if the absolute value of any of the indices was greater than 3.0 (Kline, 2011). If non-normality appeared to be problematic, then a robust estimation method based on the Huber-White estimator as implemented in MPlus (Muthen \& Muthen, 2012) was utilized. Both non-model based and model based outliers were assessed. For the non-model-based techniques, leverage statistics were examined. Leverage indices for each individual with a value greater than 4 times the mean leverage was considered an outlier. For model-based outlier detection, standardized DFBetas were examined. A standardized DFBeta with an absolute value greater than one was considered an influential outlier. In addition, multivariate normality was evaluated using Mardia's test for multivariate normality when applicable. Any outliers found were checked for coding errors and analyses were conducted both with and without the outliers. If results differ, then the outliers were considered consequential and outlier resistant analytic strategies were pursued (Wilcox, 1997, 1999, 2003). 
SEM is an advanced statistical procedure which uses multivariate analyses to test and confirm relationships between variables a priori (Kline, 2011). Basically, SEM allows the testing of an entire theory, simultaneously, by confirming whatever theories have been hypothesized. In such, SEM uses a confirmatory approach to test whether the relationships between variables are supported by the data by specifying models and using significance testing to confirm model fit (Kline, 2011). SEM works best when using large datasets (typically of $\mathrm{N}=200$ or more) and SEM works with both continuous and discrete variables. Moreover, a benefit of SEM is that the approach is useful in reducing measurement error in a statistical model by accounting for more of the variance within the model (Kline, 2011).

There are two primary types to SEM, (1) a measurement model (i.e. confirmatory factor analysis) and (2) a structural model (i.e. path analysis). A confirmatory factor analysis (CFA), one of the most common statistical procedures used in the applied sciences, is used to determine the relationship between observed measures indicators and latent variables factors (Brown, 2006). Observed variables are akin to items on a measure or scale, and latent variables are the constructs or theoretical concepts that the indicators are aimed at measuring. CFAs are commonly used in evaluating psychometric tests and construct validation. In this study, reliability and/or CFAs were explored for measures prior to making final decisions on how to model each of the constructs in the final analyses.

A structural model is like a path analysis and is used to test a hypothesized model explaining a relationship between latent and exogenous (predictors) variables using sample data (Kline, 2011). In this case, causality cannot be determined, and theories are 
not proven. What can be determined however, is that the model fits or, is consistent with, the data (Kline, 2011). The latent variable (theoretical construct), is what signifies a structural model and without the use of latent variables, these are called path analyses. This study used single observed variables or indicators and not latent constructs. Therefore, path analyses were conducted to examine the relationships between the independent variables, also known as predictors or exogenous variables, and the dependent variables, also referred to as outcome or endogenous variables.

Following the recommendations of Bollen and Long (1993), a variety of global fit indices were used, including indices of absolute fit, indices of relative fit, and indices of fit with a penalty function for lack of parsimony. These include the traditional overall chi square test of model fit (which should be statistically non-significant), the Root Mean Square Error of Approximation (RMSEA; which should be less than 0.08 to declare satisfactory fit), the $\mathrm{p}$ value for the test of close fit (which should be statistically nonsignificant), the Comparative Fit Index (CFI; which should be greater than 0.95); and the standardized root mean square residual (which should be less than 0.05).

\section{Chapter Summary}

In summary, this chapter has explained the methodology used in this study. A synopsis of the parent study, including data collection and recruitment, and sample demographics were provided. Exclusion and inclusion criteria for this present study were reviewed, and an overview of the final sample and measures used were described. In addition, the analytical approach used in research questions one through 4 were summarized. The following chapter will present findings of this study which will include both preliminary and primary analyses for each hypothesis. 


\section{CHAPTER 4: RESULTS}

This chapter presents the findings for the four research questions and the accompanying hypotheses evaluated in this study. Due to the skip patterns embedded in the parent study survey, each conceptual model has a corresponding data set, resulting in a separate subsample of the overall data per each hypothesis. This chapter will be structured in the following way per specific aim: (1) research question, (2) hypothesis/es, (3) descriptive statistics, (4) analysis(es) findings and, (5) corresponding figures and tables per question/hypothesis.

\section{Specific Aim 1}

The first aim of this study was to empirically examine the experiences of microaggressions among emerging adult sexual minorities of color and the association between microaggressions and PWB among emerging adult SMPOC.

Research question 1. Do SMPOC report greater experiences of microaggressions and lower PWB as compared with White non-Hispanic sexual minorities and heterosexuals?

Hypothesis 1a. Sexual minorities of color will report experiencing more racial/ethnic microaggressions and lower PWB compared to heterosexual POC.

Descriptive statistics. Participants $(n=637)$ were included in the analysis for hypothesis 1a only if they were administered the REMS measure during original data collection. This sample includes all POC. The mean age was $21.9(S D=3.0)$, and $82.6 \%$ $(n=526)$ of the sample were female. Almost three-quarters of the sample identified as heterosexual $(71.3 \%, \mathrm{n}=454)$ and $28.7 \%$ identified as a SMPOC $(\mathrm{n}=183)$. Most of the 
sample (72.4\%) reported at least some college experience and slightly over half of the sample (52.8\%) reported an income between $\$ 0$ and $\$ 34,999$.

Analysis. The model that was fit is in Figure 3. This model was just-identified so the model fit indices were uninformative. Missing values at the item level for the outcome variables were $2.2 \%$ to $4.9 \%$ for racial/ethnic microaggressions (REMFREQ) and $4.7 \%$ to $5.7 \%$ for PWB. Examination of univariate indices of skewness and kurtosis indicated the presence of non-normality (skewness $=1.3$ and 1.2 and kurtosis $=3.9$ and 1.9 for REMFREQ and PWB, respectively). Six outliers were detected. The model was run with and without the identified outliers. There were no statistically significant differences with or without the presence of outliers, therefore the outliers were retained in the analysis. Figure 3 presents the unstandardized and standardized (in parenthesis) path coefficients for the model. Results of the analysis supported the hypothesis and revealed that, on average, the mean score of experiences of REMFREQ was greater for SMPOC $(\mathrm{M}=2.03)$ than heterosexual POC $(\mathrm{M}=1.91)$ by .12 units $(p<.01)$ and the mean score of PWB was lower for SMPOC $(\mathrm{M}=4.37)$ than for heterosexual POC $(\mathrm{M}=4.56)$ by -.19 units $(p<.01)$. Table 5 presents the unstandardized regression coefficients (B) and intercept, the p-value, and the upper and lower bound confidence intervals. 
Figure 3. Path Model for Research Question 1 Hypothesis 1 a

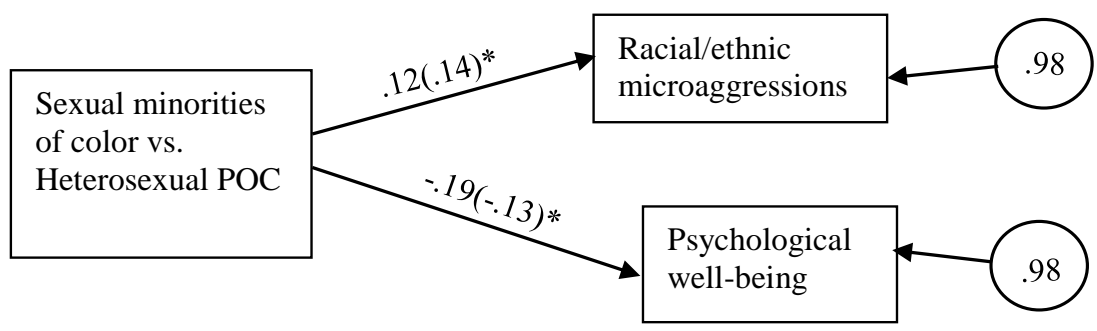

$* \mathrm{p}<.01$. Note: Heterosexual POC $=0$, Sexual minorities of color $=1$. All endogenous variables are continuous. Racial/ethnic microaggressions are based on a 12 - month retrospective account. Values on paths represent unstandardized and standardized (in parenthesis) regressions coefficients, and values in circles represent the percent of variance unexplained (residual terms).

Table 5. Mean Comparisons of Racial/Ethnic Microaggressions and Psychological WellBeing Predicted by Sexual Orientation for all POC

\begin{tabular}{llllcc}
\hline \hline & & & \multicolumn{2}{c}{$\mathbf{9 5 \% \text { Confidence Intervals }}$} \\
Endogenous Variables & $\mathbf{B}$ & $\mathbf{B e t a}$ & $\mathbf{p}$ & Lower Bound & Upper Bound \\
$\begin{array}{l}\text { Racial/Ethnic } \\
\text { Microaggressions }\end{array}$ & .118 & .136 & $.002 *$ & .043 & .194 \\
Psychological Well-Being & -.187 & -.131 & $.003 *$ & -.310 & -.064 \\
\hline \hline
\end{tabular}

Note: Sexual orientation was the predictor. Heterosexual POC $=0$, Sexual minorities of color $=1$

Hypothesis 1b. Sexual minorities of color will report experiencing more sexual orientation related microaggressions and lower PWB compared to White non-Hispanic sexual minorities.

Descriptive statistics. Participants $(\mathrm{n}=232)$ were included in the analysis for hypothesis $1 \mathrm{~b}$ only if they were administered the DHEQ measure during original data collection. This sample includes all sexual minorities. The mean age was 22.4 ( $S D=$ 3.1), and $72.4 \%(\mathrm{n}=168)$ of the sample were female. Slightly more than two-thirds of the sample identified as SMPOC $(78.9 \%, \mathrm{n}=183)$. Most of the sample $(66.7 \%)$ reported at least some college experience and slightly over half of the sample (53.5\%) reported an income between $\$ 0$ and $\$ 34,999$. 
Analysis. The model that was fit is in Figure 4. This model was just-identified so the model fit indices were uninformative. Missing values at the item level for the outcome variables were $2.6 \%$ to $5.6 \%$ for sexual orientation microaggressions (DHEQIMP) and 5.6\% to 6.9\% for PWB. Examination of univariate indices of skewness and kurtosis indicated the presence of non-normality (skewness $=.61$ and .13 and kurtosis $=-.11$ and -.56 for DHEQIMP and PWB, respectively). One outlier was detected. The model was run with and without the identified outlier. There were no statistically significant differences with or without the presence of the outlier, therefore the outlier was retained in the analysis. Figure 4 presents the unstandardized and standardized (in parenthesis) path coefficients. Analysis results partially supported the hypothesis and revealed that, on average, the mean score of experiences of DHEQIMP was lower for SMPOC $(M=2.34)$ than White non-Hispanic sexual minorities $(M=2.65)$ by -.31 units $(p<.05)$ however, there were no statistically significant differences between the mean score of PWB for SMPOC $(\mathrm{M}=4.37)$ compared to White non-Hispanic sexual minorities $(\mathrm{M}=4.30)(\beta=.04, p=.485)$. Table 6 presents the unstandardized regression coefficients (B) and intercept, the p-value, and the upper and lower bound confidence intervals. 
Figure 4. Path Model for Research Question 1 Hypothesis $1 b$

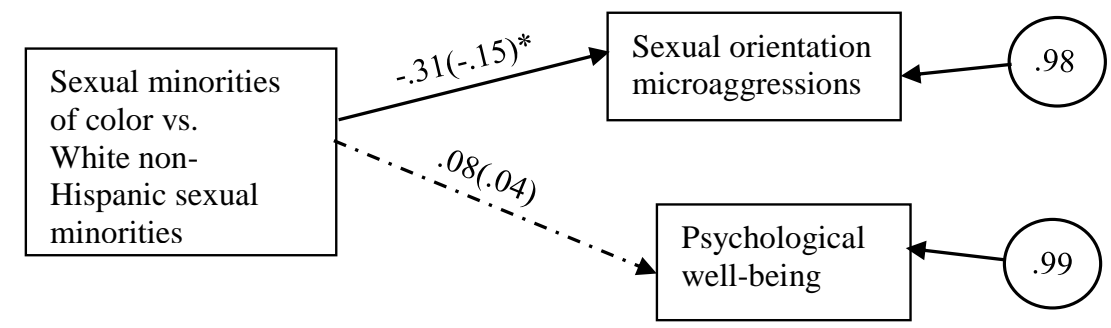

\footnotetext{
$* \mathrm{p}<.05$ Note: White non-Hispanic sexual minorities $=0$, Sexual minorities of color $=1$. Endogenous variables are continuous. Sexual orientation microaggressions are based on a $12-$ month retrospective account. Values on paths represent unstandardized and standardized (in parenthesis) regression coefficients, values in circles represent the percent of variance unexplained (residual terms), and dotted lines represent non-significant paths.
}

Table 6. Mean Comparisons of Sexual Orientation Microaggressions and Psychological Well-Being Predicted by Race/Ethnicity for all Sexual Minorities

\begin{tabular}{llllcc}
\hline \hline & & & & \multicolumn{2}{c}{$\mathbf{9 5 \% \text { Confidence Intervals }}$} \\
$\begin{array}{l}\text { Endogenous Variable } \\
\begin{array}{l}\text { Sexual orientation } \\
\text { microaggressions }\end{array}\end{array}$ & $\mathbf{b}$ & Beta & $\mathbf{p}$ & Lower Bound & Upper Bound \\
$\begin{array}{l}\text { Psychological Well-Being } \\
\text { Psych }\end{array}$ & -.310 & -.154 & $.021^{*}$ & -.572 & -.047 \\
\hline \hline
\end{tabular}

Note: Race/ethnicity was the predictor. White non-Hispanic sexual minorities $=0$, sexual minorities of color $=1$

Hypothesis 1c. Sexual minorities of color will report lower overall PWB than White non-Hispanic sexual minorities and heterosexuals.

Descriptive statistics. PWB was the only measure administered to all participants during the original data collection of the parent study and therefore all participants who met the criteria for this current study $(\mathrm{N}=741)$ were included in the analysis for hypothesis 1c. This sample includes White non-Hispanic sexual minorities $(n=49)$, White non-Hispanic heterosexuals $(\mathrm{n}=55)$, heterosexual POC $(\mathrm{n}=454)$ and SMPOC $(\mathrm{n}=$ 183). The mean age was $22.0(S D=3.0)$, and $79.4 \%(n=588)$ of the sample were 
female. Most of the sample (70.8\%) reported at least some college experience and slightly over half of the sample (52.2\%) reported an income between $\$ 0$ and $\$ 34,999$. Analysis. The model that was fit is in Figure 5. This model was just-identified so the model fit indices were uninformative. Missing values at the item level for PWB was $4.5 \%$ to $5.3 \%$. Examination of univariate indices of skewness and kurtosis indicated the presence of relatively normally distributed data (skewness $=.25$ and kurtosis $=.41$ ). No outliers were detected for this model. Figure 5 presents the unstandardized and standardized (in parentheses) path coefficients. Results of the hypothesis were partially supported. On average, the mean score of PWB was lower for SMPOC than heterosexual POC by -.19 units $(p<.01)$. This path maintained statistical significance when a Holms modified Bonferroni correction was used to control the familywise error rate at 0.05 (see Table 7). There were no significant differences in mean scores on PWB between SMPOC and White non-Hispanic heterosexuals $(\beta=-.14, \mathrm{p}=152)$ or White non-Hispanic sexual minorities $(\beta=.08, \mathrm{p}=.476)$. Table 7 presents the unstandardized regression coefficients (B) and intercept, the p-value, the upper and lower bound confidence intervals, and the Holm's Modified Bonferroni results. Table 8 presents the means, standard deviations, and range for all mean scores by comparison group. 
Figure 5. Path Model for Research Question 1 Hypothesis 1c

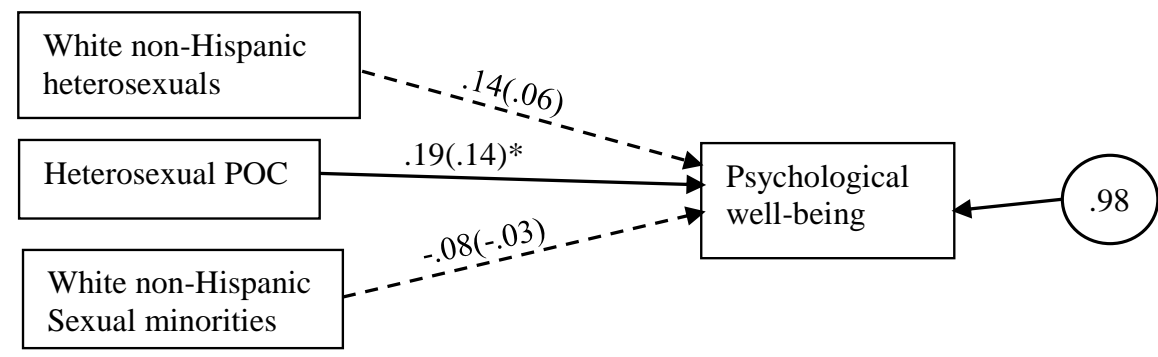

$* \mathrm{p}<.01$. Note: Sexual minorities of color are the reference group for all paths. Values on paths represent unstandardized and standardized (in parenthesis) regression coefficients, value in the circle represents the percent of variance unexplained (residual terms), and dotted lines represent non-significant paths.

Table 7. Mean Comparison of All Groups on Psychological Well-Being

95\% Confidence Intervals

\begin{tabular}{lcccccc} 
Comparison Groups & $\mathbf{b}$ & Beta & $\mathbf{p}$ & $\begin{array}{l}\text { Lower } \\
\text { Bound }\end{array}$ & $\begin{array}{l}\text { Upper } \\
\text { Bound }\end{array}$ & $\begin{array}{l}\text { Holm's } \\
\text { Modified } \\
\text { Bonferroni }\end{array}$ \\
$\begin{array}{l}\text { Sexual minorities of color to } \\
\text { heterosexual POC }\end{array}$ & -.186 & -.123 & $.003 *$ & -.309 & -.062 & $.05 / 3=.017$ \\
$\begin{array}{l}\text { Sexual minorities of color to } \\
\begin{array}{l}\text { White non-Hispanic } \\
\text { heterosexuals }\end{array}\end{array}$ & -.143 & -.094 & .152 & -.338 & .053 & \\
$\begin{array}{l}\text { Sexual minorities of color to } \\
\text { White non-Hispanic sexual } \\
\text { minorities }\end{array}$ & .078 & .052 & .476 & -.137 & .294 & \\
\hline \hline
\end{tabular}

Note: $* \mathrm{p}<.01$

Table 8. Means and Standard Deviations for Psychological Well-Being

\begin{tabular}{llc}
\hline \hline Groups & Means (SD) & Range (Min. - Max.) \\
White non-Hispanic & $4.52(.61)$ & $3.21-5.88$ \\
Heterosexuals & & \\
White non-Hispanic Sexual & $4.30(.66)$ & $2.85-5.67$ \\
Minorities & & $2.96-6.00$ \\
$\begin{array}{l}\text { Heterosexual People of Color } \\
\text { Sexual Minorities of Color }\end{array}$ & $4.56(.61)$ & $2.69-6.00$ \\
\hline
\end{tabular}


Research question 2. Does racial/ethnic identity moderate the relationship between experiencing microaggressions and PWB?

Hypothesis $2 \boldsymbol{a}$. The associations between experiencing microaggressions and PWB will be stronger among sexual minorities of color than among White non-Hispanic sexual minorities.

Descriptive statistics. Participants $(\mathrm{n}=232)$ were included in the analysis for hypothesis $2 \mathrm{a}$ only if they were administered the DHEQ measure during original data collection. The mean age was $22.4(S D=3.1)$, and $72.4 \%(\mathrm{n}=168)$ of the sample were female. Slightly more than two-thirds of the sample identified as a SMPOC $(78.9 \%, \mathrm{n}=$ 183). Most of the sample (66.7\%) reported at least some college experience and slightly over half of the sample (53.5\%) reported an income between $\$ 0$ and $\$ 34,999$.

Analysis. The model that was fit is in Figure 6 This model was just-identified so the model fit indices were uninformative. Missing values at the item level for DHEQIMP was $2.6 \%$ to $5.6 \%$ and missing values for PWB was $5.6 \%$ to $6.9 \%$. Examination of univariate indices of skewness and kurtosis indicated the presence of non-normality (skewness $=.61$ and .13 and kurtosis $=-.13$ and -.56 for DHEQIMP and PWB, respectively). One outlier was detected. The model was run with and without the identified outlier. There were no statistically significant differences with or without the presence of the outlier, therefore the outlier was retained in the analysis. Figure 6 presents the model for the path analysis. The interaction was not significant; therefore, the hypothesis was not supported. For sexual minorities, race/ethnicity did not moderate the relationship between DHEQIMP and PWB $(\beta=-.37, p=.08)$. Table 9 presents the 
unstandardized regression coefficients (B) and intercept, the p-value, and the upper and lower bound confidence intervals.

Figure 6. Path Model for Research Question 2 Hypothesis $2 a$

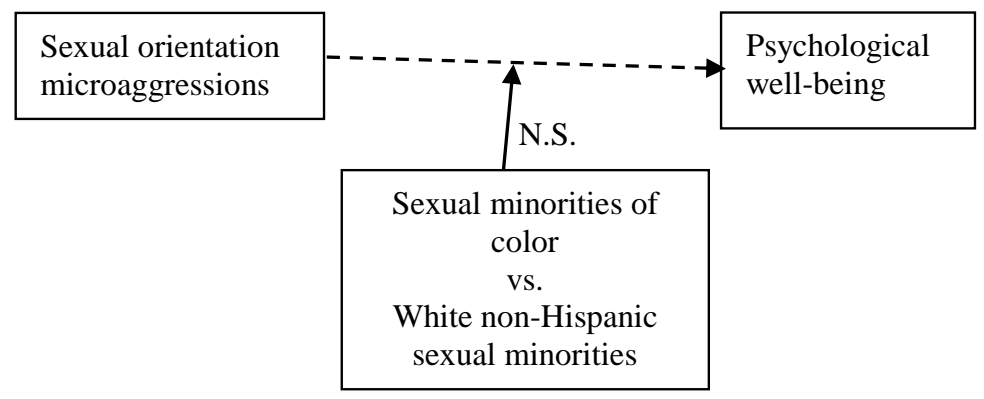

Note: No moderation found between White non-Hispanic sexual minorities $=0$, and Sexual minorities of color $=1$. Exogenous variable, sexual orientation microaggressions, and endogenous variable, psychological well-being, are continuous. Sexual orientation microaggressions are based on a 12 - month retrospective account. The dotted line represents a non-significant path.

Table 9. Psychological Well-Being Predicted from Sexual Orientation Microaggressions as Moderated by Race/Ethnicity for Sexual Minorities

\begin{tabular}{llllcc}
\hline \hline & & & & \multicolumn{2}{c}{ 95\% Confidence Intervals } \\
Predictor & $\mathbf{b}$ & Beta & $\mathbf{p}$ & Lower Bound & Upper Bound \\
Sexual Orientation Microaggressions & .114 & .128 & .297 & -.100 & .328 \\
Race/Ethnicity & .635 & .367 & .083 & -.083 & 1.352 \\
Sexual Orientation Microaggressions & -.224 & -.369 & .083 & -.476 & .029 \\
x Race/Ethnicity & & & & & \\
\hline \hline
\end{tabular}

Note: Race/ethnicity - White non-Hispanic sexual minorities $=0$, sexual minorities of color $=1$

Research question 3. Does outness mediate the relationship between experiencing microaggressions and PWB among sexual minorities?

Hypothesis 3a. Among sexual minorities, the level of outness will mediate the relationship between experiencing sexual orientation related microaggressions and PWB. Descriptive statistics. Participants $(\mathrm{n}=232)$ were included in the analysis for hypothesis $2 \mathrm{a}$ only if they were administered the DHEQ measure during original data 
collection. The mean age was $22.4(S D=3.1)$, and $72.4 \%(\mathrm{n}=168)$ of the sample were female. Slightly more than two-thirds of the sample identified as sexual minority of color $(78.9 \%, \mathrm{n}=183)$. Most of the sample $(66.4 \%)$ reported at least some college experience and slightly over half of the sample (52.6\%) reported an income between $\$ 0$ and $\$ 34,999$. Analysis. The model that was fit is in Figure 7. This model was just-identified so the model fit indices were uninformative. Missing values at the item level were $2.6 \%$ to 5.6\% for DHEQIMP, .4\% to $11.2 \%$ for level of OUTOVR, and 5.6\% to $6.9 \%$ for PWB. Examination of univariate indices of skewness and kurtosis indicated the presence of non-normality (skewness $=1.04, .61$, and -.14 and kurtosis $=.34,-.11$ and -.56 for OUTOVR, DHEQIMP and PWB, respectively). No outliers were detected for this model. Figure 7 presents the unstandardized and standardized (in parentheses) path coefficients. The hypothesis was not supported and therefore a mediated relationship, by OUTOVR, between DHEQIMP and PWB was not found. While there was no mediated relationship, one indirect path revealed statistically significant results. On average, people who are more out in the community were higher on PWB, holding constant their experiences of DHEQIMP, by .12 units $(p<.01)$. Table 10 presents the unstandardized regression coefficients (B) and intercept, the p-value, and the upper and lower bound confidence intervals for indirect and direct paths. 
Figure 7. Path Model for Research Question 3 Hypothesis $3 a$

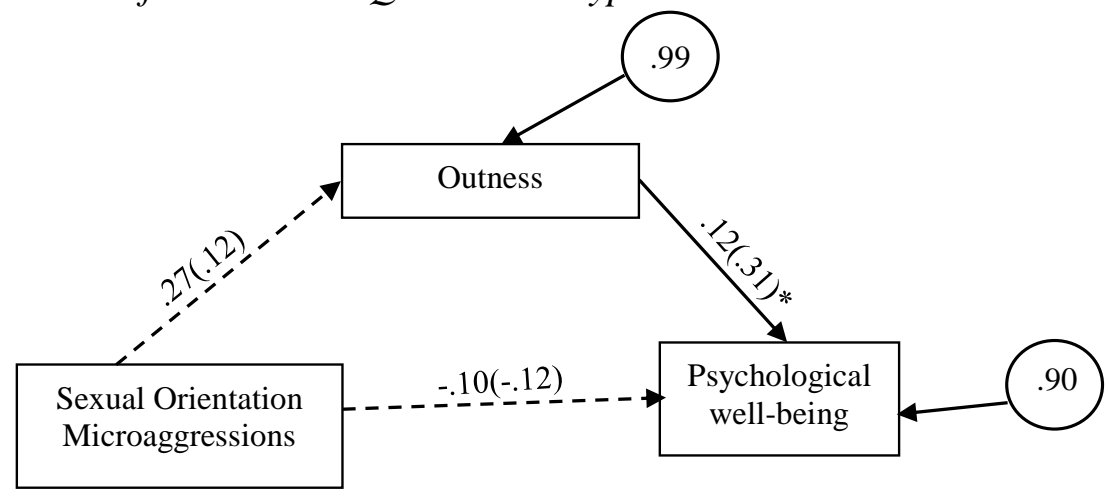

$* \mathrm{p}>.01$. Note: All exogenous and endogenous variables are continuous. Sexual orientation microaggressions are based on a 12 - month retrospective account. Values on paths represent unstandardized and standardized (in parenthesis) regression coefficients, values in circles represent the percent of variance unexplained (residual terms), and dotted lines represent non-significant paths.

Table 10. Relationship Between Sexual Orientation Microaggressions and Psychological Well-Being as Mediated by Level of Outness for Sexual Minorities

95\% Confidence Intervals

\begin{tabular}{lllllc}
\hline \multicolumn{1}{c}{$\begin{array}{c}\text { Direct Path: } \\
\text { b }\end{array}$} & Beta & $\mathbf{p}$ & $\begin{array}{c}\text { 95\% Confidence Intervals } \\
\text { Lower Bound }\end{array}$ & Upper Bound \\
$\begin{array}{l}\text { Sexual Orientation Microaggressions to } \\
\text { Psychological Well-Being }\end{array}$ & -.102 & -.117 & .064 & -.210 & .006 \\
$\begin{array}{l}\text { Indirect Paths: } \\
\text { Sexual Orientation Microaggressions to }\end{array}$ & .273 & .118 & .094 & -.047 & .592 \\
$\begin{array}{l}\text { Outness } \\
\text { Outness to Psychological Well-Being }\end{array}$ & .117 & .311 & $.000 *$ & .070 & .164 \\
\hline \hline
\end{tabular}

Note: Only 1 path was significant at $* \mathrm{p}<.01$

Hypothesis $3 \boldsymbol{b}$. Among sexual minorities of color, the level of outness will mediate the relationship between experiencing intersectional microaggressions and PWB.

Descriptive statistics. Participants $(\mathrm{n}=183)$ were included in the analysis for hypothesis $3 b$ only if they were administered the LGBT-PCMS measure during original data collection. The mean age was $22.2(S D=3.0)$, and $77.0 \%(\mathrm{n}=141)$ of the sample were female. Slightly more than half of sample identified as bisexual $(62.3 \%, \mathrm{n}=114)$, 
21.3\% ( $(n=39)$ identified as lesbian, and $16.4 \%(n=30)$ identified as gay. Most of the sample (72.0\%) reported at least some college experience and slightly over half of the sample (53.6\%) reported an income between $\$ 0$ and $\$ 34,999$.

Analysis. The model that was fit is in Figure 8. This model was just-identified so the model fit indices were uninformative. Missing values at the item level were .5\% to $7.7 \%$ for level of OUTOVR, $6.6 \%$ to $8.2 \%$ for intersectional microaggressions (PCMSIMP), and $6.6 \%$ to $8.2 \%$ for PWB. Examination of univariate indices of skewness and kurtosis indicated the presence of non-normality (skewness $=1.19,1.87$ and -.47 and kurtosis $=-.84,4.21$ and -.55 for outness, PCMS and PWB, respectively). Two outliers were detected. The model was run with and without the identified outliers. There were no statistically significant differences with or without the presence of outliers, therefore the outliers were retained in the analysis. Figure 8 presents the unstandardized and standardized (in parenthesis) path coefficients. The hypothesis was not supported and therefore a mediated relationship by OUTOVR between PCMSIMP and PWB was not found. While there was no mediated relationship, two paths in the model revealed statistically significant results; one indirect path and one direct path. For the indirect path, on average, SMPOC who were more out in the community were more likely to report higher PWB, holding constant their experiences with PCMSIMP, by .12 units $(p<.01)$. For the direct path, on average, SMPOC who reported greater experiences of PCMSIMP, holding constant their level of outness in the community, were more likely to report lower PWB by -.15 units $(\mathrm{p}<.01)$. Table 11 presents the unstandardized regression coefficients (B) and intercept, the p-value, and the upper and lower bound confidence intervals for indirect and direct paths. 
Figure 8. Path Model for Research Question 3 Hypothesis $3 b$

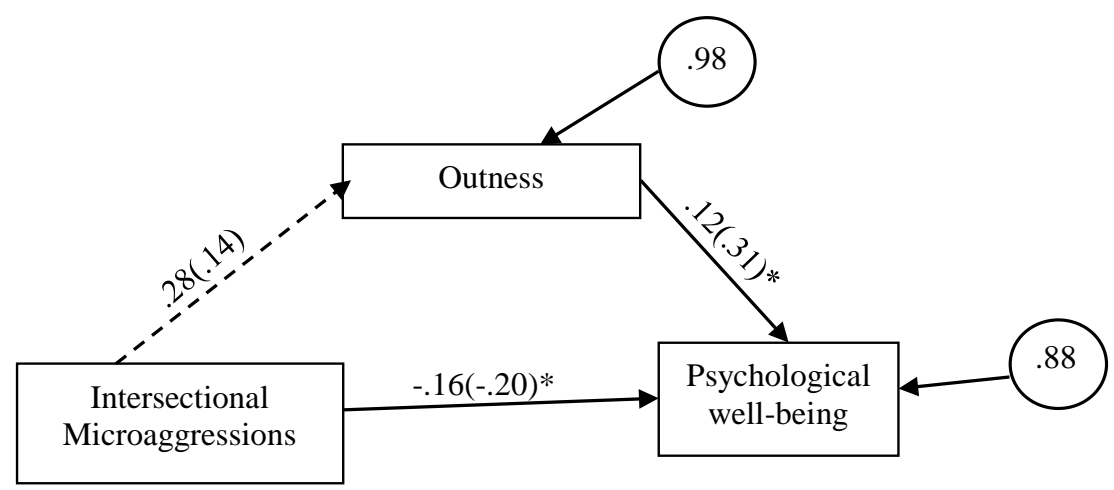

$* \mathrm{p}<.01$. Note: All exogenous and endogenous variables are continuous. Intersectional microaggressions are based on a 12 - month retrospective account. Values on paths represent unstandardized and standardized (in parenthesis) regression coefficients, values in circles represent the percent of variance unexplained (residual terms), and dotted lines represent non-significant paths.

Table 11. Relationship Between Intersectional Microaggressions and Psychological Well-Being as Mediated by Level of Outness for Sexual Minorities of Color

\begin{tabular}{|c|c|c|c|c|c|}
\hline \multirow[b]{2}{*}{ Direct Path: } & \multirow[b]{2}{*}{ b } & \multirow[b]{2}{*}{ Beta } & \multirow[b]{2}{*}{$\mathbf{p}$} & \multicolumn{2}{|c|}{ 95\% Confidence Intervals } \\
\hline & & & & Lower Bound & $\overline{\text { Upper Bound }}$ \\
\hline $\begin{array}{l}\text { Intersectional Microaggressions to } \\
\text { Psychological Well-Being }\end{array}$ & -.156 & -.195 & $.015^{*}$ & -.281 & -.030 \\
\hline Indirect Paths: & & & & & \\
\hline $\begin{array}{l}\text { Intersectional Microaggressions to } \\
\text { Outness }\end{array}$ & .284 & .142 & .085 & -.039 & 607 \\
\hline Outness to Psychological Well-Being & .124 & .310 & $.000 *$ & .068 & 179 \\
\hline
\end{tabular}

Note: 2 paths were significant at $* \mathrm{p}<.01$

\section{Specific Aim 2}

The secondary aim of this study explored the relationship between microaggressions and outness among emerging adult sexual minorities.

Research question 4. Does racial/ethnic identity moderate the relationship between sexual orientation related microaggressions and outness among sexual minorities? 
Hypothesis $4 a$. The associations between experiencing microaggressions and outness will be stronger among sexual minorities of color than among White nonHispanic sexual minorities.

Descriptive Statistics. Participants $(\mathrm{n}=232)$ were included in the analysis for hypothesis $2 \mathrm{a}$ only if they were administered the DHEQ measure during original data collection. The mean age was $22.4(S D=3.1)$, and $72.4 \%(\mathrm{n}=168)$ of the sample were female. Slightly more than two-thirds of the sample identified as SMPOC $(78.9 \%, \mathrm{n}=$ 183). Most of the sample (66.7\%) reported at least some college experience and slightly over half of the sample (53.5\%) reported an income between $\$ 0$ and $\$ 34,999$.

Analysis. The model that was fit is in Figure 9. This model was just-identified so the model fit indices were uninformative. Missing values at the item level for DHEQIMP was $2.6 \%$ to $5.6 \%$ and missing values for OUTOVR was .4\% to $11.2 \%$. Examination of univariate indices of skewness and kurtosis indicated the presence of non-normality (skewness $=-.08$ and .65 and kurtosis $=-1.41$ and .01 for OUTOVR and DHEQIMP, respectively). Two outliers were detected. The model was run with and without the identified outliers. There were no statistically significant differences with or without the presence of outliers, therefore the outliers were retained in the analysis. Figure 9 presents the unstandardized and standardized (in parentheses) path coefficients. Results of the analysis supported the hypothesis. Results revealed that for sexual minorities, on average, sexual orientation microaggressions was significantly related to outness in the community, and race/ethnicity significantly moderated that relationship $(\beta=-.60, p<$ .01). Table 12 presents the unstandardized regression coefficients (B) and intercept, the p-value, and the upper and lower bound confidence intervals. 
Figure 9. Path Model for Research Question 4 Hypothesis 4 a

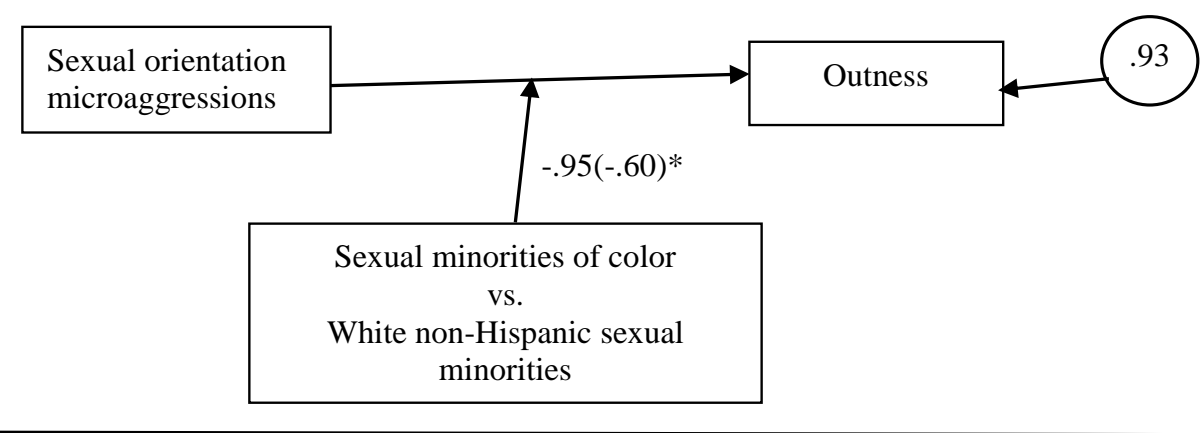

$* \mathrm{p}<.01$. Note: White non-Hispanic sexual minorities $=0$, Sexual minorities of color $=1$. Exogenous variable, sexual orientation microaggressions, and endogenous variable, psychological well-being, are continuous. Sexual orientation microaggressions are based on a 12 - month retrospective account. Value on path represents unstandardized and standardized (in parenthesis) regression coefficients, value in the circle represents the percent of variance unexplained (residual terms).

Table 12. Outness Predicted from Sexual Orientation Microaggressions as Moderated by Race/Ethnicity for Sexual Minorities

\begin{tabular}{llllcc}
\hline \hline & & & & \multicolumn{2}{c}{ 95\% Confidence Intervals } \\
Predictor & $\mathbf{b}$ & Beta & $\mathbf{p}$ & Lower Bound & Upper Bound \\
Sexual Orientation Microaggressions & .956 & .413 & .001 & .405 & 1.508 \\
Race/Ethnicity & 1.709 & .367 & .073 & -.158 & 3.576 \\
Sexual Orientation Microaggressions x & -.948 & -.596 & $.005^{*}$ & -1.609 & -.286 \\
Race/Ethnicity & & & & & \\
\hline
\end{tabular}

Note: Race/ethnicity - White non-Hispanic sexual minorities $=0$, sexual minorities of color $=1$ $* \mathrm{p}<.01$

\section{Chapter Summary}

In this chapter, I present the results of the statistical analyses of the four research questions and corresponding hypotheses performed in this study. Figures and tables also were provided as supporting visual representation of the written analyses for all hypotheses. Among the seven hypotheses tested, six hypotheses received at least partial support, and one hypothesis (moderation analysis 2a) went unsupported. Each of these results will be discussed further in the next chapter, specifically in regard to implications for social welfare research, practice, and policy. In addition, study limitations and plans for future research will be described. 


\section{CHAPTER 5: DISCUSSION}

This study explored the impact of microaggressions on the PWB of emerging adult sexual minorities. Two specific aims and four corresponding research questions were evaluated. The first aim was to empirically examine the experiences of microaggressions among emerging adult SMPOC, and to explore the association between microaggressions and PWB among emerging adult SMPOC. I hypothesized that emerging adult SMPOC would report greater experiences of microaggressions and lower PWB compared to emerging adult heterosexuals and emerging adult White non-Hispanic sexual minorities. I further hypothesized that the relationship between microaggressions and PWB among sexual minorities would be stronger among SMPOC than for White non-Hispanics, and that the relationship between microaggressions and PWB would be explained by their level of outness in the community. The second aim of this study was exploratory and examined the relationship between microaggressions and outness among emerging adult sexual minorities. I hypothesized that among sexual minorities, the relationship between microaggressions and outness would be stronger for SMPOC than for White non-Hispanic sexual minorities. Chapter 4 presented the findings from the tested hypotheses. This chapter will provide context to Chapter 4's reported results through a discussion of the study's findings on microaggressions, outness, and PWB among emerging adult sexual minorities. Following the discussion of the results, study limitations and implications for social work research, education, and practice will be discussed.

The results of this study showed that on average, emerging adult SMPOC reported experiencing more racial/ethnic microaggressions compared to emerging adult 
heterosexual POC and reported experiencing less sexual orientation microaggressions compared to emerging adult White non-Hispanic sexual minorities. While it was expected that emerging adult SMPOC would report greater experiences of microaggressions compared to emerging adult heterosexual POC, it was not expected that emerging adult SMPOC would report less experiences of microaggressions compared to emerging adult White non-Hispanic sexual minorities.

Despite these contrary findings, these results are still consistent with the literature (Balsam et al., 2011; Bowleg, 2013; Follins, 2014; Grov et al., 2006; Holloway et al., 2015; Hudson, 2015). Reasons for the current study's findings may be related to the type of microaggressions experienced and the level of outness among the emerging adult SMPOC who participated in this study. Perhaps these SMPOC are more likely to engage in communities that are unique to their sexuality (e.g. LGBT community) which will not be a commonly shared experience among most heterosexual POC (Balsam et al., 2011; Bowleg, 2013; DeBlaere et al., 2010). Moreover, this group of emerging adult SMPOC may not be as out in their respective racial/ethnic communities compared to the emerging adult White non-Hispanic sexual minorities in this study. As a result, these emerging adult SMPOC may experience more racial/ethnic microaggressions within the LGBT community but may not directly experience sexual orientation microaggressions in their racial/ethnic communities (Grov et al., 2006; Holloway et al., 2015; Hudson, 2015); resulting in greater experiences of racial/ethnic microaggressions and lesser experiences of sexual orientation microaggressions overall. Moreover, some SMPOC may not necessarily identify with the "coming out" experience, and therefore may not truly 
identify as a sexual minority, which would also limit their exposure to sexual orientationrelated discrimination (Choi et al., 2011).

This reasoning could also explain why outness did not mediate the relationship between microaggressions and PWB among sexual minorities in this study. Despite the study's findings not supporting the hypothesized full mediation model, those who were more out in their communities reported better PWB, even when they had experienced microaggressions. This was evident for all emerging adult sexual minorities when exploring sexual orientation microaggressions, and this was also true for the subset of emerging adult SMPOC when examining intersectional microaggressions.

Emerging adult SMPOC reported statistically significant lower mean scores of PWB compared to emerging adult heterosexual POC. Given that emerging adult SMPOC also reported significantly greater experiences of racial/ethnic microaggressions compared to emerging adult heterosexual POC, these findings were expected. What was not expected, was that there were no statistically significant differences on the mean scores of PWB between emerging adult SMPOC and White non-Hispanic sexual minorities and White non-Hispanic heterosexuals. Furthermore, when exploring the interaction of race/ethnicity as a predictor in the relationship between microaggressions and PWB among sexual minorities, the results were not significant.

The literature suggests that minority stress experienced by marginalized groups (Meyer, 2010) and the compounded stress associated with those who have intersecting identities (e.g. SMPOC) would be particularly deleterious to PWB (Balsam et al., 2011; Follins, 2014; Lewis, 2019; Nadal, 2013), but this was not the case in this study. The lack of statistically significant differences in PWB between SMPOC and White non-Hispanic 
groups could be due to factors such as identity salience with racial/ethnic communities and resiliency despite experiences of chronic and overt racial/ethnic discrimination (Bowleg, 2013; Cobb et al., 2018; Giamo et al., 2012; Rasmussen, 2004). This reasoning also supports why there was a significant difference between the groups of POC in this study. SMPOC who are out and/or who identify as a sexual minority may be experiencing similar racial/ethnic microaggressions as heterosexual POC. However, they also may be experiencing them two-fold via their identification with, and interactions within, the LGBT community (DeBlaere et al., 2010); resulting in experiencing intersectional or compounded microaggressions.

The literature suggests that outness can serve as both a risk and protective factor for sexual minorities; outness both can boost PWB and elevate the risk of negative mental health outcomes (Holloway et al., 2015; Riggle et al., 2017). To this end, the current study found that race/ethnicity was a strong predictor of the relationship between microaggressions and outness, suggesting that for emerging adult SMPOC, the more sexual orientation microaggressions experienced, the less likely they will be out in their communities (Holloway et a., 2015; Riggle et al., 2017).

Perhaps the most notable finding of the study is that intersectional microaggressions were associated with low PWB among emerging adult SMPOC, regardless of outness. In other words, people who are multiply marginalized, like SMPOC, appear to experience the compounding effects of microaggressions that negatively impacts PWB among this group (Bowleg et al., 2003; Lewis, 2019; Nadal, 2013). Emerging adult SMPOC navigate among different social worlds, often unsure of how and to whom to present themselves (Hudson, 2015; Lewis, 2019; Nadal, 2013). It is 
for exactly these reasons that intersectionality (Collins \& Bilge, 2016; Lewis, 2019) is a strong and supportive theoretical framework that should be used to explore the various intricacies of research exploring multiply marginalized identities. While Riggle and colleagues (2017) suggested that outness could serve as both a risk and protective factor for subgroups of sexual minorities, their study sample was predominantly non-Hispanic white. Moreover, while studies have shown that SMPOC do experience intersectional microaggressions, and that SMPOC may experience low PWB due to these intersectional microaggressions (Balsam et al., 2011; Follins, 2014), no studies to date have examined similar variables among both White non-Hispanic sexual minorities and SMPOC. It is suggested that the lack of these studies is due to experiences of discrimination and distrust in research by POC in general (DeBlaere et al., 2010). The significance of this study's focus on SMPOC and the statistically significant findings reported here will be a contribution the literature.

\section{Study Limitations}

This study is a secondary analysis of data originally collected at one point in time via an anonymous online survey. As such, the study is limited in regard to addressing causality, generalizability across time and geography, and the possibility of response bias. The parent study was cross-sectional and consisted of a retrospective account of microaggressive experiences. True to cross-sectional studies, causality cannot be inferred. However, this study's findings are consistent with the literature on experiences and impacts of microaggressions among sexual minorities, a NIMHD designated health disparities population (Perez-Stable, 2016). 
It is important to note that one of the many methodological barriers to research with sexual minorities is recruitment (DeBlaere et al., 2010). Research has supported online recruitment and online data collection for studies including sexual minorities and/or POC (DeBlaere et al., 2010; Silenzio et al., 2009). Recruitment for the parent study included a combination of online promotion via social media, snowballing techniques, and target sampling at local and non-local LGBT-related events. However, data was not collected on the geographic location of participants in the parent study, which could lessen the generalizability of results.

Recall and response bias are also limitations in this study. The respondents were requested to provide a 12-month retrospective account of their experiences of various types of microaggressions. Given such, a bias in memory recall could have impacted the results of this study. Moreover, many sexual minorities, and more specifically SMPOC, may fear being out in the community because of experiences of overt and covert types of sexual orientation discrimination in their respective racial/ethnic communities (DeBlaere, 2010; Harris, 1991; Nadal, 2013). As such, many of the respondents who participated in this study were recruited at LGBT-related events. This may have led them to be more open about their sexual orientation and more willing to participate in the survey in general. Additionally, many of the respondents recruited at these events could have experienced a greater sense of positive PWB, as they were already connected with, and identified with, the LGBT community. Also, a general note, participants in survey research may be different from those who do not participate, in ways that could skew findings. Despite these reasons and given the paucity of research in general on SMPOC 
(Huang et al., 2010; Nadal et al., 2016), this study will still be a contribution to the discourse on this topic.

Approximately 88 cases were removed from the analyses of this study due to nonresponse on key items that were required for exclusion and inclusion criteria (e.g. lack of consent, no indication of sexual orientation, and/or they did not indicate age). Structural equation modeling, the type of analyses used in this study is typically most effective with sample sizes greater than $\mathrm{N}=200$. While this study included approximately 741 cases, the embedded skip patterns resulted in smaller subsets of the overall sample per hypothesis.

This study was not able to explore differences in experiences of microaggressions among the various subgroups of POC due to too small sample sizes per subgroup. DeBlaere et al. (2010) have provided an in-depth review about the methodological challenges and barriers of working with diverse samples. While NIMHD calls for more research with minority populations (Perez-Stable, 2016), the challenges in doing such research became more than evident in this study. Many respondents indicated multiple races and ethnicities, which on one hand, showed how diverse this sample was; on the other hand, the diversity made it difficult to run analyses because of small sub-samples. As such, race/ethnicity was collapsed into a dichotomous variable (White non-Hispanic vs. POC), for all analyses in this study. Collapsing all POC into one group overshadows the theoretical underpinnings of intersectionality itself and silences individuation (Riggle et al., 2017; Wong, Derthick, David, Saw, \& Ozazaki, 2014). Moreover, research suggests that many subgroups of POC have significantly different experiences with microaggressions (Choi et al., 2017; Nadal et al., 2014b). 
A final limitation required participants to access a computer and the internet for an extended period. According to the Williams Institute, sexual minorities experience higher poverty rates compared to their heterosexual counterparts, and the rate of poverty among SMPOC is the worst of all (Diaz, Ayala, Bein, Henne, \& Marin, 2001; Sears \& Badgett, 2012). Consequently, there may be a subset of this population that was not reached during recruitment and/or could not participate in this study because of lack of computer access. This reason also speaks to the importance of intersectionality in social sciences research. Understanding the ways in which various levels of power and privilege oppress underserved groups (Collins \& Bilge, 2015) gives voice to the voiceless and sheds light on how the gaps in research on certain groups are facilitated.

\section{Research Implications and Future Directions for Social Work}

Recently, sexual minorities were designated as a health disparities research priority by the NIMHD (Perez-Stable, 2016). A contributing factor to this designation was recent reports on NIH-funded studies that found that less than $1 \%$ of all NIH-funded studies were LGBT-related. Of that small percentage, nearly $80 \%$ of those studies focused on HIV/AIDS, overshadowing all other social determinants of health disparities among sexual minorities (Coulter, Kenst, Bowen, \& Scout, 2014). The dearth in research on sexual minorities is not limited to funded studies from NIH. In fact, private foundations such as the Anne E. Casey Foundation and Aqua Girl have noted these gaps and have offered funding for LGBTQ-specific research, of which the former specifically targets research on SMPOC. Moreover, social work scholars have noted an overall absence of sexual minority-related content in key social work journals (Pelts, Rolbiecki, 
\& Albright, 2014) and in the literature focusing on emerging adults (Woodford et al., 2015).

There is only a small social work literature on microaggressions (Spencer, 2017; Sterzing et al., 2017; Nadal et al., 2016). While microaggressions discourse is "new" to social work, social work scholars have called for attention to this important topic. An example of this is a recent special issue in the Journal of Ethnic \& Cultural Diversity in Social Work on Microaggression in Social Work Practice, Education and Research (Spencer, 2017; Sterzing et al., 2017). While sexual orientation discrimination has been explored in social work scholarship, this research is often limited to interpersonal relations among social work students, relations between faculty and students, and clienttherapeutic relationships, and does not specifically reference microaggressions (Brownlee et al., 2005; Fish, 2008; Gates, 2011; Hylton, 2005; McCave, Shepard, \& Winter, 2014).

Research on microaggressions is even more scant for SMPOC (Nadal et al., 2016). Currently, an intersectionality framework is considered the "gold standard" for social work research with POC (Mehrotra, 2010). The use of intersectionality frameworks in research provides avenues for social work scholars and future practitioners to explore the ways in which power and oppression has rendered silent the voices of people like SMPOC (Lewis, 2019). This current study's approach and findings represent an innovative contribution to social work research scholarship and will help guide efforts to promote PWB and health equity among historically and systematically disenfranchised groups. In a broader scope, these findings did not explore additional intersecting identities beyond sexual orientation, age, and race/ethnicity. While there is limited research on the experiences of microaggressions among emerging adult SMPOC, 
exploring how additional marginalized identities, such as gender/gender identity/expression (Jones, 2014; Oshi-Ojuri, 2013) and/or religion (Husain \& Howard, 2017), may intersect to create an even more compounded experience of minority stress should be part of the next steps in research on this topic.

Some conceptual and methodological issues in microaggressions research should also be considered in next steps. In a review of the research on microaggressions, Wong, Derthick, David, Saw, and Ozazaki (2014) documented the following: (a) the need for larger research sample sizes; (b) further operationalizing of the concept of microaggressions within the context of other stress models; (c) sound quantitative measures that explore overlapping marginalized identities; and (d) exploration into (i) within group differences (e.g., experiences of African Americans vs. Hispanic Americans), (ii) the perspective of those who perpetrate microaggressions, and (iii) the long-term mental and physical effects of microaggressions on well-being. Scholars have attempted to address some of these areas in microaggressions research already (Elias et al., 2017; Oshi-Ojuri, 2013). This study has contributed to the call by a) conducting analyses with a large sample size, b) exploring microaggression through an intersectional lens, and c) using scales that explore overlapping marginalization, of which the former two points have already been discussed earlier in this section.

To date, the LGBT-PCMS microaggressions scale (Balsam et al., 2011), a scale that was used in this study, and the MII (Oshi-Ojuri, 2013) are the only questionnaires, to my knowledge, that are aimed at measuring intersectional microaggressions for SMPOC. The lack of valid and reliable scales measuring intersectional microaggressions is a critical gap in the literature (DeBlaere, Brewster, Sarkees, \& Moradi, 2010; Wong et al., 
2014; Woodford, Sterzing, Fisher, \& Gartner, 2015). The parent study of this current study included items that were added to each of the microaggressions measures to capture either (a) frequency of microaggressions or (b) impact of microaggressions on the respondent. Future research could use these added items and validate the new measures. Continued validation of existing scales and/or creating and validating new measures with POC vs. predominantly White samples are important steps to closing the gap in research on POC and most importantly, SMPOC (DeBlaere et al., 2010; Huang et al., 2010).

This study reported findings on overall microaggressions, overall outness, and overall PWB among sexual minorities. Future research should explore microaggressions, levels of outness, and PWB at the subscale levels, as scholars have suggested that exploring subscales of measures vs. the overall composite of the scale may reveal significantly different results for various subgroups (Balsam et al., 2011). Moreover, additional research attention should be paid to group differences among the subgroups of sexual minorities (i.e. lesbian SMPOC vs bisexual SMPOC or African American lesbians vs Hispanic lesbians) for scholars have suggested that various subgroups of SMPOC may experience microaggressions vastly differently from one another (Poteat, Aragon, Espelage, \& Koenig, 2009; Riggle et al., 2017).

Lastly, it is important that research on SMPOC explore factors of resilience in the face of distress (Craig, Austin, Alessi, McInroy, \& Keane, 2017; Meyer et al., 2010; Wilson et al., 2016; Huang et al., 2010). Scholars have suggested that SMPOC may not experience microaggressions like White non-Hispanic sexual minorities (Balsam et al., 2011; Nadal, 2013), and that one of the contributing factors is the development of resilience in response to experiences of racial/ethnic discrimination (Craig et al., 2017; 
Holloway et al., 2015; Huang et al., 2010; Hudson, 2015). While this study did not find statistically significant differences in PWB when comparing SMPOC to White nonHispanic sexual minorities, exploring the relationship between resiliency and PWB may support the development of interventions for the SMPOC who do report lower PWB due to the compounding impact of intersectional microaggressions. POC of color have expressed willingness to seek therapeutic services and a willingness to trust some health professionals (Holloway et al., 2015). Research on evidenced-based interventions aimed at properly training future clinicians and practitioners in working with SMPOC may be supportive in the safe spaces required to foster a formative therapeutic alliance.

\section{Implications for Social Work Education and Practice}

The Educational Policy and Accreditation Standards (EPAS) of the Council on Social Work Education (CSWE; 2015) requires social work programs to include core competencies on advancing human rights, the promotion of social justice, and engagement in diversity and ethical practice within their course curriculums. Despite these efforts to mandate the inclusion of education and training on diverse groups, social work students and faculty often report a lack of competence in working with sexual minorities (Craig, McInroy, Dentato, Austin, \& Messinger, 2015; Logie, Bridge, \& Bridge, 2007; Papadaki, 2016), despite the availability of course curricula with experiential case studies for working with sexual minorities (Craig et al., 2016; Dente, 2019; Fredrickson-Goldsen, Hoy-Ellis, Goldsen, Emlet, \& Hooyman, 2014; Gerdes \& Norman, 1998; Profit, 2015; Pugh, 2014; Swan \& McConnel, 2015; Todd \& Coholic, 2015). 
Microaggressions research in the social work literature is still in its relative infancy stage and as such, specific examples of case studies on how to address microaggressions in social work classrooms, or out in the social work field, are almost non-existent. It is vital that social work students and faculty become familiar with, and address microaggressions. Social work scholars and educators have even called for the exploration of microaggressions in social work education and the "Queering" of social work education (Lewis, 2019; O’Neill, Swan, \& Mule, 2015; Sterzing et al., 2017; Turner, Pelts, \& Thompson, 2018). While not explicitly referring to microaggressions, Lewis (2019) provides a case example, including reflection questions that explore intersectional approaches to bias prevention when working with LGBTQ clients. Microaggressions present in social work education can negatively impact the experiences of both LGBTQ students and faculty, and if not addressed, these negative experiences may influence the delivery of professional therapeutic services. Moreover, implicit bias, like microaggressions, impacts patient mental and physical healthcare (Maina, Belton, Ginzberg, Singh, \& Johnson, 2018). Social workers could also explore literature in the field of psychology where there are specific examples on how to address microaggressions present in a variety of settings, including communities, schools, workplaces, and home environments (Nadal, 2013).

The ongoing history of distrust with the health professions for both sexual minorities (Bayer \& Spitzer, 1982; Silverstein, 2009) and POC (Sue et al., 2007) are barriers to help seeking (Calton, Cattaneo, \& Gebhard, 2016; Hudson, Eaton, Banks, Sewell, \& Neighbors, 2016). Despite this distrust, research has shown that while certain POC subgroups (e.g. African Americans/Blacks, Hispanics, and American Indian/Native 
Americans) are the least likely to seek mental health services, some POC may still be open to being seen by a health/mental health professional (Hudson et al., 2016; Cook et al., 2018; Venner et al., 2012).

Scholars also have argued that the subjectivity of microaggressions could lead to practitioners being constantly concerned with their unconscious biases surfacing during sessions resulting in inappropriate professional behavior and malpractice suits (Campbell \& Manning, 2015; Thomas, 2008). Other scholars have responded in kind, positing that exploring microaggressions may help some practitioners recognize their own hidden biases in their clinical work and everyday lives (Goodstein, 2008) which could lead to building better therapeutic alliances (Constantine, 2007).

It is important to continue to emphasize educating the future clinical practitioner, as education and practice go hand in hand. The National Association of Social Workers (NASW; 2017) places great emphasis on eliminating discrimination of all types. Moreover, an ethical obligation has been endowed upon social workers to be competent in interventions and to promote sexual and social justice (Turner \& Crane, 2016) and empowerment among marginalized and oppressed groups (NASW, 2017). The CSWE Council on Sexual Orientation and Gender Identity and Expression (C-SOGIE) has even created a guideline for affirmative social work education and practice (Craig et al., 2016). Findings derived from this study could: a) increase education on implicit biases such as microaggressions; b) promote cultural competence in the social work student/practitioner; c) facilitate the importance of exploring social problems via an intersectional lens; and, d) lead to prevention and intervention programs, like gay affirmative therapies (Craig, Austin, \& Alessi, 2013; Pachankis, Hatzenbuehler, Rendina, Safren, \& Parsens, 2015), 
aimed at increasing well-being and reducing mental health and health disparities among underserved groups.

\section{Chapter Summary and Conclusions}

Discrimination is a contributing factor to the health and mental health disparities experienced by sexual minorities and POC (HHS, 2015; Lee et al., 2016; Schmitt, et al., 2014; Williams \& Mann, 2017). Emerging adult sexual minorities, and especially emerging adult SMPOC are especially vulnerable to low PWB (Balsam et al., 2011; Bowleg, 2013; Follins, 2014). In a nation that to this date, has limited respect for the lives and PWB of POC (Hsu \& Patton, 2019), and even less for SMPOC (Herek, 2008; Herek, Gillis, \& Cogan, 1999; LeMignot, 2019), it is incumbent upon social workers to lead the way in promoting social justice for these overtly and covertly marginalized groups.

The current study found that microaggressions, a type of discrimination, are in fact occurring, and that microaggressions may impact the quality of life for some emerging adult sexual minorities. Individuals who hold multiple minority statuses, like emerging adult SMPOC, may experience more microaggressions compared to other groups and may be significantly more impacted by these microaggressions in their daily lives. This study was conducted to contribute to the literature in the following areas: a) general research on sexual minorities; b) microaggressions research on SMPOC; c) sexuality among emerging adults; d) intersectionality theory as used in social work research; and e) use of measures that evaluate the impact of minority stress on multiple minority identities. It is hoped that this study will contribute to pushing the conversation forward about addressing health disparities, especially in regard to the PWB of SMPOC. 


\section{REFERENCES}

Alexander, M. (2010). The new Jim Crow: Mass incarceration in the age of colorblindness. The New Press.

Arnett, J. J. (2000). Emerging adulthood: A theory of development from the late teens through the late twenties. American Psychologist, 55(5), 469-480. doi: 10.1037/0003-066.X.55.5.469

Arnett, J. J. (2004). Emerging adulthood: The winding road from the late teens through the twenties. New York: Oxford University Press.

Arnett, J. J. (2007). Emerging adulthood: What is it, and what is it good for? Childhood Development Perspectives, 1-2, 68-73.

Arnett, J. J. (2014). Presidential address: The emergence of emerging adulthood: A personal history. Emerging Adulthood, 2(3), 155-162. doi: $10.1177 / 2167696814541096$

Araújo, B. Y., \& Borrell, L.N (2006). Understanding the link between discrimination, mental health outcomes, and life chances among Latinos. Hispanic Journal of Behavioral Sciences, 28(2), p. 245-266. doi: https://doi.org/10.1177/0739986305285825

Asante, G. \& Roberts, M. N. (2014). Reliving oppression: Becoming Black, becoming gay. In S. C. Howard (Ed.), Critical articulations of race, gender, and sexual orientation (pp. 123-139). Lanham, MD: Lexington Books.

Austin, A., Craig, S. L., Alessi, E. J., Wagaman, M. A., Paceley, M. S., Dziengel, L., \& Balestrery, J. E. (2016). Guidelines for transgender and gender nonconforming (TGNC) affirmative education: Enhancing the climate for TGNC students, staff and faculty in social work education. Alexandria, VA: Council on Social Work Education.

Baldwin, J. (1956). Giovanni's room; A novel. New York, Dial Press, 1956 
Balsam, K. F., Beadnell, B., \& Molina, Y. L. (2013). The daily heterosexist experiences questionnaire: measuring multiple minority stress among lesbian, gay, bisexual, and transgender adults. Measurement and Evaluation in Counseling and Development, 46(3), 3-15. doi: 10.1177/0748175612449743

Balsam,K. F., Molina, Y., Beadnell, B., Simoni, J., \& Walters, K. (2011). Measuring multiple minority stress: The LGBT people of color microaggressions scale. Cultural Diversity $\quad$ and Ethnic Minority Psychology, 17(2), 163-174. doi: $10.1037 / \mathrm{a} 0023244$

Banaji, M. R., \& Greenwald, A. G. (2013). Blindspot: Hidden biases of good people. New York: Delacorte Press.

Baron, R. M., \& Kenny, D. A. (1986). The moderator-mediator variable distinction in social psychological research: Conceptual, strategic, and statistical considerations. Journal of Personality and Social Psychology, 5, 1173-1182.

Bastos, J. L., Harnois, C. E., \& Paradies, Y. C. (2018). Health care barriers, racism, and intersectionality in Australia. Social Science \& Medicine, 199, 209-218. http://dx.doi.org/10.1016/j.socscimed.2017.05.010

Battle, J. \& Crum. M. (2006) Black LGB health well-being. In I. H. Meyer and M. E. Northridge (Eds.), The health of sexual minorities: Public health perspectives on lesbian, gay, bisexual, and transgender populations (pp. 320-352). Springer Press.

Bayer, R. \& Spitzer R. L. (1982). Edited correspondence on the status of homosexuality in DSM-111. Journal of the History of the Behavioral Sciences, 18,32-52.

Beckles, G. L. \& Truman, B. I. (2013). Education and income - United States, 20092011. National Center for Injury Prevention and Control, CDC Center for Surveillance, Epidemiology, and Laboratory Services, CDC Centers for Disease Control and Prevention. MMWR 62(Suppl 3), [9-19].

Blinder, A. \& Perez-Pena, R. (2015, September 1). Kentucky clerk denies same-sex marriage licenses, defying court. The New York Times. Retrieved from https://www.nytimes.com/2015/09/02/us/same-sex-marriage-kentucky-kimdavis.html 
Boehmer, U., Bowen, D. J., \& Bauer, G. R. (2007). Overweight and obesity in sexualminority women: evidence from population-based data. American Journal of Public Health, 97(6), 1134-1140.

Bollen, K. \& Long, S. (1993). Testing structural equation models. Newbury Park: Sage.

Bostwick, W. \& Hequembourg, A. (2014). 'Just a little hint': bisexual specific microaggressions and their connection to epistemic injustices. Culture, Health \& Sexuality: An International Journal for Research, Intervention and Care, 16(5), 488-503. doi: 10.1080/13691058.2014.889754

Bouris, A., Everett, B. G., Heath, R. D., Elsaesser, C. E., \& Neilands, T. B. (2016). Effects of victimization and violence on suicidal ideation and behaviors among sexual minority and heterosexual adolescents. LGBT health, 3(2), 153-161.

Bowleg, L. (2012). The problem with the phrase women and minorities: Intersectionalityan important theoretical framework for public health. American Journal of Public Health, 102(7), 1267-1273. doi: 10.2105/AJPH.2012.300750

Bowleg, L. (2013). “Once you've blended the cake, you can't take the parts back to the main ingredients": Black gay and bisexual. Sexual Roles, 68, 754-767. doi $10.1007 / \mathrm{s} 11199-012-0152-4$

Bowleg, L., Huang, J., Brooks, K., Black, A., \& Burkholder, G. (2003). Triple jeopardy and beyond: Multiple minority stress and resilience among Black lesbians. Journal of Lesbian Studies, 7(4), 87-108. http://dx.doi.org/10.1300/J155v07n04_06

Bowleg, L., Teti, M., Malebranch, D. J., \& Tschann, J. M. (2013). "It's an uphill battle everyday": Intersectionality, low-income black heterosexual men, and implications for HIV prevention research and interventions. Psychology of Men \& Masculinity, 14(1), 25-34. doi: 10.1037/a0028392

Boylan, J. M., \& Ryff, C. D. (2015). Psychological well-being and metabolic syndrome: Findings from the midlife in the United States national sample. Psychosomatic Medicine, 77(5), 548-558. doi:http://dx.doi.org.ezproxy.fiu.edu/10.1097/PSY.0000000000000192 
Brown, T. A. (2006). Confirmatory factor analysis for applied research. Guilford Publications.

Brownlee, K., Sprakes, A., Saini, M., O’Hare, R. O., Kortes, Miller, K., \& Graham, J. (2005). Heterosexism in social work students. Social Work Education, 24(5), 485494.

Bureau of Labor Statistics (2018, January 19). Labor force statistics from the current population survey. Retrieved from: https://www.bls.gov/cps/cpsaat03.htm

Burton, C., Marshal, M. P., Chisolm, D. J., Sucato, G. S., \& Friedman, M. (2013). Sexualminority-related victimization as a mediator of mental health disparities in sexual minority youth: a longitudinal analysis. Journal of Youth and Adolescence, 42, 394-402. doi: 10.1007/s10964-012-99001-5

Burwick, A., Gates, G., Baumgartner, S., \& Friend, D. (2014). Human services for lowincome and at-risk LGBT populations: An assessment of the knowledge base and research needs (No. 5d6ee2c749e346f2a6fd6d6357ead26a). Mathematica Policy Research.

Calton, J. M., Cattaneo, L. B., \& Gebhard, K. T. (2016). Barriers to help seeking for lesbian, gay, bisexual, transgender, and queer survivors of intimate partner violence. Trauma, Violence, \& Abuse, 17(5), 585-600. https://doi.org/10.1177/1524838015585318

Campbell, B., \& Manning, J. (2015). Microaggression and changing moral cultures. The Chronicle of Higher Education, 61, 41.

Campbell, R. C. \& Mowbray, O. (2016). The stigma of depression: Black American experiences. Journal of Ethnic \& Cultural Diversity in Social Work, 25(4), 253269. doi: 10.1080/15313204.2016.1187101

Chang, J., Huang, C. \& Lin, Y. (2015). Mindfulness, basic psychological needs fulfillment, and well-being. Journal of Happiness Studies, 16(5), 1149-1162. doi: $10.1007 / \mathrm{s} 10902-014-9551-2$

Chapple, R. (2012). Being a deaf woman in college is hard. Being Black just adds: Understanding the complexities of intersecting the margins (Doctoral dissertation, Arizona State University). 
Charlton, B. M., Corliss, H. L., Missmer, S. A., Frazier, A. L., Rosario, M., Kahn, J. A., \& Austin, S. B. (2011). Reproductive health screening disparities and sexual orientation in a cohort study of US adolescent and young adult females. Journal of Adolescent Health, 49(5), 505-510.

Chauncey, G. (1995). Gay New York: The making of the gay male world, 1890-1940. Flamingo.

Chetty, R., Hendren, N., Jones, M. R., \& Porter, S. R. (2018). Race and economic opportunity in the United States: An intergenerational perspective (No. w24441). National Bureau of Economic Research. Retrieved from: http://www.nber.org/papers/w24441

Choi, S., Lewis, J. A., Harwood, S., Mendenhall, R., \& Huntt, M. B. (2017) Is ethnic identity a buffer? Exploring the relations between racial microaggressions and depressive symptoms among Asian-American individuals. Journal of Ethnic \& Cultural Diversity in Social Work, 26(1-2), 18-29. doi: $10.1080 / 15313204.2016 .1263815$

Chonody, J. M., Rutledge, S. E., \& Smith, S. (2012). "That's so gay": Language use and antigay bias among heterosexual college students. Journal of Gay \& Lesbian Social Services, 24(3), 241-259. doi: 10.1080/10538720.2012.697036

Civil Rights Act 1964, Pub. L. 88-352, 78 Stat. 241 (1964).

Cobb, C. L., Meca, A., Branscombe, N. R., Schwartz, S. J., Xie, D., Zea, M. C., Fernandez, C. A., \& Sanders, G. L. (2018). Perceived discrimination and wellbeing among unauthorized Hispanic immigrants: The moderating role of ethnic/racial group identity centrality. Cultural Diversity and Ethnic Minority Psychology. http://dx.doi.org/10.1037/cdp0000227

Cohen, K. \& Cairns, D. (2012). Is searching for meaning in life associated with reduced subjective well-being? Confirmation and possible moderators. Journal of Happiness Studies, 13, 313-331. doi: 10.1007/s/10902-011-9265-7

Colen, C. G., Ramey, D. M., Cooksey, E. C., \& Williams, D. R. (2018). Racial disparities in health among nonpoor African Americans and Hispanics: The role of acute and chronic discrimination. Social Science \& Medicine, 199, 167-180. 
Colby, S L. \& Ortman, J. M. (2015, March). Projections of the size and composition of the U.S. Population: 2014 to 2060. Current Population Reports, P25-1143, U.S. Census Bureau, Washington, DC, 2014.

Combahee River Collective (1977). A Black feminist statement. In McCann, C. R. \& Kim, S. K. (Eds.), Feminist theory reader: Local and global perspectives (pp. 115-121). New York: Routledge Taylor and Francis Group

Constantine, M. G. (2007). Racial microaggressions against African American clients in cross-racial counseling relationships. Journal of Counseling Psychology, 54(1), 116. doi: 10.1037/0022-0167.54-1.1

Contrada, R. J., Ashmore, R. D., Gary, M. L., Coups, E., Egeth, J. D., Sewell, A., ... \& Chasse, V. (2000). Ethnicity-related sources of stress and their effects on wellbeing. Current Directions in Psychological Science, 9(4), 136-139.

Cook, B. L., Hou, S. S. Y., Lee-Tauler, S. Y., Progovac, A. M., Samson, F., \& Sanchez, M. J. (2018). A Review of mental health and mental health cae disparities research: 2011-2014. Medical Care Research and Review, 1 -28. doi: 1077558718780592 .

Coulter, R. W., Kenst, K. S., \& Bowen, D. J. (2014). Research funded by the National Institutes of Health on the health of lesbian, gay, bisexual, and transgender populations. American Journal of Public Health, 104(2), 105-112. doi: 10.2105/AJPH.2013.30150

Council for Social Work Education (CSWE; 2015). Educational policies and accreditation standards. CSWE Press.

Craig, S. L., Austin, A., \& Alessi, E. (2013). Gay affirmative cognitive behavioral therapy for sexual minority youth: A clinical adaptation. Clinical Social Work Journal, 41(3), 258-266.

Craig, S. L., Austin, A., Alessi, E. J., McInroy, L., \& Keane, G. (2017). Minority stress and heroic coping among ethnoracial sexual minority girls: Intersections of resilience. Journal of Adolescent Research, 32(5), 614-641. doi: $10.1177 / 0743558416653217$ 
Craig, S. L., McInroy, L. B., Dentato, M. P., Austin, A., \& Messinger, L. (2015). Social work students speak out! The experiences of lesbian, gay, bisexual, transgender, and queer students in social work programs: A study report from the CSWE Council on Sexual Orientation and Gender Identity and Expression. Toronto, Canada: Author.

Crenshaw, K. (1991). Mapping the margins: Intersectionality, identity politics, and violence against women of color. Stanford Law Review, 43, 1241-1299.

Crosby, A. E., Ortega, L., \& Stevens, M. R. (2013). Suicides — United States, 20052009. National Center for Injury Prevention and Control, CDC Center for Surveillance, Epidemiology, and Laboratory Services, CDC Centers for Disease Control and Prevention. MMWR 62(Suppl 3), [179-183].

Dale, S. K., Bogart, L. M., Galvan, F. H., Wagner, G. J., Pantalone, D. W., \& Klein, D. J. (2016). Discrimination and hate crimes in the context of neighborhood poverty and stressors among HIV-positive African-American men who have sex with men. Journal of community health, 41(3), 574-583. doi: 10.1007/s10900-015$0132-\mathrm{z}$

Davis, K., Heilbroner, D., \& Samuels, M. (Producers) \& Davis, K., \& Heilbroner (Directors). (2010). Stonewall Uprising [Documentary]. United States: PBS American Experience.

Davis, T. S., Saltzburg, S., \& Locke, C. R. (2009). Supporting the emotional and psychological well being of sexual minority youth: Youth ideas for action. Children and Youth Services Review, 31, 1030-1041. doi:10.1016/j.childyouth.2009.05.003

DeBlaere, C., Brewster, M. E., Sarkees, A., \& Moradi, B. (2010). Conducting research with LGB people of color: Methodological challenges and strategies. The Counseling Psychologist, 38(3), 3331-362. doi: 10.1177/0011000009335257

Dentato, M. P., Craig, S. L., Messinger, L., Lloyd, M., \& McInroy, L. B. (2014). Outness among LGBTQ social work students in North America: The contribution of environmental supports and perceptions of comfort. Social Work Education, 33(4), 485-501. 
Dente, C. L. (Ed.). (2019). Social work practice with LGBTQIA populations: An intersectional perspective. NY: Routledge.

Detrie, P. M., \& Lease, S. H. (2007). The relation of social support, connectedness, and collective self-esteem to the psychological well-being of lesbian, gay, and bisexual youth. Journal of Homosexuality, 53(4), 173-199.

de Vougue, A. \& Watkins, E. (2018, June 25). Supreme Court won't take up case of florist who refused service for same-sex couple. CNN.com. Retrieved from https://www.cnn.com/2018/06/25/politics/supreme-court-flowers/index.html

Diaz, R. M., Ayala, G., Bein, E., Henne, J., \& Marin, B. (2001). The impact of homophobia, poverty, and racism on the mental health of gay and bisexual Latino men: Findings from 3 US cities. American Journal of Public Health, 91(6), 927932.

Diemer, E. W., Grant, J. D., Munn-Chernoff, M. A., Patterson, D. A., \& Duncan, A. E. (2015). Gender identity, sexual orientation, and eating-related pathology in a national sample of college students. Journal of Adolescent Health, 57(2), 144149 .

Dill, B. T., \& Zambrana, R. E. (2009). Critical thinking about inequality: An emerging lens. In Dill, B. T. \& Zambrana, R. E. (Eds.), Emerging intersections: Race, class, and gender in theory, policy, and practice, 1-21. New Jersey: Rutgers State University.

Douglas, C. B. (2007). From duty to desire: Emerging adulthood in Europe and its consequences. Child Development Perspectives, 1-2, 101-108.

Dunlap, A. (2016). Changes in coming out milestones across five age cohorts. Journal of Gay \& Lesbian Social Services, 28(1), 20-38. doi:

$10.1080 / 10538720.2016 .1124351$

Edwards, J. R. \& Lambert, L. S. (2007). Methods for integrating moderation and mediation: A general analytical framework using moderated path analysis. Psychological Methods, 12(1), 1 -22. doi: 10.1037/1082-989X.12.1.1 
Eguchi, S. (2014). Coming in/out of the closet. In S. C. Howard (Ed.), Critical articulations of race, gender and sexual orientation, (pp. 5-21). Lanham, MD: Lexington Books.

Elias, T., Jaisle, A., \& Morton-Padovano, C. (2017). Ethnic identity as a predictor of microaggressions toward Blacks, Whites, and Hispanic LGBs by Blacks, Whites, and Hispanics. Journal of homosexuality, 64(1), 1-31. doi: 10.1080/00918369.2016.1172888

Ellis, J. M., Powell, C. S., Demetriou, C. P., Huerta-Bapat, C., \& Panter, A. T. (2018). Examining first-generation college student experiences with microaggressions and microaffirmations at a predominantly White public research university. Cultural Diversity and Ethnic Minority Psychology, 1-14. doi: http://dx.doi.org/10.1037/cdp0000198

Fish, J. (2008). Far from mundane: Theorising heterosexism for social work education. Social Work Education, 27(2), 182-193. doi: 10.1080/02615470701709667

Floyd, F. J. \& Bakeman, R. (2006). Coming-out across the life course: Implications of age and historical context. Archives of Sexual Behaviour, 35(3), 287-296. doi: 10.1007/s10508-006-9022-x

Follins, L. D. (2014). Young Black and Latino gay men's experiences with racial microaggressions. In S. C. Howard (Ed.), Critical articulations of race, gender, and sexual orientation (pp. 47-63). Lanham, MD: Lexington Books.

Fredrikson-Goldsen, K. I., Woodford, M. R., Luke, K. P., \& Gutierrez, L. (2011). Support of sexual orientation and gender identity content in social work education: Results from national surveys of U.S. and Anglophone Canadian faculty. Journal of Social Work Education, 47(1). doi: 10.5175/JSWE.2011.200900018

Fredriksen-Goldsen, K. I., Hoy-Ellis, C. P., Goldsen, J., Emlet, C. A., \& Hooyman, N. R. (2014). Creating a vision for the future: Key competencies and strategies for culturally competent practice with lesbian, gay, bisexual, and transgender (LGBT) older adults in the health and human services. Journal of Gerontological social work, 57(2-4), 80-107. 
Fuligni, A. J. (2007). Family obligation, college enrollment, and emerging adulthood in Asian and Latin American families. Child Development Perspectives, 1-2, 96100.

Galambos, N. L. \& Martinez, M. L. (2007). Poised for emerging adulthood in Latin America: A pleasure for the privileged. Child Development Perspectives, 1-2, 109-114.

Galambos, N. L., Barker, E. T., \& Krahn, H. J. (2006). Depression, self-esteem, and anger in emerging adulthood: Seven-year trajectories. Developmental psychology, $42(2), 350$.

Gartner, R. E., \& Sterzing, P. R. (2016). Gender microaggressions as a gateway to sexual harassment and sexual assault: Expanding the conceptualization of youth sexual violence. Affilia, 31(4), 491-503.

Gates, G. J. (2011). How many people are lesbian, gay, bisexual, and transgender? The Williams Institute, UCLA School of Law, UC Los Angeles.

Gates, G. J. \& Newport, F. (2012, October, 18). Special Report: 3.4\% of U.S. Adults Identify as LGBT. Gallup Poll. Retrieved from: http://www.gallup.com/poll/158066/special-report-adults-identifylgbt.aspx?version=print

Gerdes, K. E., \& Norman, J. (1998). Teaching social work students the breadth of gay and lesbian identity development. Journal of Teaching in Social Work, 17(1-2), 137-154. doi: 10.1300/J067v17n01_10

Giamo, L. S., Schmitt, M. T., \& Outten, H. R. (2012). Perceived discrimination, group identification, and life satisfaction among multiracial people: A test of the rejection-identification model. Cultural Diversity and Ethnic Minority Psychology, 18(4), 319.

Gibbons, F. X., O'hara, R. E., Stock, M. L., Gerrard, M., Weng, C. Y., \& Wills, T. A. (2012). The erosive effects of racism: Reduced self-control mediates the relation between perceived racial discrimination and substance use in African American adolescents. Journal of personality and social psychology, 102(5), 1089. 
Gilley, B. J. (2006). Becoming two-spirit: Gay identity and social acceptance in Indian country. U of Nebraska Press.

Gonzales, G., \& Ortiz, K. (2015). Health insurance disparities among racial/ethnic minorities in same-sex relationships: An intersectional approach. American Journal of Public Health, 105(6), 1106-1113. doi:10.2105/AJPH. 2014.302459

Goodstein, R. (2008). What's missing from the dialogue on racial microaggressions in counseling and therapy. American Psychologist, 63, 276-277. doi: 10.1037/0003066X.63.4.276

Graham, R., Berkowitz, B., Blum, R., Bockting, W., Bradford, J., de Vries, B., ... \& Makadon, H. (2011). The health of lesbian, gay, bisexual, and transgender people: Building a foundation for better understanding. Washington, DC: Institute of Medicine.

Grov, C., Bimbi, D. S., Nanín, J. E., \& Parsons, J. T. (2006) Race, ethnicity, gender, and generational factors associated with the coming-out process among gay, lesbian, and bisexual individuals. The Journal of Sex Research, 43(2), 115-121. Doi: $10.1080 / 00224490609552306$

Haas, A. P., Eliason, M., Mays, V. M., Mathy, R. M., Cochran, S. D., D'Augelli, A. R., ... \& Russells, S. T. (2011). Suicide and suicide risk in lesbian, gay, bisexual, and transgender populations: review and recommendations. Journal of Homosexuality, 58, 10-51. doi:10.1080/00918369.2011.534038.

Haider, A. H., Schneider, E. B., Kodadek, L. M., Adler, R. R., Ranjit, A., Torain, M., ... \& German, D. (2017). Emergency department query for patient-centered approaches to sexual orientation and gender identity: the EQUALITY study. Journal of American Medical Association Internal Medicine, 177(6), 819-828.

Halperin-Meerking, S., Manning, W. D., Giordano, P. C., \& Longmore, M. A. (2012). Relationship churning in emerging adulthood: On/off relationships and sex with an ex. Journal of Adolescent Research, 28(2), 166-188. doi: $10.1177 / 0743558412464524$

Hammond, W. P. (2012). Taking it like a man: Masculine role norms as moderators of the racial discrimination-depressive symptoms association among African 
American men. American Journal of Public Health, 102, 232-241. doi: 10.21 05/AJPH.2011.300485

Hankivsky, O. (Ed.). (2012). An intersectionality-based policy analysis framework. Institute for Intersectionality Research and Policy. Simon Fraser University: Vancouver, BC. Retrieved: www.sfu.ca/iirp/ibpa.html

Harris, E. L. (1991). Invisible life. Anchor.

Harrison, T. W. (2003). Adolescent homosexuality and concerns regarding disclosure. Journal of School Health, 73(3), 107 - 112.

Hate Crime Statistics (2017). Victims - Uniform crime report: Hate crime statistics. U.S. Department of Justice, Federal Bureau of Investigation. Retrieved from: https://ucr.fbi.gov/hate-crime/2017/topic-pages/victims

Hate Crime Statistics (2016). ictims - Uniform crime report: Hate crime statistics. U.S. Department of Justice, Federal Bureau of Investigation. Retrieved from: https://ucr.fbi.gov/hate-crime/2016/topic-pages/victims

Hatzenbuehler, M. L. (2011). The social environment and suicide attempts in lesbian, gay, bisexual youth. Pediatrics, 127(5), 896-903. doi: 10.1542/peds.2010-3020

Hatzenbuehler, M. L., Bellatorre, A., Lee, Y., Finch, B., Muennig, P., \& Fiscella, K. (2014). Structural stigma and all-cause mortality in sexual minority populations. Social Science \& Medicine, 103, 33-41.

Healthy People 2020 Initiative (2010). HealthyPeople.gov. Retrieved from: https://www.healthypeople.gov/

Hendry, L. B. \& Kloep, M. (2010) How universal is emerging adulthood? An empirical example. Journal of Youth Studies, 13(2), 169-179. doi:

$10.1080 / 13676260903295067$

Herek, G. M. (2008). Hate crimes and stigma related experiences among sexual minority adults in the United States: Prevalence estimates from a national probability samples. Journal of Interpersonal Violence, 24(1), 54-74. doi: $10.1177 / 0886260508316477$ 
Herek, G. M., Gillis, J. R., \& Cogan, J. C. (1999). Psychological sequalae of hate-crime victimization among lesbian, gay, and bisexual adults. Journal of Consulting and Clinical Psychology, 67(6), 945-954. doi: 0022-006X/99

HHS. (2018, February, 22). "Glossary of Terms". National partnership for action to end health disparities: Office of Minority Health. Washington, DC; 2011. Retrieved from: https://minorityhealth.hhs.gov/npa/templates/browse.aspx?lvl=1\&lvlid=34

HHS LGBT Policy Coordinating Committee. (2016). Advancing LGBT health and wellbeing - 2016 Report. US Department of Health and Human Services.

Hill-Collins, P. (1990). Black feminist thought: Knowledge, consciousness, and the politics of empowerment. New York, NY: Routledge.

Hill-Collins, P. \& Bilge, S. (2016). Intersectionality. Massachusetts: Polity Press.

Hodge, D. R. (2019). Spiritual microaggressions: Understanding the subtle messages that foster religious discrimination. Journal of Ethnic \& Cultural Diversity in Social Work, 1-17. doi: 10.1080/15313204.2018.1555501

Holley, L. C., Tavassoli, K. Y., \& Stromwall, L. K. (2016). Mental illness discrimination in mental health treatment programs: Intersections of race, ethnicity, and sexual orientation. Journal of Community Mental Health, 52, 311-322. doi: $10.1007 / \mathrm{s} 10597-016-9990-9$

Holloway, I. W., Padilla, M. B., Willner, L., \& Guilamo-Ramos, V. (2015). Effects of minority stress processes on the mental health of Latino men who have sex with men and women: a qualitative study. Archives of sexual behavior, 44(7), 20872097. doi: 10.1007/s10508-014-0424-x

Hong, J. S., \& Garbarino, J. (2012). Risk and protective factors for homophobic bullying in schools: An application of the social-ecological framework. Educational Psychology Review, 24(2), 271-285. doi 10.1007/s10648-012-9194-y

Hong, J. S., Woodford, M. R., Long, L. D., \& Ren, K. A. (2016). Ecological covariates of subtle and blatant heterosexist discrimination among LGBQ college students. Journal of Youth and Adolescence, 45(1), 117-131. doi:http://dx.doi.org.ezproxy.fiu.edu/10.1007/s10964-015-0362- 
hooks, B. (1981). Ain't I a woman: Black women and feminism. Boston, MA: South End Press

Huang, Y., Brewster, M. E., Moradi, B., Goodman, M. B., Wiseman, M. C. \& Martin, A. (2010). Content analysis of literature about LGB people of color $1998-2007$. The Counseling Psychologist, 38(3), 363-396. doi: 10.1177/0011000009335255

Hudson, K. D. (2015) Toward a conceptual framework for understanding community belonging and well-being: Insights from a queer-mixed perspective. Journal of Community Practice, 23(1), 27-50. doi: 10.1080/10705422.2014.986595

Hudson, D. L., Eaton, J., Banks, A., Sewell, W., \& Neighbors, H. (2018). "Down in the sewers": Perceptions of depression and depression care among African American men. American Journal of Men's Health, 12(1), 126-137.

Husain, A. \& Howard, S. (2017). Religious microaggressions: A case study of Muslim Americans. Journal of Ethnic \& Cultural Diversity in Social Work, 26(1-2), 139152. doi: 10.1080/15313204.2016.1269710

Hsu, T. \& Patton, E. $\left(2019\right.$, February, $\left.7^{\text {th }}\right)$. Gucci and Adidas apologize and drop products called racist. NYTimes.com. Retrieved from: https://www.nytimes.com/2019/02/07/business/gucci-blackface-adidasapologize.html

Hylton, M. E. (2005). Heteronormativity and the experiences of lesbian and bisexual women as social work students. Journal of Social Work Education, 41(1), 67-82. Retrieved from http://www.jstor.org/stable/23044033

Hyunh, V. W., \& Fuligni, A. J. (2010). Discrimination hurts: The academic, psychological, and physical well-being of adolescents. Journal of Research on adolescence, 20(4), 916-941.

IBM Corp. (2011). IBM SPSS Statistics for Windows, Version 20.0. Armonk, NY: IBM Corp.

Jamieson, J. P., Koslov, K., Nock, M. K., \& Mendes, W. B. (2013). Experiencing discrimination increases risk taking. Psychological Science, 24(2), 131-139. 
Johns, M. M., Zimmerman, M., \& Bauermeister, J. A. (2013). Sexual attraction, sexual identity, and psychosocial wellbeing in a national sample of young women during emerging adulthood. Journal of Youth and Adolescence, 42(1), 82-95.

Johnston-Goodstar, K., \& VeLure Roholt, R. (2017). “Our kids aren’t dropping out; they're being pushed out": Native American students and racial microaggressions in schools. Journal of Ethnic \& Cultural Diversity in Social Work, 26(1-2), 30-47.

Jones, J. M. (2012, December, 6). Most in U.S. say gay/lesbian bias is a serious problem. Gallup.com/Poll. Retrieved from: http://www.gallup.com/poll/159113/most-saygay-lesbian-bias-serious-problem.aspx?utm_source=email-afriend\&utm_medium=email\&utm_campaign=sharing\&utm_content=morelink

Jones, R. G. (2014). Divided loyalties: Exploring the intersections of queerness, race, ethnicity, and gender. In S. C. Howard (Ed.), Critical articulations of race, gender, and sexual orientation (pp. 23-45). Lanham, MD: Lexington Books.

Kanny, D., Liu, Y., Brewer, R. D., \& Lu, H. (2013). Binge Drinking — United States, 2011. National Center for Chronic Disease Prevention and Health Promotion, CDC Centers for Disease Control and Prevention. MMWR, 62(Suppl 3), [77-80].

Kaskan, E. R. \& Ho, I. K. (2016). Microaggressions and female athletes. Sex Roles, 74(78), 275-287. doi:10.1007/s11199-014-0425-1

Kelleher, C. (2009). Minority stress and health: Implications for lesbian, gay, bisexual, transgender, and questioning (LGBTQ) young people. Counselling psychology quarterly, 22(4), 373-379. doi: 10.1080/09515070903334995

Kessler, R. C., Amminger, G. P., Aguilar-Gaxiola, S., Alonso, J., Lee, S., \& Ustun, T. B. (2007). Age of onset of mental disorders: a review of recent literature. Current opinion in psychiatry, 20(4), 359.

King, M., Semlyen, J., Tai, S. S., Killaspy, H., Osborn, D., Popelyuk, D., \& Nazareth, I. (2008). A systematic review of mental disorder, suicide, and deliberate self harm in lesbian, gay and bisexual people. BMC psychiatry, 8(1), 70. doi: 10.1186/1471$244 \mathrm{X}-8-70$ 
Kline, R. B. (2011). Principles and practice of structural equation modeling. Third Edition. Guilford publications.

LeBrón, A. M., Spencer, M., Kieffer, E., Sinco, B., Piatt, G., \& Palmisano, G. (2017). Correlates of interpersonal ethnoracial discrimination among Latino adults with diabetes: Findings from the REACH Detroit Study. Journal of Ethnic \& Cultural Diversity in Social Work, 26(1-2), 48-67. http://dx.doi.org/10.1080/15313204.2016.1263820

Lee, J. H., Gamarel, K. E., Bryant, K. J., Zaller, N. D., \& Operario, D. (2016). Discrimination, mental health, and substance use disorders among sexual minority populations. LGBT Health, 3(4), 258-265.

Lehavot, K., \& Simoni, J. M. (2011). The impact of minority stress on mental health and substance abuse among sexual minority women. Journal of Counseling and Clinical Psychology, 79(2), 159-170. doi: 10.1037/a0022839

LeMignot, S. (2019, February, 6th). Police investigate origin of rope used in 'Empire' actor Jussie Smollett's attack. Chicago.cbslocal.com. Retrieved from: https://chicago.cbslocal.com/2019/02/06/empire-jussie-smollett-attack-chicagorope-hate-crime-chicago-police-department/

Lewis, T. O. (2019). Race, ethnicity, sexual orientation, and gender identity: Intersectionality in the lives of LGBTQIA people of color. In Dente, C. L. (Ed.). Social Work Practice with LGBTQIA Populations (pp. 114 -133). NY: Routledge.

Liao, K. Y., Weng, C., \& West, L. M. (2016). Social connectedness and intolerance of uncertainty as moderators between racial microaggressions and anxiety among Black individuals. Journal of Counseling Psychology, 63(2), 240-246. http://dx.doi.org/10.1037/cou0000123

Liu, R. \& Mustanski, B. (2012). Suicidal ideation and self-harm in lesbian, gay, and transgender youth. American Journal of Preventive Medicine, 42(3), 221-228.

Logan, J. E., Hall, J., McDaniel, D., \& Stevens, M. R. (2013). Homicides - United States, 2007-2009. National Center for Injury Prevention and Control, CDC Center for Surveillance, Epidemiology, and Laboratory Services, CDC Centers for Disease Control and Prevention. MMWR 62(Suppl 3), [164-170]. 
Logie, C., Logie, T. J. \& Bridge, P. D. (2007). Evaluating the phobias, attitudes, and cultural competence of master of social work students toward the LGBT populations. Journal of Homosexuality, 53(4), 201-221. doi: $10.1080 / 00918360802103472$

Mack, K. A. (2013). Drug-Induced Deaths — United States, 1999-2010. National Center for Injury Prevention and Control, CDC Center for Surveillance, Epidemiology, and Laboratory Services, CDC Centers for Disease Control and Prevention. MMWR 62(Suppl 3), [161-163].

MacKinnon, D. P., Lockwood, C. M., Hoffman, J. M., West, S. G., \& Sheets, V. (2002). A comparison of methods to test mediation and other intervening variable effects. Psychological Methods, 7, 83-104. doi:10.1037/1082-989X.7.1.83

Maina, I. W., Belton, T. D., Ginzberg, S., Singh, A., \& Johnson, T. J. (2018). A decade of studying implicit racial/ethnic bias in healthcare providers using the implicit association test. Social Science \& Medicine, 199, 219-229. http://dx.doi.org/10.1016/j.socscimed.2017.05.009

Marcia, J.E., (1980). Identity in adolescence. In: J. Adelson, ed. Handbook of adolescent psychology. New York: Wiley, 159187.

Mack, K. A. (2013). Drug-Induced Deaths - United States, 1999-2010. National Center for Injury Prevention and Control, CDC Centers for Disease Control and Prevention. MMWR, 62(Suppl 3), [161-163].

Marshal, M. P., Dietz, L. J., Friedman, M. S., Stall, R., Smith, H. A., McGinley, J., ... Brent, D. A. (2011). Suicidality and depression disparities between sexual minority and heterosexual youth: A meta-analytic review. Journal of Adolescent Health, 49, 115-124.

Marzullo, A., \& Libman, A. J. (2009). Research overview: Hate crimes and violence against lesbian, gay, bisexual and transgender people. Human Rights Campaign.

Maslow, A. H. (1968). Toward a psychology of being. New York: Van Nostrand.

Mayer, K. H., Bradford, J. B., Makadon, H. J., Stall, R., Goldhammer, H., \& Landers, S. (2008). Sexual and Gender Minority Health: What We Know and What Needs to 
Be Done. American Journal of Public Health, 98(6), 989-995. http://doi.org/10.2105/AJPH.2007.127811

McBride, D. (2005). Why I hate Abercrombie \& Fitch: Essays on race and sexuality. NYU Press.

McCave, E., Shepard, B., \& Winter, V. R. (2014). Human sexuality as a critical subfield in social work. Advances in Social Work, 15(2), 409-427.

McFarland, J., Hussar, B., de Brey, C., Snyder, T., Wang, X., Wilkinson-Flicker, S., ..., and Hinz, S. (2017). The Condition of Education 2017 (NCES 2017-144). U.S. Department of Education. Washington, DC: National Center for Education Statistics. Retrieved from: https://nces.ed.gov/pubsearch/pubsinfo.asp?pubid=2017144.

Mehrotra, G. (2010). Toward a continuum of intersectionality theorizing for feminist social work scholarship. Affilia: Journal of Women and Social Work, 25(4), $417-$ 430. doi: 10.1177/0886109910384190

Metzger, I. W., Salami, T., Carter, S., Halliday-Boykins, C., Anderson, R. E., Jernigan, M. M., \& Ritchwood, T. (2018). African American emerging adults' experiences with racial discrimination and drinking habits: The moderating roles of perceived stress. Cultural Diversity and Ethnic Minority Psychology, 24(4), 489.

Meyer, I. H. (1995). Minority stress and mental health in gay men. Journal of Health and Social Behavior, 36(1), 38-56.

Meyer, I. H. (2003). Prejudice, social stress, and mental health in Lesbian, Gay, and Bisexual populations: Conceptual issues and research evidence. Psychological Bulletin, 129(5), 674-697. doi: 10.1037/0033-2909.129.5.674

Meyer, I. H. (2010). The right comparisons in testing the minority stress hypothesis: Comment on Savin-Williams, Cohen, Joyner, and Rieger (2010). Archives of Sexual Behavior, 39, 1217-1219. doi: 10.1007/s10508-010-9670-8

Meyer, I. H., Ouellette, S. C., Haile, R., \& McFarlane, T. A. (2012). "We'd be free": Narrative of life without homophobia, racism, or sexism. Sexuality Research and Social Policy, 8, 204-214. doi: 10.1007/s 13178-011-0063-0 
Meyer, P. A., Yoon, P. W., \& Kaufmann, R. B. (2013). Introduction: CDC health disparities and inequalities report-United States. MMWR Supplements, 62(3), 3-5.

Miller, R. L. (2007). Legacy denied: African American gay men, AIDS, and the Black church. Social Work, 52(1), 51-61.

Mohr, J., \& Fassinger, R. (2000). Measuring dimensions of lesbian and gay male experience. Measurement and Evaluation in Counseling and Development, 33(2), 66-66.

Moonesinghe, R., Chang, M., \& Truman, B. I. (2013). Health insurance coverage United States, 2008 - 2010. National Center for Injury Prevention and Control, CDC Center for Surveillance, Epidemiology, and Laboratory Services, CDC Centers for Disease Control and Prevention. MMWR 62(Suppl 3), [61-64].

Moradi, B. \& DeBlaere, C. (2010). Replacing either/or with both/and: Illustrations of perspective alternation. The Counseling Psychologist, 38(3), 455-468. doi: $10.1177 / 0011000009356460$

Moradi, B., Wiseman, M. C., DeBlaere, C., Goodman, M. B., Sarkees, A., Brewster, M. E., \& Huang, Y. (2010). LGB of color and White individuals' perceptions of heterosexist stigma, internalized homophobia, and outness: Comparisons of levels and links. The Counseling Psychologist, 38(3), 397-424. doi: $10.1177 / 0011000009335263$

Morris, J. F., Waldo, C. R., \& Rothblum, E. D. (2001). A model of predictors and outcomes of outness among lesbian and bisexual women. American Journal of Orthopsychiatry, 71(1), 61-71.

Mouzon, D. M., Taylor, R. J., Woodward, A. T., \& Chatters, L. M. (2017). Everyday racial discrimination, everyday non-racial discrimination, and physical health among African-Americans. Journal of Ethnic \& Cultural Diversity in Social Work,26(1-2), 68-80. doi: 10.1080/15313204.2016.1187103

Mustanski, B., Andrews, R., \& Puckett, J. A. (2016). The effects of cumulative victimization on mental health among lesbian, gay, bisexual, and transgender adolescents and young adults. American Journal of Public Health 106(3), 527533. doi: 10.2105/AJPH.2015.302976 
Muthén, L. K., \& Muthén, B. O. (2012). Mplus: Statistical analysis with latent variables: User's guide (pp. 1998-2012). Los Angeles: Muthén \& Muthén.

Nadal, K. L. (2011). The racial and ethnic microaggressions scale (REMS): Construction, reliability, and validity. Journal of Counseling Psychology, 58(4), 470-480. doi: $10.1037 / \mathrm{a} 0025193$

Nadal, K. L. (2013). That's so gay! microaggressions and the lesbian, gay, bisexual, and transgender community. Washington D.C.: American Psychological Association.

Nadal, K. L. (2014, February, 7). Stop saying "that's so gay!": 6 types of microaggressions that harm LGBTQ people. Psychology Benefits Society. Retrieved from: https://psychologybenefits.org/2014/02/07/anti-lgbtmicroaggressions/

Nadal, K. L., Issa, M., Leon, J., Meterko, V., Wideman, M., \& Wong, Y. (2011). Sexual orientation microaggressions: "Death by a thousand cuts" for lesbian, gay, and bisexual youth. Journal of LGBT Youth, 8(3), 234-259.

doi:10.1080/19361653.2011.584204

Nadal, K. L., \& Griffin, K. E. (2012). The psychology of hate: How heterosexist biases and subtle discrimination influence the bullying and victimization of lesbian, gay, bisexual, and transgender youth. The psychology of love (vols 1-4). (pp. 131-147) Praeger/ABC-CLIO, Santa Barbara, CA. Retrieved from http://ezproxy.fiu.edu/login?url=http://search.proquest.com.ezproxy.fiu.edu/docvi ew/1017618961? accountid=10901

Nadal, K. L., Griffin, K. E., Wong, Y., Davidoff, K, C., \& Davis, L. S. (2017). The injurious relationship between racial microaggressions and physical health: Implications for social work. Journal of Ethnic \& Cultural Diversity in Social Work, 26(1-2), 6-17. doi: 10.1080/15313204.2016.1263813

Nadal, K.L., Griffin, K. E., Wong, Y., Hamit, S., \& Rasmus, M. (2014a). The impact of racial microaggressions on mental health: Counseling implications for clients of color. Journal of Counseling \& Development, 92, 57-66. doi: 10.1002/j.15566676.2014.00130.x 
Nadal, K. L., Mazzula, S. L., Rivera, D. P., \& Fujii-Doe, W. (2014b). Microaggressions and Latina/o Americans: An analysis of nativity, gender, and ethnicity. Journal of Latino/a Psychology, 2(2), 67-78. doi: 10.1037/lat0000013

Nadal, K. L., Rivera, D. P., \& Corpus, M. J. H. (2010). Sexual orientation and transgender microaggressions. In D. W. Sue (Ed.), Microaggressions and marginality: Manifestation, dynamics, and impact (pp. 217-240). Hoboken, NJ: Wiley \& Sons.

Nadal, K. L., Whitman, C. N., Davis, L. S., Erazo, T., \& Davidoff, K. C. (2016). Microaggressions toward lesbian, gay, bisexual, transgender, queer, and genderqueer people: A review of the literature. The Journal of Sex Research, 53(4-5), 488-508. doi: 10.1080/00224499.2016.1142495

Nadal, K. L., Wong, Y., Sriken, J., Griffin, K., \& Fujii-Doe, W. (2015). Racial microaggressions and Asian Americans: An exploratory study on within-group differences and mental health. Asian American Journal of Psychology, 6, 136144. doi: $10.1037 / \mathrm{a} 0038058$

Nash, J. C. (2008). Re-thinking intersectionality. Feminist Review, 89, 1-15.

National Advisory Commission on Civil Disorders (1988). The Kerner report: The 1968 report of the National Advisory Commission on Civil Disorders. New York: Pantheon Books.

National Association of Social Workers. (2017). Code of ethics of the National Association of Social Workers. Washington, DC: NASW Press.

National Healthcare Quality \& Disparities Report (2016). U.S. Department of Health and Human Services: Agency for Healthcare Research and Quality (AHRQ). Retrieved from: https://www.ahrq.gov/research/findings/nhqrdr/index.html

Nelson, L. J. \& Barry, C. M. (2005). Distinguishing features of emerging adulthood: The tole of self-classification as an adult. Journal of Adolescent Research, 20, 242262. doi: $10.1177 / 0743558404273074$

Nelson, L. J. \& Chen, X. (2007). Emerging adulthood in China: The role of social and cultural factors. Child Development Perspectives, 1-2, 86-91. 
Nicholas, C. L. (2014). Coming out, covering, connecting: De/colonizing epistemics of ethnography and ethnographer positionality in Malaysia. In S. C. Howard (Ed.), Critical articulations of race, gender, and sexual orientation (pp. 141-156). Lanham, MD: Lexington Books.

Obergefell v. Hodges, 576 U.S. 2071 (2015).

O’Conner, M., Sanson, A., Hawkins, M. T., Letcher, P., Toumbooru, J. W., Smart, D. ... Olsson, C. A. (2011). Predictors of positive development in emerging adulthood. Journal of Youth and Adolescence, 40, 860-874. doi: 10.1007/s10964-010-9593-7

Oshi-Ojuri, M. F. (2013). A quantitative look at the impact of microaggressions on the intersecting identities of African American lesbians (Doctoral dissertation, John F. Kennedy University).

Pachankis, J. E., Hatzenbuehler, M. L., Rendina, H. J., Safren, S. A., \& Parsons, J. T. (2015). LGB-affirmative cognitive-behavioral therapy for young adult gay and bisexual men: A randomized controlled trial of a transdiagnostic minority stress approach. Journal of Consulting and Clinical Psychology, 83(5), 875-889.

Papadaki, V. (2016). Invisible students: Experiences of lesbian and gay students in social work education in Greece. Social Work Education, 35(1), 65-77. doi: $10.1080 / 02615479.2015 .1085502$

Parks, C. A., Hughes, T. L., \& Matthews, A. K. (2004). Race/ethnicity and sexual orientation: Intersecting identities. Cultural diversity and Ethnic Minority Psychology, 10(3), 241.

Parra, L. A., Benibgui, M., Helm, J. L., \& Hastings, P. D. (2016). Minority stress predicts depression in lesbian, gay, and bisexual emerging adults via elevated diurnal cortisol. Emerging Adulthood, 4(5), 365-372.

Pelts, M., Rolbiecki, A., \& Albright, D. L. (2014). An update to 'Among the Missing': Lesbian and gay content in social work journals. Social Work, 59(2), 131-138. doi: 10.1093/sw/swu005.

Perez-Stable, E. J. (2016, October 6). Director's message: Sexual and gender minorities formally designated as a health disparity population for research purposes. 
National Institute of Minority Health and Health Disparities. Retrieved from: https://www.nimhd.nih.gov/about/directors-corner/message.html

Perry, B. L., Stevens-Watkins, D., \& Oser, C. B. (2013). The moderating effects of skin color and ethnic identity affirmation on suicide risk among low-SES African American women. Racial and Social Problems, 5, 1-14. doi: 10.1007/s12552012-9080-8

Pew Research Center (2013, June, 13). A survey of LGBT Americans attitudes, experiences and values in changing times. Retrieved from: http://www.pewsocialtrends.org/2013/06/13/a-survey-of-lgbt-americans/

Pierce, C., Carew, J., Pierce-Gonzalez, D., \& Willis, D. (1978). An experiment in racism: TV commercials. In C. Pierce (Ed.), Television and education (pp. 62-88). Beverly Hills, CA: Sage.

Peer, J. W. \& McAuslan, P. (2016). Self-doubt during emerging adulthood: The conditional mediating influence of mindfulness. Emerging Adulthood, 4(3), 176185. doi: $10.1177 / 2167696815579828$

Pettit, B., \& Western, B. (2004). Mass imprisonment and the life course: Race and class inequality in U.S. incarceration. American Sociological Review, 69(2), 151-169. Retrieved from http://www.jstor.org.ezproxy.fiu.edu/stable/3593082

Phillips, J. C., Ingram, K. M., Smith, N. G., \& Mindes, E. J. (2003). Methodological and content review of lesbian-, gay-, and bisexual-related articles in counseling journals: 1990-1999. The Counseling Psychologist, 31(25). doi: $10.1177 / 011000002239398$

Pittman, D. M., Kim, S. C., Hunter, C. D., \& Obasi, E. M. (2017). The role of minority stress in second-generation Black emerging adults college students' high-risk drinking behaviors. Cultural Diversity and Ethnic Minority Psychology, 23(3), 445-455. doi: 10.1037/cdp0000135

Platt, L. F. \& Lenzen, A. L. (2013) Sexual orientation microaggressions and the experience of sexual minorities, Journal of Homosexuality, 60(7), 1011-1034. doi: $10.1080 / 00918369.2013 .774878$ 
Poscoe. A. \& Richman, L.S. (2009). Perceived Discrimination and Health: A MetaAnalytic Review. Psychological Bulletin, 135(4), 531-554. DOI: $10.1037 / \mathrm{a} 0016059$

Poteat, V. P., Aragon, S. R., Espelage, D. L. \& Koenig, B. W. (2009). Psychosocial concerns of sexual minority youth: Complexity and caution in group differences. Journal of Consulting and Clinical Psychology, 77(1), 196-201. doi: $10.1037 / \mathrm{a} 0014158$

Profit, N. J. (2015). Somewhere over the rainbow: Reflections on teaching a LGBT-S bachelor of social work course. In O, Neill, B. J., Swan, T. A., \& Mule, N. J. (Eds.), LGBTQ People and Social Work: Intersectional Perspectives (pp. 297 316). Toronto: Canadian Scholars Press.

Pugh, G. L. (2014). Revisiting the pink triangle exercise: An exploration of experiential learning in graduate social work education. Journal of Teaching in Social Work, 34(1), 17-28. doi: 10.1080/08841233.2013.863264

Pyne, J. (2016). Transfeminist theory and action: Trans women and the contested terrain of women's services. In O'Neill, B. J., Swan, T. A., \& Mule, N. J. (Eds.), LGBTQ People and Social Work: Intersectional Perspectives (pp. 129 - 149)). Toronto, Ontario: Canadian Scholar's Press.

Raifman, J., Moscoe, E., Austin, S.B., \& McConnell, M. (2017). Difference-indifferences analysis of the association between state same-sex marriage policies and adolescent suicide attempts. JAMA Pediatrics, 171(4), 350-356. doi:10.1001/jamapediatrics.2016.4529

Rasmussen, M. L. (2004). The problem of coming out. Theory into practice, 43(2), 144150. doi: 10.1207/s15430421tip4302_8

Riggle, E. D., Rostosky, S. S., Black, W. W., \& Rosenkrantz, D. E. (2017). Outness, concealment, and authenticity: Associations with LGB individuals' psychological distress and well-being. Psychology of Sexual Orientation and Gender Diversity, 4(1), 54. doi: http://dx.doi.org/10.1037/sgd0000202

Robinson, O. C. (2018). A longitudinal mixed-methods case study of quarter-life crisis during the postuniversity transition: Locked-out and locked-in forms in combination. Emerging Adulthood, 1- 13. doi: 10.1177/2167696818764144. 
Robinson, J. L., \& Rubin, L. J. (2016). Homonegative microaggressions and posttraumatic stress symptoms. Journal of Gay \& Lesbian Mental Health, 20(1), 57-69. doi: http://dx.doi.org.ezproxy.fiu.edu/10.1080/19359705.2015.1066729

Rosario, M., \& Schrimshaw, E. W. (2013). The sexual identity development and health of lesbian, gay, and bisexual adolescents: An ecological perspective. In Patterson, C. J. \& D'Augelli, A. R. (Eds.), Handbook of Psychology and Sexual Orientation, (pp. 87 -101). New York: Oxford University Press.

Ross, M. B. (2005). Beyond the closet as raceless paradigm. In E. P. Johnson and M. G. Henderson (Eds.), Black queer studies: A critical anthology, (pp. 161-89). London: Duke University Press.

Russell, S. T. \& Joyner, K. (2001). Adolescent sexual orientation and suicide risk: evidence from a national study. Research, 91(8), 1276-1281.

Rust, P. C. (1993). "Coming out" in the age of social constructionism: Sexual identity formation among lesbian and bisexual women. Gender \& Society, 7(1), 50-77. doi: $10.117 / 089124393007001004$

Ryan, R. M., \& Deci, E. L. (2001). On happiness and human potentials: A review of research on hedonic and eudaimonic well-being. Annual Review of Psychology, 52(1), 141-166.

Ryff, C. D. (1989). Happiness is everything, or is it? Explorations on the meaning of psychological well-being. Journal of Personality and Social Psychology, 57(6), 1069-1081.

Ryff, C. D., \& Keyes, C. L. M. (1995). The structure of psychological well-being revisited. Journal of Personality and Social Psychology, 69(4), 719.

Ryff, C. D., Keyes, C. L. M., \& Hughes, D. L. (2003). Status inequalities, perceived discrimination, and eudaimonic well-being: Do the challenges of minority life hone purpose and growth?*. Journal of Health and Social Behavior, 44(3), 27591.

Ryff, C. D., \& Singer, B. H. (2006). Best news yet on the six-factor model of well-being. Social Science Research, 35(4), 1103-1119. 
Ryff, C. D., Love, G. D., Urry, H. L., Muller, D., Rosenkranz, M. A., Friedman, E. M., . . . Singer, B. (2006). Psychological well-being and ill-being: Do they have distinct or mirrored biological correlates? Psychotherapy and Psychosomatics, 75(2), 8595. doi:http://dx.doi.org.ezproxy.fiu.edu/10.1159/000090892

Seelman, K. L., Woodford, M. R., \& Nicolazzo, Z. (2017) Victimization and microaggressions targeting LGBTQ college students: Gender identity as a moderator of psychological distress. Journal of Ethnic \& Cultural Diversity in Social Work, 26(1-2), 112-125. doi: 10.1080/15313204.2016.1263816

Seng, J. S., Lopez, W. D., Sperlich, M., Hamama, L., \& Meldrum, C. D. R. (2012). Marginalized identities, discrimination burden, and mental health: Empirical exploration of an interpersonal-level approach to modeling intersectionality. Social Science \& Medicine, 75(12), 2437-2445. http://dx.doi.org/10.1016/j.socscimed.2012.09.023

Schmitt, M. T., Branscombe, N. R., Postmes, T., \& Garcia, A. (2014). The consequences of perceived discrimination for psychological well-being: A meta-analytic review. Psychological bulletin, 140(4), 921.

Schuler, M. S., Rice, C. E., Evans-Polce, R. J., \& Collins, R. L. (2018). Disparities in substance use behaviors and disorders among adult sexual minorities by age, gender, and sexual identity. Drug and Alcohol Dependence. https://doi.org/10.1016/j.drugalcdep.2018.05.008

Sears, B. \& Badgett, L. (2012). Beyond stereotypes: Poverty in the LGBT community. www. williamsinstitute.law Retrieved: https://williamsinstitute.law.ucla.edu/williams-in-the-news/beyond-stereotypespoverty-in-the-lgbt-community/

Sharon, T. (2016). Constructing adulthood: Markers of adulthood and well-being among emerging adults. Emerging Adulthood, 4(3), 161-167. doi: $10.1177 / 2167696815579826$

Shire E. (2015, December). Victims and microaggressions: Why 2015 was the year students lost their minds. TheDailyBeast.com. Retrieved from: http://www.thedailybeast.com/articles/2015/12/27/victims-and-microaggressionswhy-2015-was-the-year-students-lost-theirminds.html? source=TDB\&via=FB_Page 
Silenzio, V. M., Pena, J. B., Duberstein, P. R., Cerel, J., \& Knox, K. L. (2007). Sexual orientation and risk factors for suicidal ideation and suicide attempts among adolescents and young adults. American Journal of Public Health, 97(11), 20172019.

Silenzio, V. M., Duberstein, P. R., Tang, W., Lu, N., Tu, X., \& Homan, C. M. (2009). Connecting the invisible dots: Reaching lesbian, gay, and bisexual adolescents and young adults at risk for suicide through online social networks. Social Science \& Medicine, 69(3), 469-474.

Silverstein, C. (2009). The implications of removing homosexuality from the DSM as a mental disorder. Archives of Sexual Behavior, 38, 161-163. doi: 10.1007/s10508008-9442-x

Silvestre, A., Beatty, R. L., \& Friedman, M. R. (2013). Substance use disorder in the context of LGBT health: A social work perspective. Social work in Public Health, 28(3-4), 366-376.

Simandan, G. (2014). Omitted variables in the geographical treatment of well-being and happiness. Geography Journal. doi: http://dx.doi.org/10.1155/2014/150491

Simien, J. (2014). Dear White People. New York: Atria Books.

Simon Rosser, B. R., Merengwa, E., Capistrant, B. D., Iantaffi, A., Kilian, G., Kohli, N., ... \& West, W. (2016). Prostate cancer in gay, bisexual, and other men who have sex with men: a review. LGBT Health, 3(1), 32-41.

Singh, G. K., De Los Reyes, A., Allender, M., Ramey, C., Daus, G., Martin, E., ... Vedamuthu, I. (2017). Health Equity Report. Health Resources and Services Administration, Office of Health Equity. Rockville, Maryland: U.S. Department of Health and Human Services; 2018.

Smith, G., Kippax, S., \& Chapple, M. (1998). Secrecy, disclosure, and closet dynamics. Journal of Homosexuality, 35(1), 53-73.

http://dx.doi.org/10.1300/J082v35n01_03

Smith, L. C., Shin, R. Q., \& Officer, L. M. (2012). Moving counseling forward on LGB and transgender issues: Speaking queerly on discourses and microaggressions. The Counseling Psychologist, 40. doi: 10.1177/0011000011403165 
Solozarno, D., Ceja, M., \& Yosso, T. (2000). Critical race theory, racial microaggressions, and campus racial climate: The experiences of African American college students. The Journal of Negro Education, 69(1-2), 60-73.

Spencer, M. S. (2017). Microaggressions and social work practice, education, and research. Journal of Ethnic \& Cultural Diversity in Social Work, doi:10.1080/15313204.2016.1268989

Spencer, M. S. \& Patrick, J. H. (2009). Social support and personal mastery as protective resources during emerging adulthood. Journal of Adult Development, 16, 191198. doi: 10.1007/s10804-009-9064-0

Sterzing, P. R., Gartner, R. E., Woodford, M. R., \& Fisher, C. M. (2017) Sexual orientation, gender, and gender identity microaggressions: Toward an intersectional framework for social work research. Journal of Ethnic \& Cultural Diversity in Social Work, 26(1-2), 81-94. doi: 10.1080/15313204.2016.1263819

Substance Abuse and Mental Health Services Administration. (2018). Key substance use and mental health indicators in the United States: Results from the 2017 National Survey on Drug Use and Health (NSDUH). Substance Abuse and Mental Health Services Administration, HHS Publication No. SMA 18-5068. Rockville, MD: Retrieved from https://www.samhsa.gov/data/

Substance Abuse and Mental Health Services Administration. (2015). Racial/ Ethnic Differences in Mental Health Service Use among Adults. Substance Abuse and Mental Health Services Administration, HHS Publication No. SMA-15-4906. Rockville, MD.

Substance Abuse and Mental Health Services Administration (SAMHSA). (2014). Health Disparities. Retrieved from http://www.samhsa.gov/health-disparities.

Substance Abuse and Mental Health Services Administration. (2012). Top Health Issues for LGBT Populations Information and Resource Kit. HHS Publication No. (SMA) 12-4684. Rockville, MD: Substance Abuse and Mental Health Services Administration.

Sue, D. W. (2010). Microaggressions in everyday life: Race, gender, and sexual orientation. Hoboken, N.J.: Wiley. 
Sue, D. W., Bucceri, J., Lin, A. I., Nadal, K. L., \& Torino, G. C. (2007b). Racial microaggressions and the Asian American experience. Cultural Diversity \& Ethnic Minority Psychology, 13(1), 72-81. doi: 10.1037/1099-9809.13.1.72.

Sue, D. W., Capodilupo, C. M., \& Holder, A. M. B. (2008). Racial microaggressions in the life experiences of black Americans. Professional Psychology: Research and Practice, 39(3), 329-336. doi: 10.1037/0735-7028.39.3.329.

Sue, D. W., Capodilupo, C. M., Torino, G. C., Bucerri, J. M., Holder, A. M. B., Nadal, K. L., \& Marin, E. (2007a). Racial microaggressions in everyday life: Implications for clinical practice. American Psychologist, 62(4), 271-286. doi: 10.1037/0003066X.62.4.271.

Swan, T. A. \& McConnell, S. M. (2015). Transformative engagement in LGBTQ student/field instructor relationships. In O, Neill, B. J., Swan, T. A., \& Mule, N. J. (Eds.), LGBTQ People and Social Work: Intersectional Perspectives (pp. $339-$ 359). Toronto: Canadian Scholars Press.

Swank, E., \& Fahs, B. (2013). An intersectional analysis of gender and race for sexual minorities who engage in gay and lesbian rights activism. Sex Roles, 68(11-12), $660-674$.

Syed, M., \& Mitchell, L. L. (2013). Race, ethnicity, and emerging adulthood: Retrospect and prospects. Emerging Adulthood, 1(2), 83-95. doi: $10.1177 / 2167696813480503$

Syzmanski, D. M., \& Gupta, A. (2009). Examining the relationship between multiple internalized oppressions and African American lesbian, gay, bisexual, and questioning persons' self-esteem and psychological distress. Journal of Counseling Psychology, 56(1), 110.

Syzmanski, D. M. \& Meyer, D. (2008). Racism and heterosexism as correlates of psychological distress in African American sexual minority women. Journal of LGBT Issues in Counseling, 2(2), pp. 4 - 108. doi: 10.1080/15538600802125423

Tillapaugh, D., Mitchell Jr, D., \& Soria, K. M. (2017). Considering gender and student leadership through the lens of intersectionality. New Directions for Student Leadership, (154), 23-32. https://doi.org/10.1002/yd.20237 
Thomas, K. R. (2008). Macrononsense in muticulturalism. American Psychologist, 63, 274-275. doi: 10.1037/0003-066X.63.4.274

Thomeer, M. B. (2013). Sexual minority status and self-rated health: The importance of socioeconomic status, age, and sex. American Journal of Public Health, 103(5), 881-888.

Todd, S. \& Coholic, D. (2015). Christian fundamentalism and anti-oppressive practice social work pedagogy: Rethinking the inclusion of fundamentalist beliefs within the Queer-positive classroom. In O, Neill, B. J., Swan, T. A., \& Mule, N. J. (Eds.), LGBTQ People and Social Work: Intersectional Perspectives (pp. 277 296). Toronto: Canadian Scholars Press.

Torkelson, J. (2012). A queer vision of emerging adulthood: Seeing sexuality in the transition to adulthood. Sexuality Research and Social Policy, 9(2), 132-142.

Torres, L., Driscoll, M. W., \& Burrow, A. L. (2010). Racial microaggressions and psychological functioning among highly achieving African-Americans: A mixedmethods approach. Journal of Social and Clinical Psychology, 29(10), 10741099.

Truman, H. S. (1946). To secure these rights: The report of the President's Committee on Civil Rights. Harry S. Truman Library \& Museum. Retrieved from: http://www.trumanlibrary.org/civilrights/srights1.htm\#VII.

Turner, G. W., \& Crane, B. (2016). Sexually silenced no more, adults with learning disabilities speak up: A call to action for social work to frame sexual voice as a social justice issue. The British Journal of Social Work, 46(8), 2300-2317. doi: https://doi.org/10.1093/bjsw/bcw133

Turner, G. W., Pelts, M., \& Thompson, M. (2018). Between the academy and queerness: Microaggressions in social work education. Affilia, 33(1), 1-14. doi: $10.1177 / 0886109917729664$

U.S. Census Bureau (2018). Quick facts: United States. Unites States Census Bureau. Retrieved from: https://www.census.gov/quickfacts/fact/table/US/PST045218

U.S. Census Bureau. (1901). 1900 Census: Volume 1. Population part 1. United States Census Bureau. Retrieved from: 
https://www.census.gov/content/census/en/library/publications/1901/dec/vol-01population.html

U.S. Census Bureau. (1883). 1880 census: Volume 1. Statistics of the population of the United States. United States Census Bureau. Retrieved from: https://www.census.gov/library/publications/1883/dec/vol-01-population.html

Venner, K. L., Greenfield, B. L., Vicuña, B., Muñoz, R., Bhatt, S., \& O'keefe, V. (2012). "I'm not one of them": Barriers to help-seeking among American Indians with alcohol dependence. Cultural Diversity and Ethnic Minority Psychology, 18(4), 352. doi: $10.1037 / \mathrm{a} 0029757$

Walker, J. N. J., \& Longmire-Avital, B. (2013). The impact of religious faith and internalized homonegativity on resiliency for Black lesbian, gay, and bisexual emerging adults. Developmental Psychology, 49(9), 1723-1731. doi: $10.1037 / \mathrm{a} 0031059$

Wang, J., Leu, J., \& Shoda, Y. (2011). When the seemingly innocuous "stings": Racial microaggressions and their emotional consequences. Personality and Social Psychology, 37(12), 1666-1678. doi: 10.1177/0146167211416130

Wei, M., Liao, K. Y., Chao, R. C., Mallinckrodt, B., Tsai, P., \& Botello-Zamarron, R. (2010). Minority stress, perceived bicultural competence, and depressive symptoms among ethnic minority college students. Journal of Counseling Psychology, 57(4), 411-422. doi: 10.1037/a0020790

Wilcox, R. (1997). Introduction to robust estimation and hypothesis testing. San Diego: Academic Press.

Wilcox, R. (1999). Fundamentals of modern statistical methods. New York: Springer.

Wilcox, R. (2003). Applying contemporary statistical techniques. San Diego: Academic Press.

Williams, S. L., \& Mann, A. K. (2017). Sexual and gender minority health disparities as a social issue: How stigma and intergroup relations can explain and reduce health disparities. Journal of Social Issues, 73(3), 450-461. https://doi.org/10.1111/josi.12225 
Wilson, P. A., Meyer, I. H., Antebi-Gruszka, N., Boone, M. R., Cook, S. H., \& Cherenack, E. M. (2016). Profiles of resilience and psychosocial outcomes among young Black and gay men. American Journal of Psychology, 0, (1-14). doi: 10.1002.ajcp. 12018

Wong, G., Derthick, A. O., David, E. J. R., Saw, A. \& Ozazaki, S. (2014). The what, the why, and the how: A review of racial microaggressions research in psychology. Race and Social Problems, 6, 181-200. doi:10.1007/s12552-013-9107-9

Woodford, M. R., Howell, M. L., Silverschanz, P. \& Yu, L. (2012). “That's so gay!": Examining the covariates of hearing this expression among gay, lesbian, and bisexual college students. Journal of American College Health, 60(6), 429-434. doi: 10.1080/07448481.2012.673519

Woodford, M. R., Paceley, M. S., Kulick, A., \& Hong, J. S. (2015). The LGBQ social climate matters: Policies, protests, and placards and psychological well-being among LGBQ emerging adults. Journal of Gay \& Lesbian Social Services, 27(1), 116-141, doi: 10.1080/10538720.2015.990334

Woodford, M. R., Sterzing, P. R., Fisher, C., \& Gartner, R. E. (2015, January). Advancing research on discrimination: Gender, homonegative, and transnegative microaggressions. Roundtable presented at the 2015 Society for Social Work Research Conference, New Orleans: Louisiana

Woody, D. J., \& Green, R. (2001). The influence of race/ethnicity and gender on psychological and social well-being. Journal of Ethnic and Cultural Diversity in Social Work, 9(3-4), 151-166.

Wright, J. A. \& Wegner, R. T., (2012). Homonegative microaggressions and their impact on LGB individuals: A measure validity study. Journal of LGBT Issues in Counseling, 6(1),34-54. doi: 10.1080/15538605.2012.648578

Zemore, S. E., Karriker-Jaffe, K. J., Mulia, N., Kerr, W. C., Ehlers, C. L., Cook, W. K., ... \& Greenfield, T. K. (2018). The future of research on alcohol-related disparities across US racial/ethnic groups: A plan of attack. Journal of Studies on Alcohol and Drugs, 79(1), 7-21. 
APPENDICES 
Appendix A

Figure A. Institutional Review Board approval letter

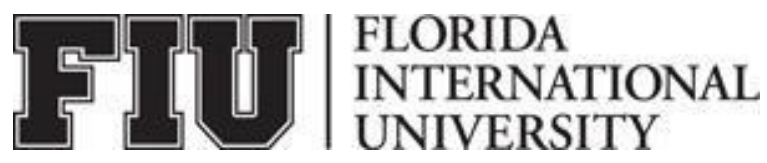

Office of Research Integrity

Research Compliance, MARC 270

\section{MEMORANDUM}

To: $\quad$ Dr. Eric Wagner

CC: $\quad$ File

From: Maria Melendez-Vargas, MIBA, IRB Coordinator

Date: $\quad$ April 1, 2014

Protocol Title: "Examining the impact of microaggressions among racial/ethnic sexual minority emerging adults"

The Florida International University Office of Research Integrity has reviewed your research study for the use of human subjects via the Exempt Review process.

IRB Protocol Exemption \#: IRB-14-0043ＩRB Exemption Date: 03/25/14

TOPAZ Reference \#: $\quad 102171$

As a requirement of IRB Exemption you are required to:

1) Submit an Event Form and provide immediate notification of:

- Any additions or changes in the procedures involving human subjects.

- Every serious or unusual or unanticipated adverse event as well as problems with the rights or welfare of the human subjects.

2) Submit a Project Completion Report Form when the study is finished or discontinued.

Special Conditions: N/A

For further information, you may visit the IRB website at http://research.fiu.edu/irb. 
Appendix B

Figure B. Study Promotional Business Card

\section{IRB Approval Did That REALLY Just Happen?}

If you are between the ages of 18 to 29 and have been made to feel uncomfortable because of your sexual orientation, we would love to hear from you.

Please complete our confidential survey at the link below:

http://tinyurl.com/noq9s5v

@MThompsonFIU

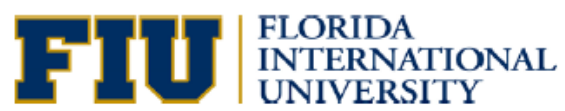




\section{Appendix C}

\section{Figure C Florida International University research participation system}

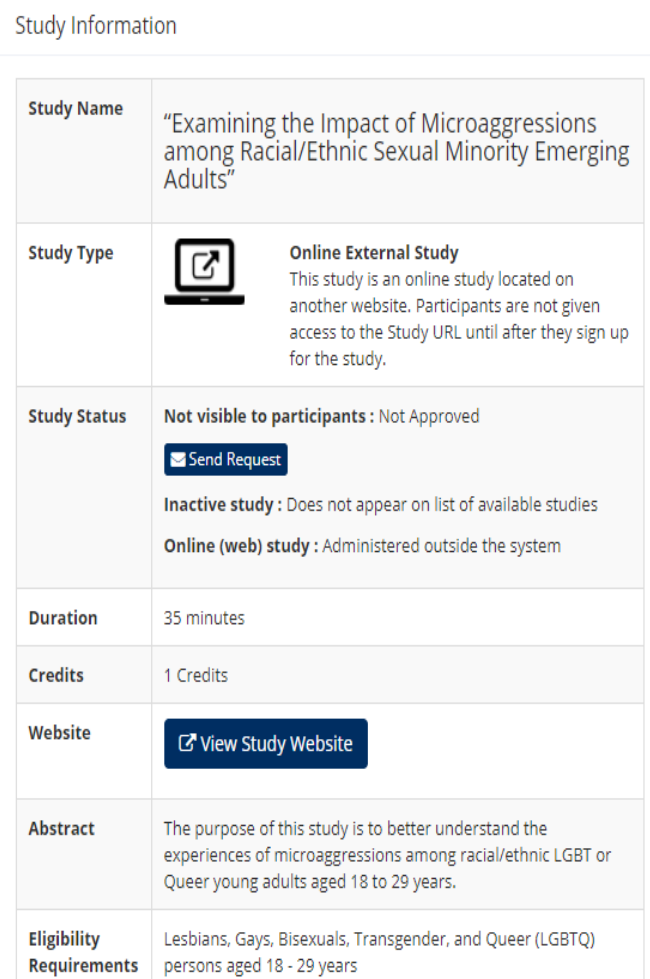

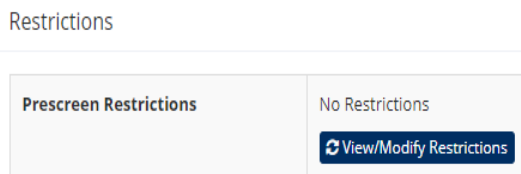

Restrictions

\begin{tabular}{|l|l}
\hline Prescreen Restrictions & No Restrictions \\
\hline EView/Modify Restrictions
\end{tabular}

Additional Study Information

Participant Sign- 1 hours before the study is to occu

Up Deadline

Participant

Cancellation

Deadline

IRB Approval

Code

Direct Study Link December 31, 2015)

24 hours before the study is to occur

24hours before the study is to occur

IRB-14-0043, IRB exemption date 3/25/2014 (expires

https://fiu.sona-systems.com/default.aspx?p_return_

This is a direct URL for participants to access the study. You may use this in an email or study advertisement.

Researcher Information

Researcher

$$
\begin{aligned}
& \text { Michelle Thompson } \\
& \text { P Office: } 305-348-4509
\end{aligned}
$$$$
\text { 305-761-3903 }
$$ 


\section{Appendix D}

\section{Figure D. Consent Form}

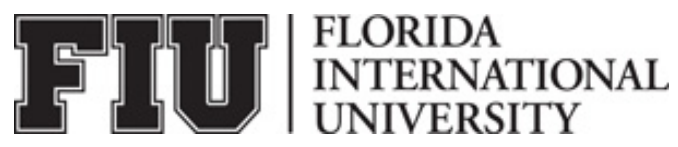

\section{ADULT ONLINE CONSENT TO PARTICIPATE IN A RESEARCH STUDY Project Title:}

\section{"Examining the Impact of Microaggressions among Racial/Ethnic Sexual Minority Emerging Adults" PURPOSE OF THE STUDY}

You are being asked to be in a research study. The purpose of this study is to better understand the experiences of microaggressions among racial/ethnic sexual minority young adults aged 18 to 29 years.

\section{NUMBER OF STUDY PARTICIPANTS}

If you decide to be in this study, you will be one of 200 people in this research study.

DURATION OF THE STUDY

If you agree to participate, you will be asked to complete a survey. It will take approximately 35 minutes to complete the survey.

\section{PROCEDURES}

Participation in this research is completely voluntary and confidential and you can stop participation at any time for any reason. If you choose to participate, here is what will happen:

1. We will ask you to complete an online survey. You will be asked questions about you and your experiences with brief, subtle discrimination. We will also ask about your overall outlook on life.

2. Upon completion of the survey, we will ask you to enter your email into our listserv in order to complete future surveys. We will also ask you to copy and paste our link to the survey and forward to others you feel may be interested in participating in our survey. These are optional and not a requirement to participate in the current survey.

\section{RISKS AND/OR DISCOMFORTS}

Participation in this study involves minimal risk. Some of the questionnaire items are sensitive, and you may feel uncomfortable or embarrassed about answering them. Although possible, it is unlikely that this will occur. You may start and stop this survey at any time.

\section{BENEFITS}

There may be no direct benefit to you from participating in this research. However, your participation in this survey may help in the development of future programs dedicated to the prevention of subtle discrimination against others.

\section{ALTERNATIVES}

There are no known alternatives available to you other than not taking part in this study. However, any significant new findings developed during the course of the research which may relate to your willingness to continue participation will be provided to you

\section{CONFIDENTIALITY}

The records of this study will be kept private and will be protected to the fullest extent provided by law. In any sort of report we might publish, we will not include any information that will make it possible to identify a subject. Research records will be stored securely and only the researcher team will have access to the records. However, your records may be reviewed for audit purposes by authorized University or other agents who will be bound by the same provisions of confidentiality.

COMPENSATION \& COSTS

You will not receive payment for your participation. Your participation is strictly on a volunteer basis. You will also not be responsible for any costs to participate in this study. 


\section{RIGHT TO DECLINE OR WITHDRAW}

Your participation in this study is voluntary. You are free to participate in the study or withdraw your consent at any time during the study. Your withdrawal or lack of participation will not affect any benefits to which you are otherwise entitled. The investigator reserves the right to remove you without your consent at such time that they feel it is in the best interest.

\section{RESEARCHER CONTACT INFORMATION}

If you have any questions about the purpose, procedures, or any other issues relating to this research study you may contact Dr. Eric Wagner at Florida International University, 305-348-5612 or Michelle Thompson, L.M.H.C. at Florida International University, 305-348-4509.

\section{IRB CONTACT INFORMATION}

If you would like to talk with someone about your rights of being a subject in this research study or about ethical issues with this research study, you may contact the FIU Office of Research Integrity by phone at 305-348-2494 or by email at ori@fiu.edu.

\section{PARTICIPANT AGREEMENT}

I have read the information in this consent form and agree to participate in this study. I have had a chance to ask any questions I have about this study, and they have been answered for me.

You must be 18 years of age or older to consent to take part in this research study. If you agree to take part in this research study and the information outlined above, please click on the "consent to participate" button below.

\section{(Insert Consent to Participate Button Here on the Website)}


Appendix E

Figure E Online study survey

Did That REALLY Just Happen?

Examining the impact of microaggressions among racial/ethnic sexual minority emerging adults

Thank you for your willingness to participate. I want to remind you that all your answers are anonymous.

So please be as honest as you can.

\section{Demographics [All PARTICIPANTS]}

1. Demo 1 Gender:

Male

Female

Transgender male to female (MTF)

Transgender female to male (FTM)

Intersex

Other, please specify

2. Demo 2 Please indicate your age:

3. Demo 3 Which of the following best describes your race/ethnicity? (Please check all that apply)

White or Caucasian

Black or African American

Hispanic/Latino

American Indian/Native American

Asian/Pacific Islander

Multicultural

Other

4. Demo 4 Which of the following best describes your sexual orientation? (Please select only one)

Heterosexual or Straight

Gay

Bisexual

Lesbian

Transgender

5. Demo 5 Please indicate your highest level of formal education

Some high school

High school graduate or GED

Some trade or technical school

Trade school or technical school graduate

Some college/4 yr. University

College/4 yr. University graduate

Post graduate degree 
6. Demo 6 Household Income

Less than $\$ 20,000$

$\$ 20,000$ - \$34,999

$\$ 35,000$ - \$49,999

$\$ 50,000$ - \$64,999

$\$ 65,000$ and above

7. Demo 6 Employment Status

Unemployed

Part-time

Full-time

Student

Other

\section{Brief Social Desirability Scale [All PARTICIPANTS]}

8. BSDS 1 Would you smile at people every time you meet them?

Yes

No

9. BSDS 2 Do you always practice what you preach to people?

Yes

No

10. BSDS 3 If you say to people that you will do something, do you always keep your promise no matter how inconvenient it might be?

Yes

No

11. BSDS 4 Would you ever lie to people?

Yes

No

\section{Outness Inventory [ALL PARTICIPANTS]}

Use the following rating scale to indicate how open you are about your sexual orientation to the people listed below. Try to respond to all of the items, but leave items blank if they do not apply to you. If an item refers to a group of people (e.g., work peers), then indicate how out you generally are to that group.

1 = person definitely does NOT know about your sexual orientation status

2 = person might know about your sexual orientation status, but it is NEVER talked about

$3=$ person probably knows about your sexual orientation status, but it is NEVER talked about

4 = person probably knows about your sexual orientation status, but it is RARELY talked about

5 = person definitely knows about your sexual orientation status, but it is RARELY talked about 
$6=$ person definitely knows about your sexual orientation status, and it is SOMETIMES talked about

7 = person definitely knows about your sexual orientation status, and it is OPENLY talked about

$0=$ not applicable to your situation; there is no such person or group of people in your life

\begin{tabular}{|c|c|c|c|c|c|c|c|c|}
\hline OI-1 12. mother & $\mathbf{1}$ & 2 & 3 & 4 & 5 & 6 & 7 & $\mathbf{0}$ \\
\hline OI-2 13. father & 1 & 2 & 3 & 4 & 5 & 6 & 7 & 0 \\
\hline OI-3 14. siblings & 1 & 2 & 3 & 4 & 5 & 6 & 7 & 0 \\
\hline oI-4 15. extended family/relatives & 1 & 2 & 3 & 4 & 5 & 6 & 7 & 0 \\
\hline oI-5 17. my new straight friends & 1 & 2 & 3 & 4 & 5 & 6 & 7 & 0 \\
\hline OI-6 18. my work peers & 1 & 2 & 3 & 4 & 5 & 6 & 7 & 0 \\
\hline OI-7 19. my work supervisor & 1 & 2 & 3 & 4 & 5 & 6 & 7 & 0 \\
\hline $\begin{array}{l}\text { oI-8 20. members of my religious community (e.g. church, } \\
\text { temple) }\end{array}$ & 1 & 2 & 3 & 4 & 5 & 6 & 7 & 0 \\
\hline $\begin{array}{l}\text { oI-9 21. leaders of my religious community (e.g. church, } \\
\text { temple) }\end{array}$ & 1 & 2 & 3 & 4 & 5 & 6 & 7 & 0 \\
\hline OI-10 22. strangers, new acquaintances & 1 & 2 & 3 & 4 & 5 & 6 & 7 & 0 \\
\hline OI-11 23. my old heterosexual friends & 1 & 2 & 3 & 4 & 5 & 6 & 7 & 0 \\
\hline
\end{tabular}

(Skip Pattern) Racial and Ethnic Microaggressions Scale (REMS) [RACIAL/ETHNIC LGBT]

(The following section will be completed by LGBT persons who indicate a race/ethnicity other than White/Caucasian)

So that we can better understand the day-to-day unique experiences of young adults of color, please answer the following:

I want to remind you that all your answers are anonymous. So please be as honest as you can.

Please indicate the number of times the following items have occurred in the past 12 months:

24. REMS 1 Someone assumed that I would have a lower education because of my race.

"Did not experience this event in the past 12 months"

"I experienced this event 1-3 times in the past 12 months"

"I experienced this event 4-6 times in the past 12 months"

"I experienced this event 7-9 times in the past 12 months"

"I experienced this event 10 or more time in the past 12 months"

25. $\operatorname{REMS}_{2}$ Someone avoided walking near me on the street because of my race.

"Did not experience this event in the past 12 months"

"I experienced this event 1-3 times in the past 12 months"

"I experienced this event 4-6 times in the past 12 months"

"I experienced this event 7-9 times in the past 12 months"

"I experienced this event 10 or more time in the past 12 months"

26. REMS 3 Someone told me that they "don't see color."

"Did not experience this event in the past 12 months"

"I experienced this event 1-3 times in the past 12 months" 
"I experienced this event 4-6 times in the past 12 months"

"I experienced this event 7-9 times in the past 12 months"

"I experienced this event 10 or more time in the past 12 months"

27. REMS 4 Someone assumed that I spoke a language other than English.

"Did not experience this event in the past 12 months"

"I experienced this event 1-3 times in the past 12 months"

"I experienced this event 4-6 times in the past 12 months"

"I experienced this event 7-9 times in the past 12 months"

"I experienced this event 10 or more time in the past 12 months"

28. REMS 5 I observed people of my race portrayed positively in movies.

"Did not experience this event in the past 12 months"

"I experienced this event 1-3 times in the past 12 months"

"I experienced this event 4-6 times in the past 12 months"

"I experienced this event 7-9 times in the past 12 months"

"I experienced this event 10 or more time in the past 12 months"

29. REMS 6 An employer or coworker was unfriendly or unwelcoming toward me because of my race.

"Did not experience this event in the past 12 months"

"I experienced this event 1-3 times in the past 12 months"

"I experienced this event 4-6 times in the past 12 months"

"I experienced this event 7-9 times in the past 12 months"

"I experienced this event 10 or more time in the past 12 months"

30. REMS 7 Someone assumed that I was poor because of my race.

"Did not experience this event in the past 12 months"

"I experienced this event 1-3 times in the past 12 months"

"I experienced this event 4-6 times in the past 12 months"

"I experienced this event 7-9 times in the past 12 months"

"I experienced this event 10 or more time in the past 12 months"

31. REMS 8 Someone clenched his/her purse or wallet upon seeing my because of my race.

"Did not experience this event in the past 12 months"

"I experienced this event 1-3 times in the past 12 months"

"I experienced this event 4-6 times in the past 12 months"

"I experienced this event 7-9 times in the past 12 months"

"I experienced this event 10 or more time in the past 12 months"

32. $\operatorname{REMS}_{9}$ Someone told me that they do not see race.

"Did not experience this event in the past 12 months"

"I experienced this event 1-3 times in the past 12 months"

"I experienced this event 4-6 times in the past 12 months"

"I experienced this event 7-9 times in the past 12 months"

"I experienced this event 10 or more time in the past 12 months" 
33. REMS 10 Someone asked me to teach them words in my "native language."

"Did not experience this event in the past 12 months"

"I experienced this event 1-3 times in the past 12 months"

"I experienced this event 4-6 times in the past 12 months"

"I experienced this event 7-9 times in the past 12 months"

"I experienced this event 10 or more time in the past 12 months"

34. REMS 11 I observed people of my race portrayed positively in magazines.

"Did not experience this event in the past 12 months"

"I experienced this event 1-3 times in the past 12 months"

"I experienced this event 4-6 times in the past 12 months"

"I experienced this event 7-9 times in the past 12 months"

"I experienced this event 10 or more time in the past 12 months"

35. REMS 12 My opinion was overlooked in a group discussion because of my race.

"Did not experience this event in the past 12 months"

"I experienced this event 1-3 times in the past 12 months"

"I experienced this event 4-6 times in the past 12 months"

"I experienced this event 7-9 times in the past 12 months"

"I experienced this event 10 or more time in the past 12 months"

36. REMS ${ }_{13}$ Someone assumed that I would not be educated because of my race.

"Did not experience this event in the past 12 months"

"I experienced this event 1-3 times in the past 12 months"

"I experienced this event 4-6 times in the past 12 months"

"I experienced this event 7-9 times in the past 12 months"

"I experienced this event 10 or more time in the past 12 months"

37. ${ }_{\text {REMS }}{ }_{14}$ Someone avoided sitting next to me in a public space (e.g. restaurants, movie theatres, subways, buses) because of my race.

"Did not experience this event in the past 12 months"

"I experienced this event 1-3 times in the past 12 months"

"I experienced this event 4-6 times in the past 12 months"

"I experienced this event 7-9 times in the past 12 months"

"I experienced this event 10 or more time in the past 12 months"

38. REMS 15 Someone told me that people should not think about race anymore.

"Did not experience this event in the past 12 months"

"I experienced this event 1-3 times in the past 12 months"

"I experienced this event 4-6 times in the past 12 months"

"I experienced this event 7-9 times in the past 12 months"

"I experienced this event 10 or more time in the past 12 months"

39. REMS ${ }_{16}$ Someone assumed that I speak similar languages to other people in my race.

"Did not experience this event in the past 12 months"

"I experienced this event 1-3 times in the past 12 months"

"I experienced this event 4-6 times in the past 12 months"

"I experienced this event 7-9 times in the past 12 months"

"I experienced this event 10 or more time in the past 12 months" 
40. REMS ${ }_{17}$ I observed people of my race portrayed positively in television.

"Did not experience this event in the past 12 months"

"I experienced this event 1-3 times in the past 12 months"

"I experienced this event 4-6 times in the past 12 months"

"I experienced this event 7-9 times in the past 12 months"

"I experienced this event 10 or more time in the past 12 months"

41. REMS 18 I was ignored at school or work because of my race.

"Did not experience this event in the past 12 months"

"I experienced this event 1-3 times in the past 12 months"

"I experienced this event 4-6 times in the past 12 months"

"I experienced this event 7-9 times in the past 12 months"

"I experienced this event 10 or more time in the past 12 months"

\section{Daily Heterosexist Experiences Questionnaire (DHEQ) [ALL PARTICIPANTS]}

So that we can better understand how young LGBT adults are affected by their unique day-to-day experiences, please answer the following:

I want to remind you that all your answers are anonymous. So please be as honest as you can.

Please indicate whether you have ever experienced the following in the past 12 months:

42. DHEQ 1 Feeling like you don't fit into the LGBT community because of your gender expression.

"Did not happen/not applicable to me"

"It happened, and it bothered me:

NOT AT ALL

A BIT

A LITTLE BIT

MODERATELY

QUITE

43. ${ }^{D H E Q} 9$ Being misunderstood by people because of your gender expression.

"Did not happen/not applicable to me"

"It happened, and it bothered me:

NOT AT ALL

A BIT

A LITTLE BIT

MODERATELY

QUITE

44. $\mathrm{DHEQ}_{2}$ Pretending that you are heterosexual.

"Did not happen/not applicable to me"

"It happened, and it bothered me:

NOT AT ALL

A BIT

A LITTLE BIT

MODERATELY

QUITE

45. DHEQ 10 Hiding your relationship from other people.

"Did not happen/not applicable to me"

"It happened, and it bothered me: 
NOT AT ALL

A BIT

A LITTLE BIT

MODERATELY

QUITE

46. DHEQ 16 Hiding part of your life from other people.

"Did not happen/not applicable to me"

"It happened, and it bothered me:

NOT AT ALL

A BIT

A LITTLE BIT

MODERATELY

QUITE

47. $\mathrm{DHEQ}$ 3 Being verbally harassed by strangers because you are LGBT.

"Did not happen/not applicable to me"

"It happened, and it bothered me:

NOT AT ALL

A BIT

A LITTLE BIT

MODERATELY

QUITE

48. DHEQ 11 Being treated unfairly in stores or restaurants because your are LGBT.

"Did not happen/not applicable to me"

"It happened, and it bothered me:

NOT AT ALL

A BIT

A LITTLE BIT

MODERATELY

QUITE

49. $\mathrm{DHEQ}_{7}$ Being called names such as "fag" or "dyke".

"Did not happen/not applicable to me"

"It happened, and it bothered me:

NOT AT ALL

A BIT

A LITTLE BIT

MODERATELY

QUITE

50. $\mathrm{DHEQ} 4$ Hearing other people being called names such as "fag" or "dyke".

"Did not happen/not applicable to me"

"It happened, and it bothered me:

NOT AT ALL

A BIT

A LITTLE BIT

MODERATELY

QUITE

51. DHEQ 12 Hearing about hate crimes (e.g. vandalism, physical or sexual assault) that happened to LGBT people you don't know.

"Did not happen/not applicable to me"

"It happened, and it bothered me:

NOT AT ALL

A BIT

A LITTLE BIT

MODERATELY

QUITE

52. $D H E Q$ 18 Hearing someone make jokes about LGBT people.

"Did not happen/not applicable to me"

"It happened, and it bothered me: 
NOT AT ALL

A BIT

A LITTLE BIT

MODERATELY

QUITE

53. ${ }_{\text {HEQ }} 6$ Family members not accepting your partner as a part of the family.

"Did not happen/not applicable to me"

"It happened, and it bothered me:

NOT AT ALL

A BIT

A LITTLE BIT

MODERATELY

QUITE

54. DHEQ 13 Your family avoiding talking about your LGBT identity.

"Did not happen/not applicable to me"

"It happened, and it bothered me:

NOT AT ALL

A BIT

A LITTLE BIT

MODERATELY

QUITE

55. $\mathrm{DHEQ} 8$ Being punched, hit, kicked, or beaten because you are LGBT.

"Did not happen/not applicable to me"

"It happened, and it bothered me:

NOT AT ALL

A BIT

A LITTLE BIT

MODERATELY

QUITE

56. $D H E Q{ }_{14}$ Being assaulted with a weapon because you are LGBT.

"Did not happen/not applicable to me"

"It happened, and it bothered me:

NOT AT ALL

A LITTLE BIT

MODERATELY

QUITE

A BIT EXTREMELY

57. DHEQ ${ }_{15}$ Difficulty finding LGBT friends.

"Did not happen/not applicable to me"

"It happened, and it bothered me:

NOT AT ALL

A BIT

A LITTLE BIT

MODERATELY

QUITE

58. DHEQ 17 Having very few people you can talk to about being LGBT.

"Did not happen/not applicable to me"

"It happened, and it bothered me:

NOT AT ALL

A BIT

A LITTLE BIT

MODERATELY

EXTREMELY

QUITE 
59. DHEQ 5 Feeling like you don't fit in with other LGBT people.

"Did not happen/not applicable to me"

"It happened, and it bothered me:

$\begin{array}{lll}\text { NOT AT ALL A LITTLE BIT MODERATELY QUTE } & \text { Q }\end{array}$ A BIT EXTREMELY

(Skip Pattern) Lesbian, Gay, Bisexual, Transgender- Person of Color Microaggressions

Scale (LGBT-PCMS) [RACIAL/ETHNIC LGBT]

(The following section will be completed by LGBT persons who indicate a race/ethnicity other than White/Caucasian)

So that we can better understand how young LGBT adults of color are affected by their unique day-to-day experiences, please answer the following:

I want to remind you that all your answers are anonymous. So please be as honest as you can.

Please indicate whether you have ever experienced the following in the past 12 months:

60. LGBT-PCMS 1 Not being able to trust White LGBT people.

"Did not happen/not applicable to me"

"It happened, and it bothered me:

NOT AT ALL

A BIT

A LITTLE BIT

MODERATELY

QUITE

61. LGBT-PCMS 2 Not being accepted by other people of your race/ethnicity because you are

LGBT.

"Did not happen/not applicable to me"

"It happened, and it bothered me:

NOT AT ALL

A BIT

A LITTLE BIT

MODERATELY

QUITE

62. LGBT-PCMS 3 Being rejected by other LGBT people of your same race/ethnicity.

"Did not happen/not applicable to me"

"It happened, and it bothered me:

NOT AT ALL

A BIT

A LITTLE BIT

MODERATELY

QUITE

63. LGBT-PCMS 4 Feeling misunderstood by White people.

"Did not happen/not applicable to me"

"It happened, and it bothered me:

NOT AT ALL

A BIT

A LITTLE BIT

EXTREMELY

MODERATELY

QUITE 
64. LGBT-PCMS 5 Feeling misunderstood by people in your ethnic/racial community.

"Did not happen/not applicable to me"

"It happened, and it bothered me:
NOT AT ALL
A BIT
A LITTLE BIT
MODERATELY
QUITE EXTREMELY

65. LGBT-PCMS 6 Being rejected by potential dating or sexual partners because of your race/ethnicity.

"Did not happen/not applicable to me"

"It happened, and it bothered me:

NOT AT ALL

A BIT

A LITTLE BIT

MODERATELY

QUITE

66. $L G B T-P C M S 7$ Having to educate White people about race issues.

"Did not happen/not applicable to me"

"It happened, and it bothered me:

NOT AT ALL

A BIT

A LITTLE BIT

MODERATELY

QUITE

67. LGBT-PCMS 8 Feeling invisible because you are LGBT.

"Did not happen/not applicable to me"

"It happened, and it bothered me:

NOT AT ALL

A BIT

A LITTLE BIT

MODERATELY

QUITE

68. LGBT-PCMS 9 Being seen as a sex object by other LGBT people because of your race/ethnicity.

"Did not happen/not applicable to me"

"It happened, and it bothered me:

NOT AT ALL

A BIT

A LITTLE BIT

MODERATELY

QUITE

69. LGBT-PCMS 10 Being the token LGBT person of color in groups or organizations.

"Did not happen/not applicable to me"

"It happened, and it bothered me:

NOT AT ALL

A BIT

A LITTLE BIT

MODERATELY

QUITE EXTREMELY 
70. LGBT-PCMS 11 Difficulty finding friends who are LGBT and from your racial/ethnic background.

"Did not happen/not applicable to me"

"It happened, and it bothered me:

NOT AT ALL A LITTLE BIT MODERATELY QUITE A BIT EXTREMELY

71. LGBT-PCMS 12 Reading personal ads that say "White people only".

"Did not happen/not applicable to me"

"It happened, and it bothered me:

NOT AT ALL A LITTLE BIT MODERATELY QUITE A BIT EXTREMELY

72. LGBT-PCMS 12 Being told that "race isn't important" by White people.

"Did not happen/not applicable to me"

"It happened, and it bothered me:

NOT AT ALL A LITTLE BIT MODERATELY QUITE

A BIT EXTREMELY

73. LGBT-PCMS ${ }_{12}$ Feeling unwelcome at groups or events in your racial/ethnic background.

"Did not happen/not applicable to me"

"It happened, and it bothered me:

NOT AT ALL

A BIT

A LITTLE BIT

MODERATELY

QUITE

73. LGBT-PCMS 12 Feeling like White LGBT people are only interested in you for your

appearance.

"Did not happen/not applicable to me"

"It happened, and it bothered me:

NOT AT ALL

A BIT

A LITTLE BIT

MODERATELY

QUITE

75. LGBT-PCMS 12 White LGBT people saying things that are racist.

"Did not happen/not applicable to me"

"It happened, and it bothered me:

NOT AT ALL

A BIT

A LITTLE BIT

MODERATELY

QUITE EXTREMELY 
76. LGBT-PCMS 12 Not having any LGBT people of color as positive role models.

"Did not happen/not applicable to me"

"It happened, and it bothered me:
NOT AT ALL
A BIT
A LITTLE BIT
MODERATELY
QUITE

77. LGBT-PCMS 12 Being discriminated against by other LGBT people of color because of your race.

"Did not happen/not applicable to me"

"It happened, and it bothered me:

NOT AT ALL

A BIT

A LITTLE BIT

MODERATELY

QUITE

Ryff's Scale of Psychological Well-Being (RPWB) [ALL PARTICIPANTS]

Below are a number of statements. Please indicate which response best describes how much you agree or disagree with each statement:

You will need to read the statements carefully because some are phrased positively and others negatively. Don't take too long over individual questions; there are no 'right' or 'wrong' answers and no trick questions. The first answer that comes into your head is probably the right one for you. If you find some of the questions difficult, please give the answer that is true for you in general or for most of the time.

78. $R P W B$ 1 My decisions are not usually influenced by what everyone else is doing.

Strongly Disagree

Moderately Disagree

Slightly Disagree

Slightly Agree

Moderately Agree

Strongly Agree

79. $\mathrm{RPWB} 2$ I often feel overwhelmed by my responsibilities.

Strongly Disagree

Moderately Disagree

Slightly Disagree

Slightly Agree

Moderately Agree

Strongly Agree 
80. $\mathrm{RPWB}_{3}$ I think it is important to have new experiences that challenge how I think about myself and the world.

Strongly Disagree

Moderately Disagree

Slightly Disagree

Slightly Agree

Moderately Agree

Strongly Agree

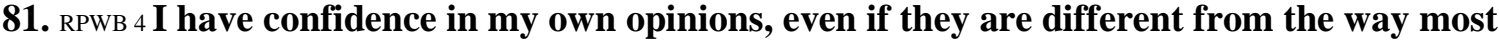
other people think.

Strongly Disagree

Moderately Disagree

Slightly Disagree

Slightly Agree

Moderately Agree

Strongly Agree

82. $\mathrm{RPWB} 5$ I do not fit very well with the people and community around me.

Strongly Disagree

Moderately Disagree

Slightly Disagree

Slightly Agree

Moderately Agree

Strongly Agree

83. $\mathrm{RPWB} 6$ I don't want to try new ways of doing things - my life is fine the way it is.

Strongly Disagree

Moderately Disagree

Slightly Disagree

Slightly Agree

Moderately Agree

Strongly Agree

84. $\mathrm{RPWB} 7 \mathrm{I}$ often change my mind about decisions if my friends or family disagree.

Strongly Disagree

Moderately Disagree

Slightly Disagree

Slightly Agree

Moderately Agree

Strongly Agree

85. $\mathrm{RPWB} 8$ I have been able to create a lifestyle for myself that is much to my liking.

Strongly Disagree

Moderately Disagree

Slightly Disagree

Slightly Agree

Moderately Agree

Strongly Agree 
86. $\mathrm{RPWB}_{9} \mathrm{I}$ judge myself by what $I$ think is important, not by what others think is important. Strongly Disagree

Moderately Disagree

Slightly Disagree

Slightly Agree

Moderately Agree

Strongly Agree

87. RPWB 10 In general, I feel I am in charge of the situation in which I live.

Strongly Disagree

Moderately Disagree

Slightly Disagree

Slightly Agree

Moderately Agree

Strongly Agree

88. RPWB 11 I often feel lonely because I have few close friends with whom to share my concerns.

Strongly Disagree

Moderately Disagree

Slightly Disagree

Slightly Agree

Moderately Agree

Strongly Agree

89. $R P W B 12 I$ am an active person in carrying out the plans I set for myself.

Strongly Disagree

Moderately Disagree

Slightly Disagree

Slightly Agree

Moderately Agree

Strongly Agree

90. $\mathrm{RPWB} 13$ In general, I feel confident and positive about myself.

Strongly Disagree

Moderately Disagree

Slightly Disagree

Slightly Agree

Moderately Agree

Strongly Agree

91. $\mathrm{RPWB}{ }_{14}$ People would describe me as a giving person, willing to share my time with others.

Strongly Disagree

Moderately Disagree

Slightly Disagree

Slightly Agree

Moderately Agree

Strongly Agree 
92. RPWB ${ }_{15}$ Some people wonder aimlessly through life but I am not one of them.

Strongly Disagree

Moderately Disagree

Slightly Disagree

Slightly Agree

Moderately Agree

Strongly Agree

93. RPWB 16 My attitude about myself is probably not as positive as most people feel about themselves.

Strongly Disagree

Moderately Disagree

Slightly Disagree

Slightly Agree

Moderately Agree

Strongly Agree

94. $R P W B$ 17 I live life one day at a time and don't really think about the future.

Strongly Disagree

Moderately Disagree

Slightly Disagree

Slightly Agree

Moderately Agree

Strongly Agree

95. RPWB 18 In many ways, I feel disappointed about my achievements in life.

Strongly Disagree

Moderately Disagree

Slightly Disagree

Slightly Agree

Moderately Agree

Strongly Agree

If you are interested in participating in future research studies, please click the link below. You will now leave this survey and be asked to provide your follow-up contact information. This information will in no way be connected to your responses on this survey. 


\section{Appendix F}

Figure F. Conceptual models for research questions $1-4$

Research Question 1

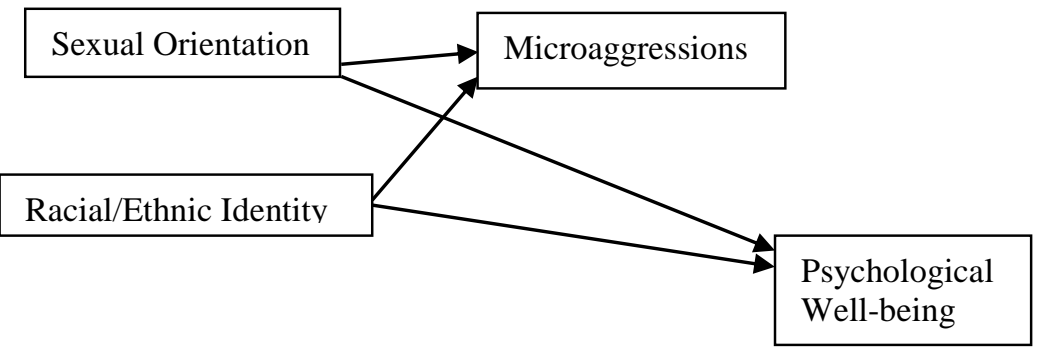

Research Question 2

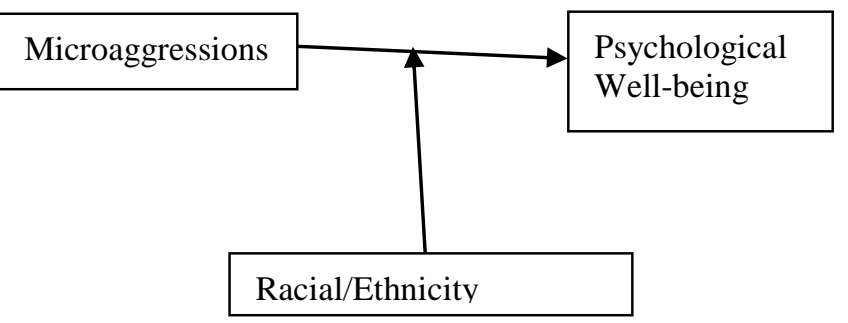

\section{Research Question 3}

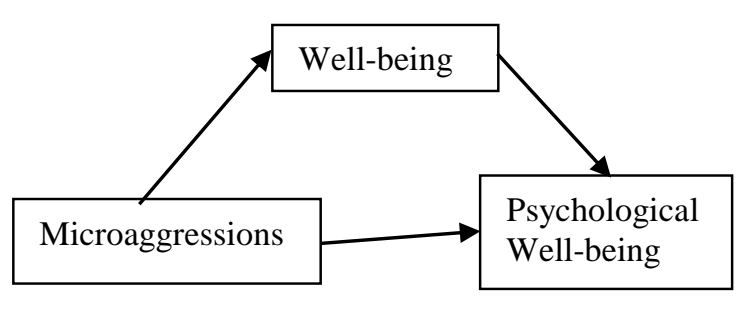

Research Question 4

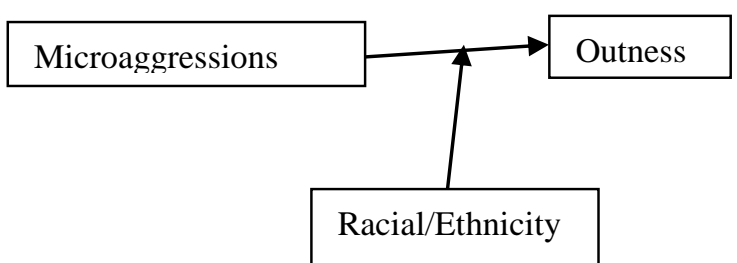


VITA

MICHELLE G. THOMPSON

Born, Mobile, Alabama

\begin{tabular}{|c|c|}
\hline $1999-2002$ & $\begin{array}{l}\text { B.A., Psychology } \\
\text { Florida International University } \\
\text { Miami, Florida }\end{array}$ \\
\hline $2004-2006$ & $\begin{array}{l}\text { M.S., Psychology } \\
\text { Florida International University } \\
\text { Miami, Florida }\end{array}$ \\
\hline $2009-2018$ & $\begin{array}{l}\text { Adjunct Lecturer, Department of Psychology } \\
\text { Florida International University } \\
\text { Miami, Florida }\end{array}$ \\
\hline $2017-2018$ & $\begin{array}{l}\text { Adjunct Lecturer, School of Social Work } \\
\text { Florida International University } \\
\text { Miami, Florida }\end{array}$ \\
\hline $2018-2019$ & $\begin{array}{l}\text { Dissertation Year Fellowship } \\
\text { Florida International University } \\
\text { Miami, Florida }\end{array}$ \\
\hline $2012-2019$ & $\begin{array}{l}\text { Doctoral Candidate } \\
\text { Florida International University } \\
\text { Miami, Florida }\end{array}$ \\
\hline & $\begin{array}{l}\text { Graduate Certificate - Women's Studies } \\
\text { Florida International University } \\
\text { Miami, Florida }\end{array}$ \\
\hline
\end{tabular}

PUBLICATIONS AND PRESENTATIONS

Estreet, A. T., Phillips, T., Thompson, M. G. (2019). Addressing behavioral health treatment among LGBTQIA. In C. Dente (Ed.), Social Work Practice with LGBTQIA Populations: An International Perspective. New York, NY: Routledge Taylor \& Francis Publishing.

Thompson, M. G. (2018, March). Suicide interventions for sexual minority youth: A systematic review. Oral presentation at the Graduate Student Appreciation Week (GSAW) Scholarly Forum, Miami, FL. 
Thompson, M. G. \& Lowe, J. (2018, March). SACRED CONNECTIONS - A substance abuse intervention with Native American Youth: Lessons and results from a NIDAfunded RCT. Oral presentation at the 31st Annual Research \& Policy Conference on Child, Adolescent, and Young Adult Behavioral Health, Tampa, Florida.

Turner, G., Pelts, M., \& Thompson, M. G. (2017). Between the academy and queerness: Microaggressions in social work education. AFFILIA: Journal of Women and Social Work, 33(1), 98-111.

Hospital, M. M., Wagner, E. F., Lowe, J., Morris, S., Riggs, C., Thompson, M., \& Sawant, M. (2017, November). SACRED Connections: A NIDA-funded RCT with Native American youth. Poster Presentation at the RCMI Translational Science 2017 Conference, Washington, D.C.

Pelts, M., Turner, G., \& Thompson, M. G. (2017, October). Between the Academy and Queerness: Microaggressions in Social Work Education. Poster presentation at the 63rd Annual Council on Social Work Education Annual Program Meeting, Dallas, Texas.

Thompson, M. G. \& Wagner, E., (2017, April). Suicide interventions for sexual minority youth: A systematic review. Oral presentation at the 2017 National LGBTQ Health Conference, Chicago, Illinois.

Turner, G., Pelts, M., Thompson, M. G., \& Meyers, L. (2017, January). The Practical Application of Sexual Literacy to Social Work. Roundtable discussion at the 2017 Society for Social Work Research Annual Conference, New Orleans, Louisiana.

Turner, G., Pelts, M., \& Thompson, M. (2016). Breaking the taboos: The power of group work for first- generation scholars. Social Work with Groups, 40(1-2), 168-173.

Thompson, M. G., Turner, G., Meyers, L \& Pelts, M. (2016, August). Sexual justice and social work in the United States: An intersection of social justice, microaggressions, and sexual literacy. Symposium presentation at the 2016 Sexuality and Social Work Conference, Olten, Switzerland.

Thompson, M., Wagner, E. F., \& Hospital, M. M. (2016, January). Characteristics of lesbian, gay, and bisexual racial/ethnic minority emerging adults experiencing microaggressions. Poster presentation at the 2016 Society for Social Work Research Annual Conference, Washington, D.C.

Thompson, M. (2014, March). Subtle insults and slights: Exploring microaggressions among racial/ethnic sexual minorities. Oral presentation at the 11th Annual Florida Collegiate Pride Coalition (FCPC) 2014 Conference, Jacksonville, Florida. 